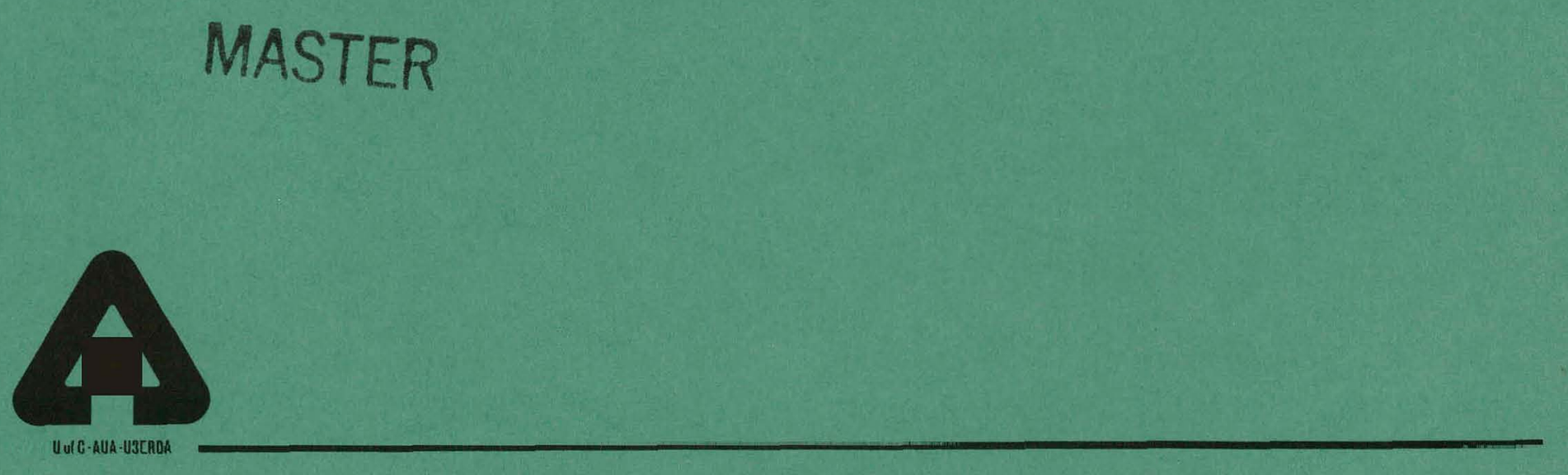

ARGONNE NATIONAL LABORATORY, ARGONNE, ILLINOIS

Prepared for the U.S. ENERGY RESEARCH

AND DEVELOPMENT ADMINISTRATION

under Contract W-31-109-Eng-38

\title{
MULTIPHASE FLOW OF GAS-LIQUID
AND GAS-COAL SLURRY MIXTURES
IN VERTICAL TUBES MULTIPHASE FLOW OF GAS-LIQUID
AND GAS-COAL SLURRY MIXTURES
IN VERTICAL TUBES MULTIPHASE FLOW OF GAS-LIQUID
AND GAS-COAL SLURRY MIXTURES
IN VERTICAL TUBES

(2)

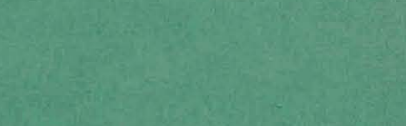

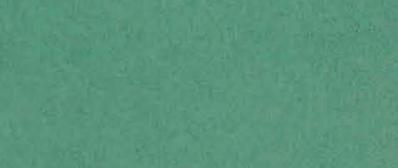
by
and Jack Fischer
walbe

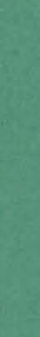

(n)

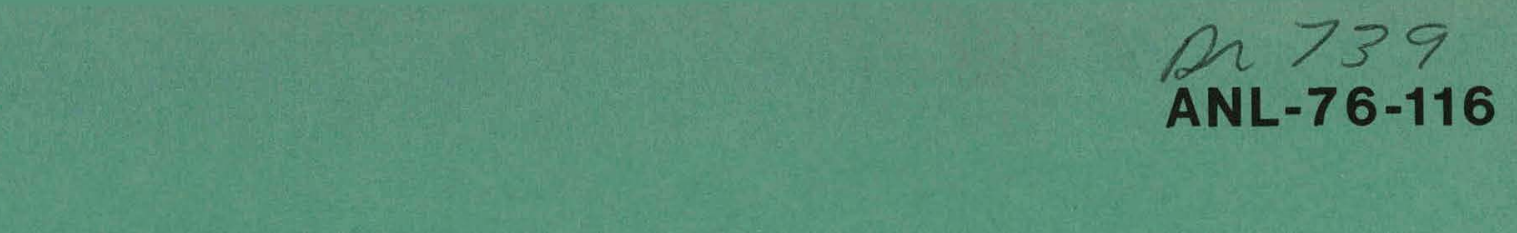

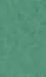

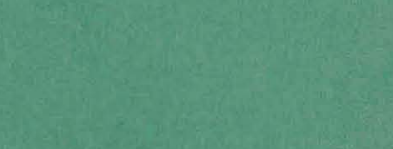

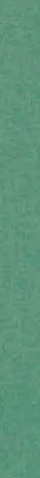

(2)




\section{DISCLAIMER}

This report was prepared as an account of work sponsored by an agency of the United States Government. Neither the United States Government nor any agency Thereof, nor any of their employees, makes any warranty, express or implied, or assumes any legal liability or responsibility for the accuracy, completeness, or usefulness of any information, apparatus, product, or process disclosed, or represents that its use would not infringe privately owned rights. Reference herein to any specific commercial product, process, or service by trade name, trademark, manufacturer, or otherwise does not necessarily constitute or imply its endorsement, recommendation, or favoring by the United States Government or any agency thereof. The views and opinions of authors expressed herein do not necessarily state or reflect those of the United States Government or any agency thereof. 


\section{DISCLAIMER}

Portions of this document may be illegible in electronic image products. Images are produced from the best available original document. 
The facilities of Argonne National Laboratory are owned by the United States Government. Under the terms of a contract (W-31-109-Eng-38) between the U. S. Energy Research and Development Administration, Argonne Universities Association and The University of Chicago, the University employs the staff and operates the Laboratory in accordance with policies and programs formulated, approved and reviewed by the Association.

\section{MEMBERS OF ARGONNE UNIVERSITIES ASSOCIATION}

The University of Arizona Carnegie-Mellon University Case Western Reserve University The University of Chicago University of Cincinnati

Illinois Institute of Technology

University of Illinois

Indiana University

Iowa State University

The Univer sity of Iowa
Kansas State University The University of Kansas Loyola University Marquette University Michigan State University The University of Michigan University of Minnesota University of Missouri Northwestern University University of Notre Dame
The Ohio State University Ohio University

The Pennsylvania State University Purdue University

Saint Louis University

Southern Illinois University

The University of Texas at Austin Washington University Wayne State University The University of Wisconsin

\section{NOTICE}

This report was prepared as an account of work sponsored by the United States Government. Neither the United States nor the United States Energy Research and Development Administration, nor any of their employees, nor any of their contractors, subcontractors, or their employees, makes any warranty, express or implied, or assumes any legal liability or responsibility for the accuracy, completeness or usefulness of any information, apparatus, product or process disclosed, or represents that its use would not infringe privately-owned rights. Mention of commercial products, their manufacturers, or their suppliers in this publication does not imply or connote approval or disapproval of the product by Argonne National Laboratory or the U. S. Energy Research and Development Administration.

Printed in the United States of America

Available from

National Technical Information Service

U. S. Department of Commerce

5285 Port Royal Road

Springfield, Virginia 22161

Price: Printed Copy $\$ 5.00 ;$ Microfiche $\$ 3.00$ 
ANL-76-116

ARGONNE NATIONAL LABORATORY

9700 South Cass Avenue

Argonne, Illinois 60439

\author{
MULTIPHASE FLOW OF GAS-LIQUID AND GAS-COAL \\ SLURRY MIXTURES IN VERTICAL TUBES \\ by
Kambiz Javdani,* Steven Schwalbe, ** and Jack Fischer

Chemical Engineering Division

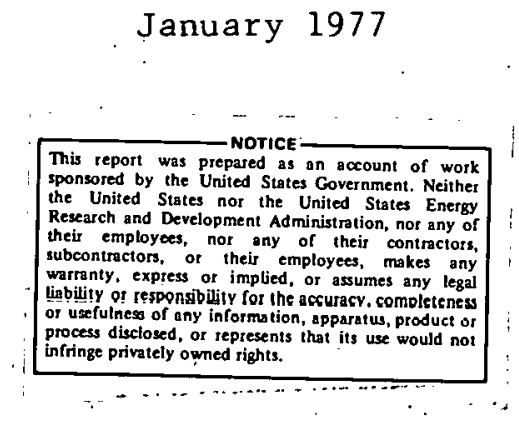

* Aryamehr University of Technology, Dept. of Chemical Engineęring, P. 0. Box 3406 , Tehran, Irán

** Graduate Student, Northwestern University 
THIS PAGE

\section{WAS INTENTIONALLY LEFT BLANK}


TABLE OF CONTENTS

$\underline{\text { Page }}$

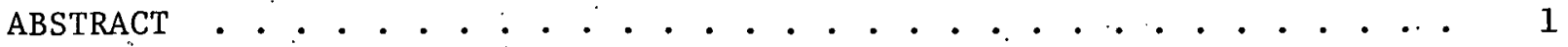

I. INTRODUCTION . . . . . . . . . . . . . . . . . . . . . . 2

A. General Features of Multiphase Flow in
Vertical Tubes... . . . . . . . . . . . . . . 6

B. Flow Pattern . . . . . . . . . . . . . . . 6

C. Holdup . . . . . . . . . . . . . . . . . . . 9

D. Pressure Drop . . . . . . . . . . . . . . . . 10

E. Relevance of the Research Project to the
SYNTHOIL Process............... . . . . . . 11

II. OBJECTIVES . . . . . . . . . . . . . . . . . . . . 12

TT.I. EXPERIMENTAL . . . . . . . . . . . . . . . . . . . . . 12

A. Apparatus . . . . . . . . . . . . . . . . . . 12

B. Gas-Liquid Mixtures . . . . . . . . . . . . . . . 15

C. Slurries ................... . 16

IV. RESUlTS . . . . . . . . . . . . . . . . . . . . 17

A. Gas-Liquid Flow. Characteristics . . . . . . . . . . . 17

1. Pressure Drop . . . . . . . . . . . . . 18

2. Holdup ..................... 37

3. Flow Patterns..... . . . . . . . . . . 49

B. Gas-Liquid-Solid Flow Characteristics . . . . . . . . . 57

1. Rheological Properties of the Slurries . . . . . . . 57

2. Pressure Diup .................. . 59

3. Holdup ...................... . 61

4. Flow Patterns................ . 61

V. SUMMARY AND CONCLUSIONS . . . . . . . . . . . . . . . . . . 65

NOMENCLATURE . . . . . . . . . . . . . . . . . . . . . . 67

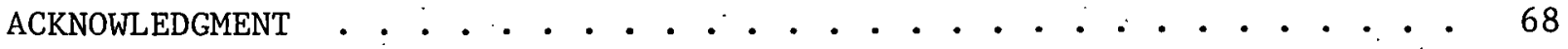

REFERENCES . . . . . . . . . . . . . . . . . . . . . 69 


\section{LIST OF FIGURES}

No.

1. SYNTHOIL Pilot Plant Flow Sheet . . . . . . . . . .... . 3

2. Flow Patterns That Can Be Observed In Upward Gas-Liquid Flow

3. Effect of the Gas and Liquid Velocity on the Patterns Developed in the Flow of Air-Water Mixtures . . . . . . . . 8

4. A Generalized Correlation for Predicting Flow Patterns . . . . . . 9

5. Hughmark-Pressburg Correlation for Pretirting Liquid Holdup . . . 10

6. Schematic Representation of Tubular Heater . . . . . . . . . . . . 12

7. Experimental Setup . . . . . . . . . . . . . . . . 13

8. Pressure Drop for the Flow of Nitrogen-Blandol 0il in the 1.27-cm-ID Tube................... 19

9. Pressure Drop for the Flow of Helium-Blandol Oil in the 1.27-cm-ID Tube.................. . 20

10. Pressure Drop for the Flow of Nitrogen-Blandol Oil Mixture in the $0.7-\mathrm{cm}$-ID Tube . . . . . . . . . . . . . .

11. Pressure Drop for the Flow of Helium-Blandol Oil Mixture in the $0.7-\mathrm{cm}$-ID Tube ................ 22

12. Pressure Drop for the Flow of Nitrogen-Kaydn1 nil Mlixture in the U.7-cm-ID Tube . . . . . . . . . . . . .

13. Pressure Drop for the Flow of Helium-Kaydol 0il Mixture in the 0.7-cm-ID Tube . . . . . . . . . . . . . 24

14. Irreversible Component of the Pressure Drop for the Flow of Nitrogen-Blandol Oil Mixture in the $0.7-\mathrm{cm}$-ID Tube . . . . . 26

15. Generalization of the Pressure Drop Data Taken from the 0.7-cm-ID Column with Lockhart-Martinelli Correlations . . . . .

16. Comparison of the Data Taken from the $0.7-\mathrm{cm}-\mathrm{dia}$ Tube with Those from the 1.27-cm-ID Tube Correlated with the Lockhart-Martinelli Parameters . . . . . . . . . . . . . 30

17. Effect of Viscosity of the Liquid Phase on the Total Pressure Drop in the 0.7-cm-ID Tube When Nitrogen is Used as the Gas Phase . . . . . . . . . . . . . . . . . . . 
LIST OF FIGURES (cont'd.)

No.

$\underline{\text { Title }}$

$\underline{\text { Page }}$

18. Effect of Viscosity of the Liquid Phase on the Total

Pressure Drop in the 0.7-cm-ID Tube When Helium is

Used as the Gas Phase . . . . . . . . . . . . . . 32

19. Effect of the Density of the Gas Phase on the Total

Pressure Drop in the 0.7-cm-ID Tube when the Less

Viscous Blandol Oil is Used as the Liquid Phase . . . . . . . . 34

20. Effect of the Density of the Gas Phase on the Total

Pressure Drop in the 0.7-cm-ID Tube When the More

Viscous Kaydol Oil is Used as the Liquid Phase. . . . . . . . . 35

21. Effect of the Tube Diameter on the Irreversible Component

of the Pressure Drop as Observed In the Flow of Nitrogen-

Blandol 0il Mixture on the 0.7-cm-ID and 1.27-cm-ID Tubes . . . 36

22. Avcrage Volumetric Liquid Holdup for the Flow of

Nitrogen-Blandol Oil Mixtures in the 1.27-cm-ID Tube . . . . . . . 38

23. Average Volumetric Liquid Holdup for the Flow of

Nitrogen-Blandol 0il Mixtures in the $0.7-\mathrm{cm}$-ID Tube . . . . .

24. Average Volumetric Liquid Holdup for the Flow of

Helium-Blandol. Oil Mixtures in the 0.7-cm-ID Tube . . . . . . . 40

25. Ave age Volumetric Liquid Holdup for the Flow of

Nit :ogen-Kaydol Oil Mixtures in the 0.7-cm-ID Tube . . . . . .

26. Ave :age Volumetric Liquid Holdup for the Flow of

Helium-Kaydol Oil Mixtures in the 0.7-cm-ID Tube . . . . . .

27. Correlation of the Holdup Data with the Hughmark-Pressburg

Paranieter and Comparison with Hughmark-Pressburg Correlation . . .

28. Effect of the Viscosity of the Liquid Phase on the Liquid Holdup in the $0.7-\mathrm{cm}-\mathrm{ID}$ Tube when Nitrogen is Used as the Gas Phase . . . . . . . . . . . . . . . . . .

29. Effect of the Viscosity of the Liquid Phase on the Liquid Holdup in the 0.7-cm-ID Tube When Helium is Used as the Gas Phase . . . . . . . . . . . . . . . . . . . .

30. Effect of the Density of the Gas Phase on the Liquid Holdup in the $0.7-\mathrm{cm}-\mathrm{ID}$ Tube . . . . . . . . . . .

31. Correlation of Holdup Data, Corresponding to Different Gases, with a Modified Superficial Gas Velocity . . . . . . . .

32. Flow Patterns Corresponding to the Flow of Nitrogen-Blandol Oil Mixtures in the 1.27-cm-ID Tube . . . . . . . . . . . . 


\section{LIST OF FIGURES (cont'd.)}

No. Title

33: Flow Patterns Corresponding to the Flow of

Helium-Blandol Oil Mixtures in the 1.27-cm-ID Tube. . . . . .

34. Flow Patterns Corresponding to the Flow of

Nitrogen-Blandol Dil Mixtures in the 0.7-cm-ID Tube . . . . . 52

35. Flow Patterns Corresponding to the Flow of

Helium-Blandol Oil Mixtures in the $0.7-\mathrm{cm}-\mathrm{ID}$ Tube . . . . . . . 53

36. Flow Patterns Corresponding to the Flow of

Nitrogen-Kaydol 0il Mixtures in the $0.7-$ m-ID Tubs . . . . . . 54

37. Flow Patterns Corresponding to the Flow of

Helium-Kaydol 0il Mixtures in the 0.7-cm-ID Tube . . . . . . . 55

38. Stress-Strain Relationship for Different Slurries

as Determined by the Straight-Tube Viscometer . . . . . . . . 58

39. Pressure Drop for the Flow of Nitrogen and 11 Percent

Coal Slurry in the $0.7-\mathrm{cm}-\mathrm{ID}$ Tube . . . . . . . . . . . . . . 60

40. Pressure Drops Corresponding to the Flow of

Nitrogen-Slurry Mixtures in the 0.7-cm-ID Tube

with the Concentration of the Slurry as a Parameter . . . . . . . 62

41. Pressure Drops Corresponding to the Flow of

Helium-Slurry Mixtures in the 0.7-cm-ID Tube

with the Concentration of the Slurry as a Parameter . . . . . .

42. Holdup Values Corresponding to the Flow of

Nitrogen-Slurry Mixtures in the 0.7-cm-ID Tube

with the Concentration of the Slurry as a Parameter . . . . . . 


\section{LIST OF TABLES}

No.

1. Physical Properties of Mineral Oils . . . . . . . . . . . . 15

2. Size Distribution of the Pulverized Coal Used in the Experiment . . . . . . . . . . . . . . . . 16

3. Densities of Slurries . . . . . . . . . . . . . . . . 16

4. Viscosities of Slurries . . . . . . . . . . . . . . 59 


\section{MULTIPHASE FLOW OF GAS-LIQUID AND GAS-COAL . SLURRY MIXTURES IN VERTICAL TUBES}

by

K. Javdani, S. Schwalbe, and J. Fischer

\section{ABSTRACT}

This research was done as a support study for the SYNTHOIL process and other coal liquefaction processes being developed to produce clean liquid fuels from coal: The objective of this work is to obtain experimental data on flow characteristics for upward flow of gas-liquid-solid mixtures in vertical tubes simulating conditions in the SYNTHOIL process. Study of the transport phenomena of multiphase mixtures is of importance to many chemical engineering operations in general and to some other coal conversion processes in particular. A brief review of the application of this work to existing processes is presented.

The first part of this program was devoted to study of the flow characteristics of two-phase gas-1iquid systems. The applicability of existing correlations in the literature to this research was tested at the conditions of high liquid viscosity and high gas density that will exist in the tubular heater of a SYNTHOIL plant. The gas-liquid flow data were then compared with results obtained in three-phase gas-slurry experiments. Gas-liquid mixtures consisting of nitrogen or helium and each of two types of mineral oils, of different viscosities, were used to provide data showing the effect on flow characteristics of a seven-fold variation in the density of the gas phase and a seven-fold variation in the viscosity of the liquid phase. In addition, two tubes of different diameters were used in the experiments to provide a means of evaluating the effect of the variation of the tube diameter on the flow characteristics.

In the second part of this research program, the flow characteristics of gas-slurry mixtures were investigated. The coal slurry was formed by adding pulverized Kentucky coal to mineral oil. Three different coal concentrations, up to 27.1 weight percent, were employed. Data on pressure drop and slurry holdup for the threephase system were obtained and were compared with the data for the flow of the two-phase gas-liquid mixtures.

The following observations pertain to the behavior in both the two-phase and the three-phase systems. The total pressure drop increases with liquid flow rate and, except tor some regions of low-liquid and low-gas superficial velocities, it also increases with gas flow rate. The frictional component of the pressure drop was correlated using the Martinelli parameters. It was found that the density of the gas phase has a large effect on the total pressure drop at large values of the superficial gas velocity corresponding to a f1lm flow regime. Tubes with small diameters were found to produce larger pressure drops at a given superficial 
velocity. This effect was small at low gas flow rates but increased as the gas flow rate increased.

The 1iquid holdup in the column decreased with increasing gas flow rate but increased with increasing liquid flow rate. Holdup increased slightly with increasing viscosity of the liquid phase. At lower densities of the gas phase, larger values of liquid holdup were obtained. The holdup data for different gases were plotted against a modified superficial gas velocity that was a function of the square root of the ratio of the densities of the two gases. The liquid holdup did not appear to be a function of tube diameter.

It was observed that film flow starts at much lower valucs of superficial gas velocity than had been previously reported for the type off twn-phase mixtures used in these experimenta. Within the range of liquid viscosities employed in these experiments (22-140 $\mathrm{cp})$, the liquid viscosity has a small effect on the location of the tilm flow border line. Within the slurry coal cuncentralion range (0-27.1 wt \%), the coal slurry behaves like a single-phase homogeneous Newtonian liquid, although the effective viscosity of the slurry changes with the coal ronrentration. Consequently, if the effective viscosity is used, the results obtained in the twophase flow experiments are equally applicable to the flow of gasslurry mixtures. Experimental data obtained with the gas-slurry mixtures verify this conclusion. Due to additional slip between the coal particles and the liquid phase, the holdup values in gas-slurry experiments are fnund to be slightly larger than the corresponding values for gas-1iquid systems.

\section{IN'RODUCTTON}

Thic reocarch project was done as a support study for the SYNI'HUIL process and other coal liquefaction processes being developed to produce clean liquid fuels from coal. The objective of this work is to obtain experimental data on flow characteristics for upward flow of gas-liquid-solid mixtures in vertical tubes simulating conditions in the SYNTHOIL process.

Study of the transport phenomena of multiphase mixtures is of importance to many chemical engineering operations in general, and to some coal conversion processes in particular. In the SYNTHOIL coal liquefaction process, a slurry composed of fine coal particles and the recycled product oil flows in a mixLure with a pressurized stream of hydrogen. 1 In this process, as seen in the flow sheet diagram of Fig. $1,{ }^{2}$ the three-phase mixture is pumped into a preheater where its temperature rises to $450^{\circ} \mathrm{C}$. At this temperature and under a hydrogen pressure of 2000-4000 psi, the molecular coal structure is broken up and most of the coal is converted to a liquid that is soluble in the carrier oil. I'he mixture then enters a fixed-bed catalytic reactor where additional liquefaction of coal particles, molecular cracking, and desulfurization occur. Subsequently, coal ash is removed, producing a clean fuel product. An almost identical situation exists in the "H-coal" liquefaction process; the only difference is that instead of a fixed-bed reactor, an ebullating catalytic reactor is used for the final stages of coal liquefaction and desulfurization. ${ }^{3}$ 


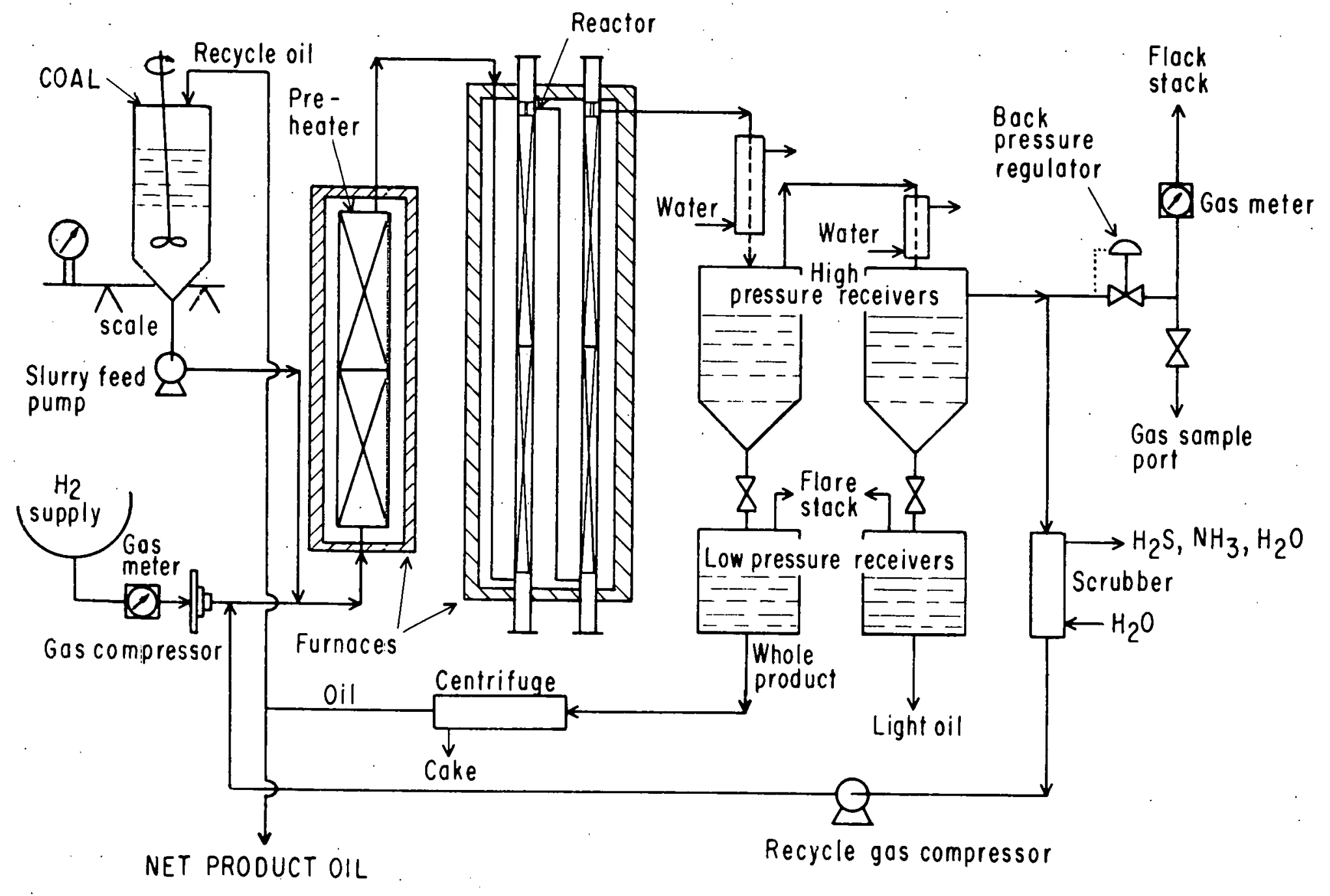

Fig. i. SYNTHOIL Pilot Plant Flow Sheet ${ }^{2}$ Used with permission of Institute of Gas Technology. 
Flow of three-phase gas-liquid-solid mixtures in pipes, tubular heaters, and reactors has other applications in industrial chemical engineering. A brief review of these applications and the existing processes has been presented by 0stergaard. ${ }^{4}$ These applications range from catalytic hydrogenation of organic material (such as liquid petroleum fractions, fatty oils, and glucose) to catalytic polymerization of ethylene in the production of certain types of polyethylene. Despite the relatively large number of applications of three-phase (gas-liquid-solid) systems in chemical engineering processes, a survey of the existing literature shows that limited research has been carried out on the fundamental characteristics of the flow of three-phase mixtures. Most previous investigations of three-phase systems were concerned with the behavior of two-phase gas-liquid mixtures flowing through fixed or fluidized beds of solid particles rather than the nature and properties of the flow of a three-phase mixture. ${ }^{5-7}$

In cuiltasl lo lie scalclly of Illeralure on three-phase flow systems, a great deal of scientific and technical information has accumulated in the literature on the characteristics of two-phase flow systems. A general index contalning over 5000 references up to the year 1966 on two-phase gas-liquid flow has been compiled by Gouse. ${ }^{8}$ More specific aspects of two-phase gasliquid flow have been reviewed by $\operatorname{Scott}^{9}$ and Alves. 10 More recent references, along with a comprehensive treatment of experimental and analytical aspects of two-phase flow in pipes, have been presented by Wallis ${ }^{\prime 1}$ and Govier and Aziz. ${ }^{2}$, The former reference emphasizes more analytical and fundamental aspects of the flow of two-phase mixtures, and the latter reference treats the problem from a more practical point of view and recommends design procedures suitable for different specific conditions.

In addition to the numerous investigations concerning flow behavior of two-phase mixtures, considerable attention has been directed toward heat trans-. fer and to some extent toward mass transfer problems related to the flow of such mixtures. Because of its specific application to the cooling of nuclear rcactors, most of the existing literature on two-phase flow heat transfer concerns heat transfer during two-phase flow with a phase change (namely, boiling). The index compiled by Gouse ${ }^{8}$ gives references up to the year 1966 on this subject too. Some experimental results on heat transfer coefficients in different flow regimes of two-phase flow in the absence of phase change have been reported by Kudirka. ${ }^{13}$ Also, a review of some past investigations on heat transfer in cocurrent gas-liquid flow in pipes has been presented by Scott ${ }^{9}$ and a more recent review by Alves. 10 Analytical techniques have been used for predicting heat transfer rates in two-phase flow systems, especia11y in the annular film flow regime. 14 Because of the complexity of the flow conflgurations and the need for approximate solutions, these techniques have not been successful. For this reason, empirical or semi-emplrfcal correlations are normally used in most of the design calculations.

The volume of literature on mass transfer in two-phase flow is relatively sma11 compared to that on heat transfer. Again, reviews by Scott ${ }^{9}$ and Alves 10 give some Indication of the state of the art on the subject of mass transfer in cocurrent gas-liquid flow. Cichy et $a$ l.15,16 have proposed mathematical models for interphase mass transfer in two-phase flow in pipes under different flow regimes and consequently have derived equations for the prediction of interphase mass transfer coefficients at different conditions. Recent publications pertaining to mass transfer in the flow of multiphase mixtures in tubes and packed and fluidized beds have increased the volume of the literature on this subject. 17-23 
The problem of immediate concern in this investigation is the flow characteristics of three-phase gas-1iquid-solid or simply gas-slurry mixtures. Unfortunately, in contrast to the two-phase flow systems, very little technical information is available on the flow behavior of gas-slurry mixtures. However, the properties of slurries themselves have been studied in more detail and it has been found that under certain circumstances and depending on the size and relative density of the solid particles, a slurry may have the flow properties of a homogeneous liquid.. When solid particles are small and their specific gravity is very close to that of the surrounding liquid, their settling rate will be minimal. Under these circumstances, the slurry behaves in the same manner as a liquid.

Criteria for distinguishing between homogeneous and heterogeneous slurry behavior have been presented in a publication by Aude et al. 24 Therefore, provided the criteria for the existence of a homogeneous slurry are satisfied, the problem involving the multiphase flow of gas-1iquid-solid (gas-slurry) mixture reduces to that of a gas-liquid two-phase flow; consequently, the analysis can be conducted using the established results for two-phase flow. systems.

It should be noted, however, that the physical properties and particularly the rheological behavior of the homogencous slurries may differ considerably from those of an ordinary Newtonian liquid. For this reason, direct application of the results obtained for two-phase flow of gas-liquid mixtures to problems involving the flow of gas-slurry systems may not be possible. Nevertheless, in the absence of any directly relevant data, the existing information on two-phase flow systems can be helpful in deciding which parameters are important in the study of gas-slurry systems and what kind of information should be obtained. Such information can be quite useful if it is found that the homogeneous liquid-solid mixture behaves very much like a Newtonian liquid.

In a recent review article, Jeffrey and Acrivos 25 discussed the general. rheological behavior or suspensions of rigid particles in liquids. Generally, it has been found that, for particles as small as a few microns or less, suspensions behave macroscopically as non-Newtonian fluids whose rheological properties are influenced by many factors, including particle size and concentration. For this reason, any experimental results in the literature involving two-phase flow of a gas and a non-Newtonian liquid may prove to be helpful in analyzing the corresponding problems in gas-slurry flows. Unfortunately, only in the last few years has attention been focussed on problems involving two-phase flow of gases and non-Newtonian liquids.26-30 Some experimental results that have been presented for pressure drop and holdup in vertical transport of a gas and a non-Newtonian liquid in cylindrical tubes show some differences from results with Newtonian liquids. However, due to a lack of sufficient data on this matter, generalization of the behavior of non-Newtonian liquids in two-phase flow can not be done with adequate confidence.

Although various generalized correlations exist in the literature for the prediction of flow characteristics of gas-liquid mixtures, it is doubtful that these correlations can be applied to all types of liquids and to all types of gases under all circumstances. Moreover, their applicability to multiphase gas-slurry systems, which is of special concern in this work, is not clear. For this reason, an experimental program was undertaken to investigate the special features involved in the flow of such mixtures. Fortunately, the 
existing results on the two-phase problems were found to be useful in setting a format for the research program.

A. General Features of Multiphase Flow in Vertical Tubes

Generally, two-phase flow studies involve the determination of three basic characteristics of flow as a function of the flow parameters. These characteristics are the flow pattern, the liquid holdup, and the pressure drop. In our fundamental research on the flow of gas-slurry mixtures, we will be looking for the same characteristics. To simplify the problem, we will limit our analysis to upward flow in circular tubes. In order to become familiar with the general behavior of a two-phase flow system, a brief description of each of the above characteristics will be presented here along with general methods that have been recommended for predicting them.

\section{B. Flow Yáeertin}

Determination of the flow pattern in a multiphase mixture is the most important step in evaluating the characteristics of the flow. In tubular flow of gas-liquid mixtures, different patterns develop due to interactions between the velocities and physical properties of the phases. These patterns relate to different flow regimes and, depending on the configuration of earh phase, they are referred to as bubble flow, slug flow, froth flow, annular film flow, and mist flow. The flow patterns that would he shserved in these regimes are seen in Fig. 2.11 This figure shows an example of the complexity of two-phase flow. Obviously, each flow regime requires a different method of analysis, and therefore one has to be able to predict the type of flow regime in a specific system. Actually, in some cases, a sequence of flow regimes may develop due to changes in operating conditions. If Fig. 2 is considered a section of an evaporator, then a sequence of flow patterns occurs as a result of more and more liquid converting into vapor.

Identification of the flow pattern in a given system is not easy. Depending on the velocities of the phases and their physical properties, different types of flow patterns can be established in a tube. Fig. 3 shows flow patterns observed in upward two-phase flow of air-water mixtures in cylindrical tubes. 12 General correlations have been proposed for the determination of the boundaries between different flow regimes.11,12 However, their validity for all types of gases and liquids is questionable since most of the experimental data have been obtained using air-water systems.

Figure 4 shows a generalized correlation for predicting the boundaries of various flow regimes in upward flow of gas-liquid mixtures in cylindrical tubes. 12 This correlation is reported to be in general agreement with most experimental results. However, no effect of viscosity or tube diameter on flow patterns is evident in this model. This result has generally been verified by some researchers, although some effect of diameter on the froth and mist regimes has been reported. This correlation has been recommended for overall assessment of the flow pattern that can be expected at specific conditions. It is believed that this correlation can be used with reasonable confidence for all gas-liquid systems. Unfortunately, considerable uncertainties exist in the use of this correlation for a practical application such as the SYNTHOIL process. The boundaries that separate different flow regimes in Fig. 4 are not as exact as is shown, and considerable deviation might occur in certain cases. 


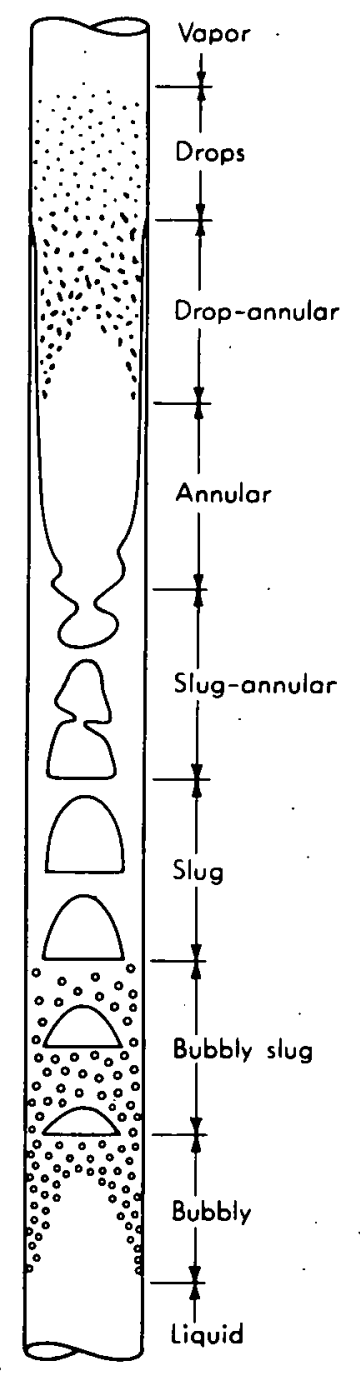

Fig. 2 .

Flow Patterns That Can Be Observed In Upward Gas-Liquid Flow 11 From One Dimensional Two-Phase Flow by G. B. Wallis, 1969. Used with permission of McGraw-Hill Book Company.

The uncertainties are relatively large in the SYNTHOIL process because of the rather extreme values of the physical properties (such as viscosity) of the fluids. Also, the effect of the solid particles on this flow classification is not clear. These results (Fig. 4) were obtained at long distances from the tube entrance; in a short tube, features may differ. The shape of a device used to mix the phases before they enter the tube is important in establishing a flow regime, especially in short tubes. For these reasons, correlations such as those in Fig. 4 may not be helpful in characterizing the type of llow that occurs in the SYNTHOIL proress. Identification of the flow. regimes should be done in an experiment that simulates the actual conditions existing in the SYNTHOIL process. 


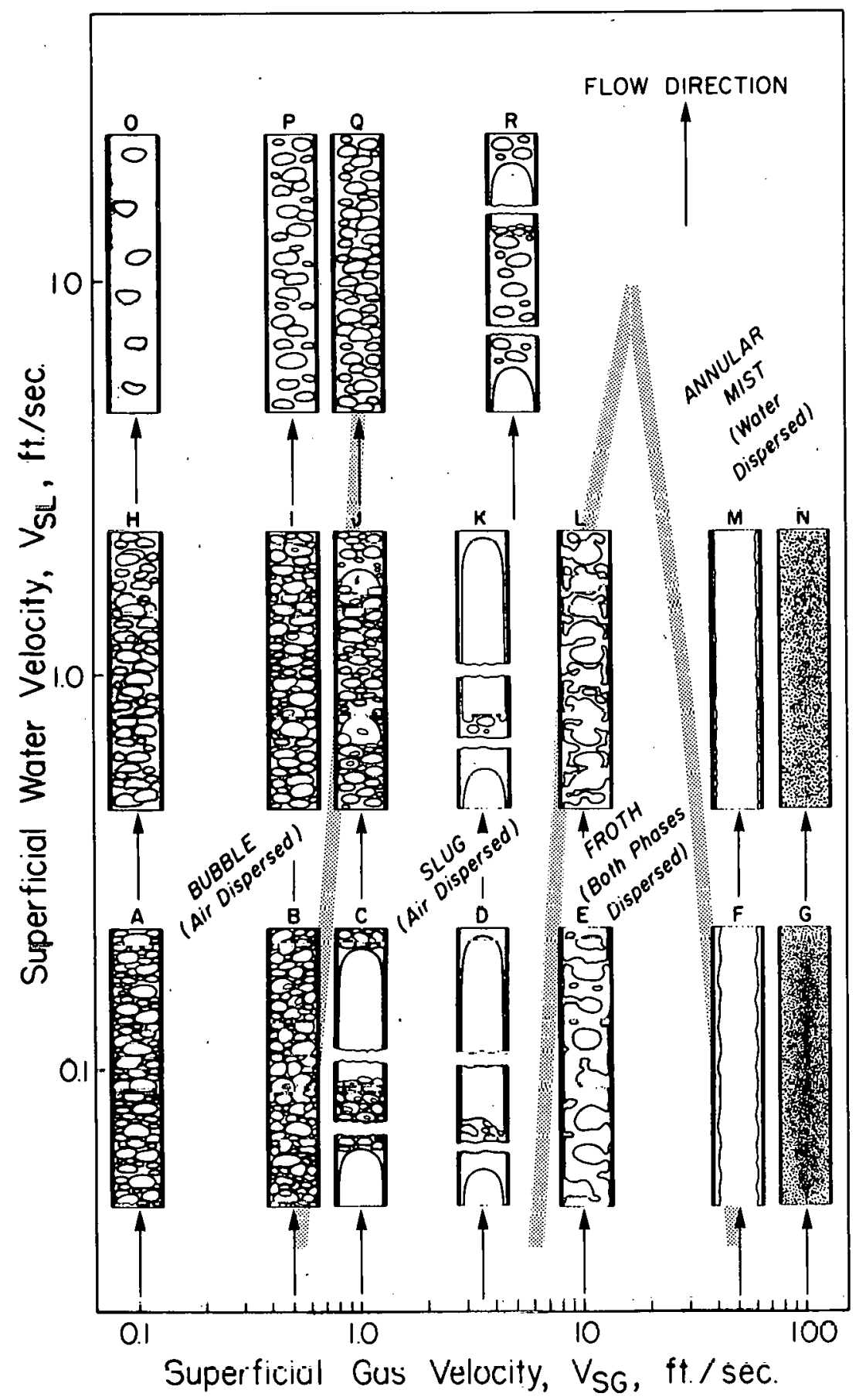

Fig. 3. Effect of the Gas and Liquid Velocity on the Patterns Developed in the Flow of Air-Water Mixtures 12 From The Flow of Complex Mixtures Through Pipes by G. W. Govier and K. Aziz. c 1972 by Litton Educational Publishing, Inc. Reprinted by permission of Van Nostrand Reinhold Company. 


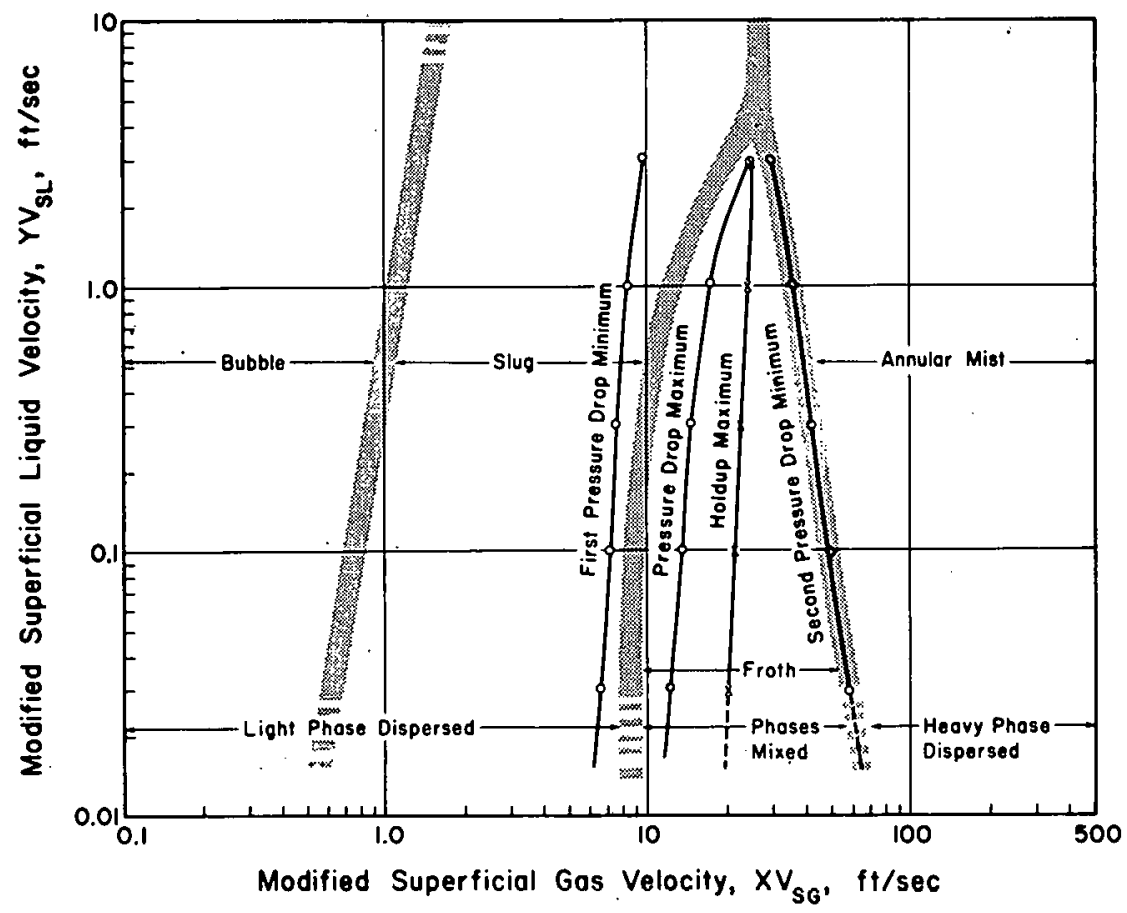

Fig. 4. A Generalized Correlation for Predicting Flow Patterns ${ }^{12}$ From The Flow of Complex Mixtures Through Pipes by G. W. Govier and K. Aziz. c 1972 by Litton Educational Publishing, Inc. Reprinted by permission of Van Nostrand Reinhold Company.

\section{Holdup}

In the flow of multiphase mixtures, each phase may have a velocity which differs than that for the other phase(s). This has normally been referred to as the slip velocity between phases. This slip velocity causes one of the phases to accumulate with respect to the other in the tube so that the ratio of the quantities of phases in a tube differs from the ratio of the entering quantities. This accumulation has been referred to as the holdup, which is a major characteristic of the flow. This characteristic has also been reported in the literature in terms of slip factor, holdup ratio, or volume fraction of liquid (in situ; cross sectional average, or volumetric average) in the column.11,12 As mentioned previously, data corresponding to three-phase mixtures cannot be found; numerous data in the literature pertain only to the flow of two-phase mixtures, mostly air-water systems. A typical correlation is given in Fig. 5.31 The data for this correlation has been obtained in a 1-in. pipe, using mixtures of air and liquids having viscosities ranging from that of water to $30 \mathrm{cp}$. The effect of tube diameter does not appear in this correlation. This has been checked against air-water data of other studies in which tube diameters ranging from 0.4 to 3.24 in. were used. Generally good agreement has been found. 


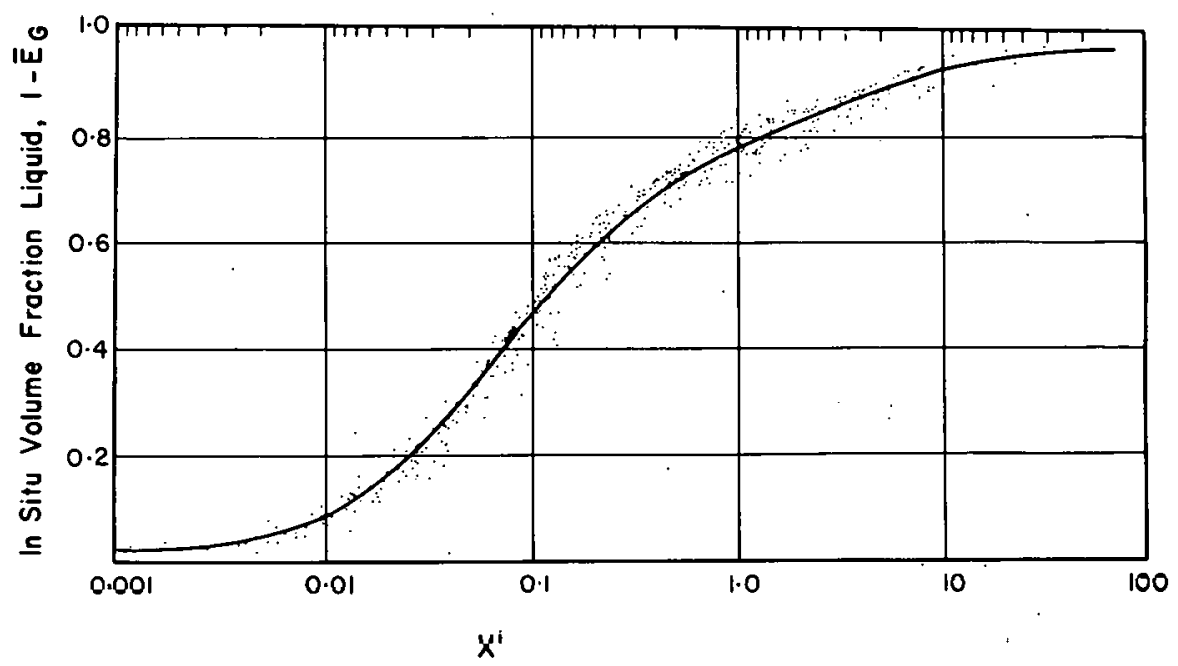

Fiz. 5. Ilughulah-Pressburg Correlation for fredicling Liquid Holdup 31 Reprinted by permission of Chemical Engineering Progress.

\section{Pressure Drop}

Pressure drop in the flow of multiphase mixtures in tubes is important for the design of tubular sections of the process equipment and for the selection of pulms and compressnrs. In addition, abrupt changes in the slopes of pressure drop curves can be attributed to changes from one type of flow to another and hence can be used to identify the conditions corresponding to border lines between different flow patterns.

The pressure drop, measured experimentally for the flow of a inultiphase mixture in a vertical tube, usually consists of (1) the pressure drop due to the static head of the mixture in the tube and (2) that due to frictional losses and acceleration effects. Arbitrary definitions have been used to. separate these components from the total pressure $108 \varepsilon$ and to usc the frictional component of the pressure drop to define dimensionless quantities used in generallzation and correlation of experimental data with different flow variables. Among the dimensionless quantities that have heen proposed for gas-1iquid two-phase flow, one can refer to the Martinelli parameter ${ }^{32}$ that is essentially the ratio of the frictional pressure drop of the twn-phase flow to the frictional pressure drop that would have existed if only one phase was flowing by itself. Another quantity that has been defined as a measure of frictional pressure drop in the tube is the conventional friction factor (for two-phase flow) based on the superficial velocities of gas or liquid. However, as was the case with the determination of flow pattern and the prediction of holdup, all existing correlations correspond to two-phase flow systems, mostly involving air and water, and hence may not agree with experimental data obtained under all conditions.

It should be reemphasized that the correlations available in the literature for predicting the flow characteristics of two-phase mixtures may not be applicable in a given situation, especially if the physical properties of the 
fluids being studied at ANL deviate greatly from those corresponding to the bulk of the data used for obtaining the correlations. Indeed, such a situation exists in the SYNTHOIL process. In addition to solid particles being present, the nature and physical properties of the gas and liquids involved make it uncertain whether the correlations in the literature can be applied to the problem at hand. For this reason, a series of experiments was carried out using fluids closely resembling those used in the SYNTHOIL process, and the applicability of the correlations in the literature for predicting the flow characteristics in the SYNTHOIL tubes was tested.

\section{E. Relevance of the Research Project to the SYNTHOIL Process}

In the SYNTHOIL coal liquefaction process, ${ }^{1}$ the feed mixture to the preheater vessel (upstream from the catalytic reactor) consists of hydrogen, recycled oil product, and pulverized coal particles. The feed oil mixture has a coal concentration of about $35 \mathrm{wt} \%$. A temperature of $450^{\circ} \mathrm{C}$ is maintained in: the reactor, and the hydrogen pressures used have been in the range of 2000 to 4000 psia. ${ }^{2}$ The hydrogen flow rate is reported to be $1300 \mathrm{scfh}$, corresponding to a slurry flow rate of $25 \mathrm{lb} / \mathrm{hr}$. These figures yield a hydrogen to slurry volume ratio of approximately 70 to 1 at $450^{\circ} \mathrm{C}$ and 2000 psia and 35 to 1 at $450^{\circ} \mathrm{C}$ and $4000 \mathrm{psi}$. The slurry flow rate was calculated assuming a specific gravity of 1.1 for the slurry. Thus in the SYNTHOIL process, we encounter a three-phase flow of gas, liquid, and solid. The flow properties of this mixture have a direct effect on the physical and chemical changes that occur in the process. Physical and chemical changes occur in the following steps: heating and cooling of the mixture in tubular heaters and coolers, devolati1ization and subsequent change in the volume of the coal particles, generation of gases due to hydrogenation and hydrocracking, and eventual dissolution and hydrogenation of coal particles in the preheater and reactor. Theoretical analysis, as well as interpretation of experimental data for such changes, requires an understanding of the flow characteristics of the mixture. Also, optimum design, scaleup, and efficient operation of the SYNTHOIL process are dependent on information about the flow characteristics of the three-phase mixture at various stages of the process. Figure 6 shows a schematic representation of one stage of the process, namely, heating in the tubular preheater. Heat transfer coefficient data are needed for the design of such heat exchangers. In fact, investigations to obtain such data are currently under way. ${ }^{3} 3$ Such data is normally obtained by measuring the inlet and outlet bulk temperatures and the heat flux from the wall. Obviously, the heat transfer rate between the wail and the mixture inside the tube will depend on the type of flow and on the fractional amounts of liquid and solid in the tube. Moreover, knowledge of these flow characteristics inside the tubular heater is essential for correlating the experimental data and for choosing appropriate dimensionless numbers to correlate the results. Furthermore, utilization of this data in the design and scaleup of the actual SYNTHOIL process requires that the flow patterns and fractional holdup in the actual scaled-up heat exchanger be predicted. 


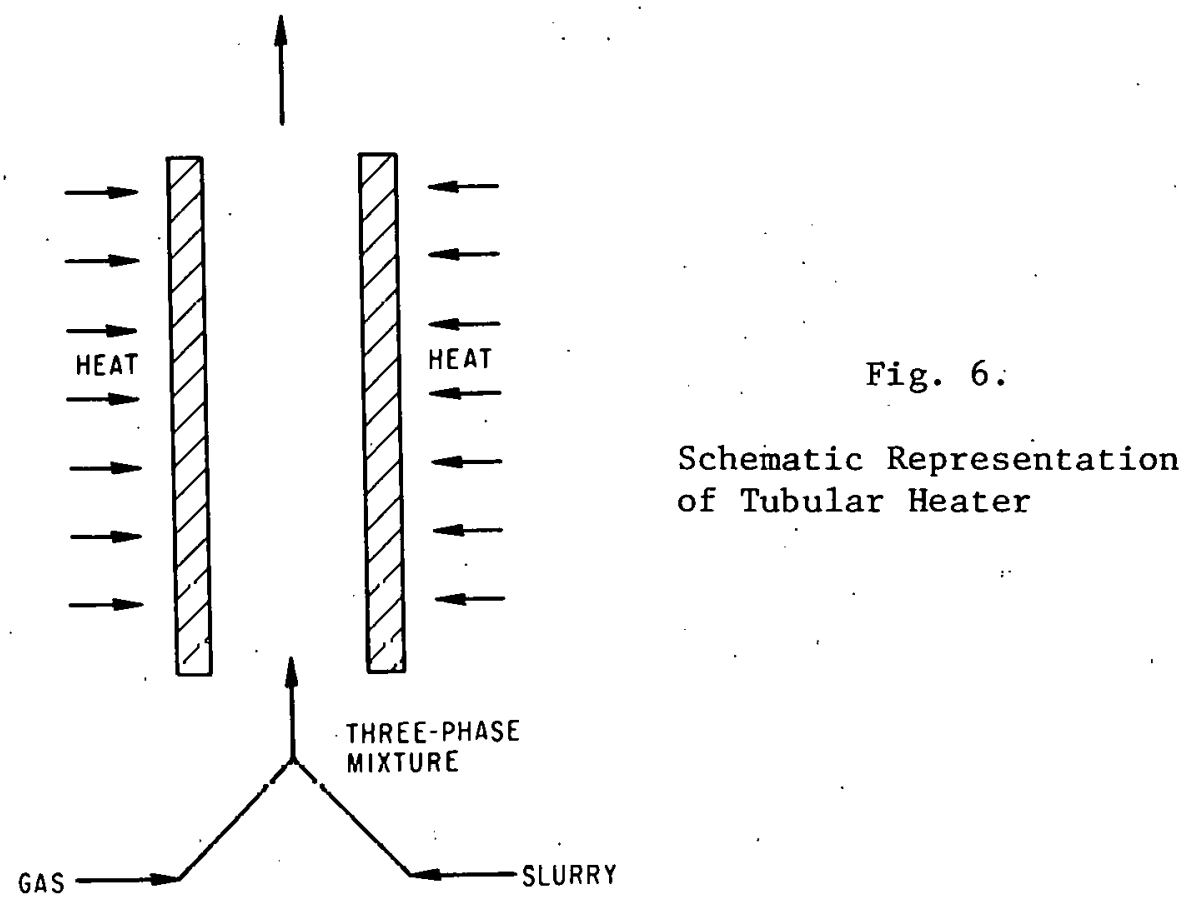

II. OBJECTIVES

The objectives of this research are to measure the important parameters of multiphase upward flow in cylindrical tubes, using fluids that at ambient conditions closely resemble those that exist in the SYNTHOIL process at the prevailing temperature and pressure, and to produce results that will be helpful in clarifying the flow characteristics encountered in the SYNTHOIL process...

The parameters that were investigated were pressure drop and holdup during: upward flow of gas-slurry mixtures in cylindrical tubes. The types of flow regimes that occur under different flow conditions were identified. Although a large volume of data and a number of correlations for the prediction of these characteristics exist for gas-liquid systems, some experiments were carried out using gas-liquid mixtures as well. This was done because of the uncertainty of applying the existing correlations to the special gas-liquid systems of the SYN'LHOIL process since the viscosity of the circulating-oil product in the SYNTHOIL process differs considerably from the viscosities of the liquids generally used in previous experiments. Also, due to the high pressure in the SYNTHOIL process, the density of the gas is considerably greater than was used in earlier experiments. Moreover, since the behavior of gas-liquid-solid (gasslurry) flow had to be compared with the flow behavior of the mixture in the absence of the solid particles, it was essential that some experiments on the two-phase flow of gas-liquid systems also be performed.

\section{EXPERIMENTAL}

\section{A. Apparatus}

The experimental unit used for measuring the flow characteristics is shown schematically in Fig. 7. It consisted of a vertical glass tube approximately 


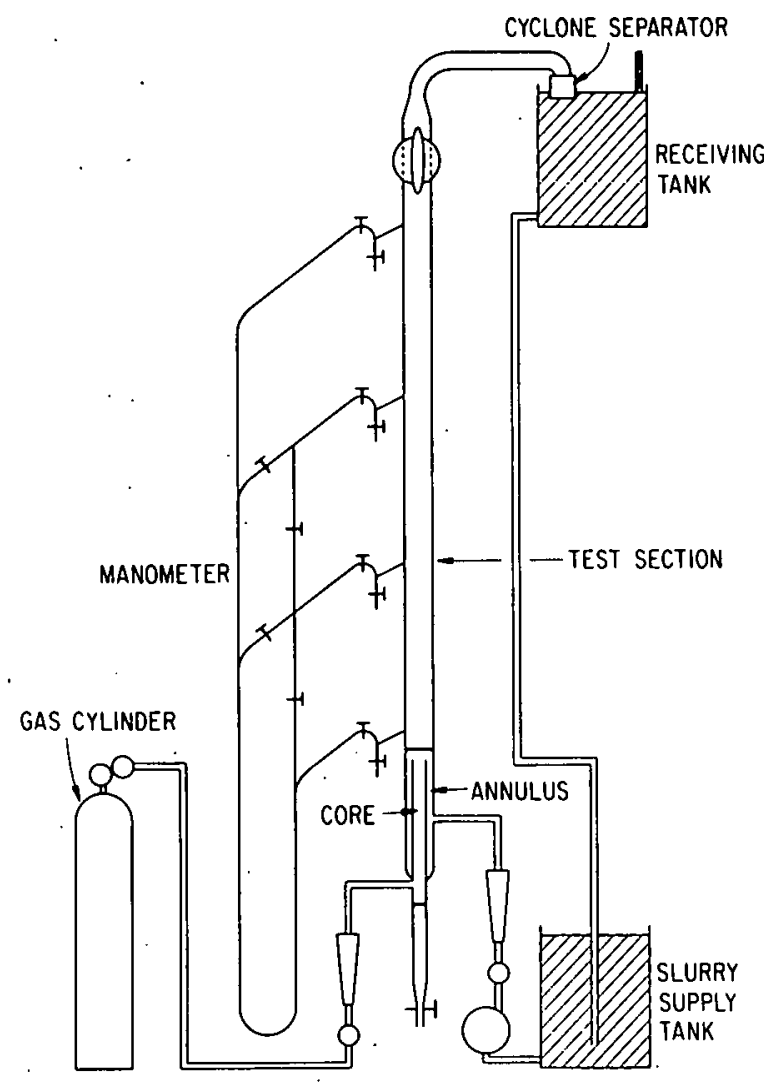

Fig. 7.

Experimental Setup (not to scale)

$240 \mathrm{~cm}$ long which was used as the test section for measuring the pressure drop and holdup and for observing the flow patterns in the gas-liquid (or gas-slurry) flow. In order to determine the effect of the diameter of the tube on the above flow characteristics, experiments were conducted using two columns, one with $0.70-\mathrm{cm}$ ID and the other with $1.27-\mathrm{cm}$ ID.

The liquid or slurry was pumped from a tank through the annular space of the inlet scction into the bottom of the vertical glass tube test section. An Oberdorfer helical rotary positive displacement pump was used for this purpose. This type of pump, designed to handle slurries and high viscosity liquids, was driven by a 1/3-hp a-c motor, and was equipped with a "Zero-Max" gear reduction drive to permit adjustment and control of the flow rate.

The rate of flow of liquid into the column was measured with calibrated rotameters. However, use of the rotameters proved to be impractical for measuring the slurry flow rate during the gas-slurry experiments. The coal particles in the slurry lodged between the rotameter bob and the inner wall of the rotameter tube and prevented proper positioning of the bob. For this reason, the slurry flow rate was determined by measuring the pressure drop across a flow restriction. A horizontal straight-tube viscometer was used to measure the slurry flow rate. By measurement of the pressure drop produced in this horizontal tube and use of a predetermined $\mathrm{D} \Delta \mathrm{P} / 4 \mathrm{~L}$ vs. $8 \mathrm{u}_{\mathrm{m}} / \mathrm{D}$ curve (equation) 2 in Section $C$, below), the average velocity in the tube and hence the flow rate could be easily determined. The only disadvantage of using this device for 
flow measurement is that the pressure drop in the tube is produced by viscous effects and is therefore sensitive to variations in temperature. This effect could have been minimized by using a venturi-meter, but because deposition of coal particles in its throat that would have resulted in a change in the throat area and loss of accuracy, the idea of using a venturi-meter was discarded.

Gas from a pressurized cylinder entered the test section through the core of the annular inlet section. Gas flow rate from the cylinder was controlled by a pressure regulator and a needle valve and was measured using two Brooks rotameters, one for high flow rates and one for low flow rates. The readings from the rotameters, calibrated at atmospheric pressure, were corrected for the higher pressure that normally existed in the gas line during the experiments. This pressure was measured with a mercury mamometer permanently connected to the pressure tap on the test section nearest to the inlet device (see Fig. 7). Both the liquid and the gas inlet lines could be direrter through ball valveo to cither tube.

The gas-1iquid (gas-slurry) mixture passed through a large stopcock at the top of the test section into a cyclone separator and was collected in a receiving tank. The cyclone separator captured the liquid droplets entrained in the mixture in the form of mist. The receiving tank was connected to the atmosphere through a 20-cm-long column packed with small metal Raschig rings as a precaution for capturing still-entrained droplets and particles. In gas-: liquid experiments, the receiving tank was connected to the supply tank so that a continuous flow of oil was maintained during the experiment. In gasslurry experiments, however, the pumped slurry was kept in the receiving tank until the end of the experiment, after which it was mixed thoroughly and returned into the supply tank. In the supply tank, the slurry was kept well mixed with a 1/8-hp "Lightning" mixer and by frequent manual stirring.

Four pressure taps were provided on the side of the test section at intervals of $61 \mathrm{cml}$. Pressure drop measurements were taken between the top two taps, located $134 \mathrm{~cm}$ and $195 \mathrm{~cm}$ from the inlet device. Depending on the magnitude. of the pressure drop, water or mercury differential manometers were connected to the taps. To prevent the liquid in the test section from entering the manometer tube, a $125-\mathrm{m} 1$ separatory funnel was located between each tap and the manometer tube as a pressure vesse1. Appropriate minor corrections were then applied to the manometer reading, which actually measured the pressure difference between the vessels. Such vessels were used with all manometers in the equipment.

The volumetric fraction of the liquid. (or slurry) in the test section was measured by shutting off the liquid (or slurry) and gas inlet 1 ines, simultaneously closing the stopcock on the top of the test section, and measuring the amount of liquid (or slurry) captured in the test section. For this purpose, both the gas and liquid inlet lines were equipped with solenoid valves that, when actuated, would turn off the liquid pump and stop the flow of liquid and gas into the column.

The establishment of different flow patterns and their transition from one regime to another as a function of the liquid and gas flow rates was detected visually. Such visual observations became more difficult in gas-slurry experiments, especially at low flow rates in slug and froth flow regimes. 


\section{B. Gas-Liquid Mixtures}

Since the experiments were carried out at ambient pressure and temperature, the liquids and gases to be used were chosen in such a way that their physical properties at ambient conditions resembled those of the fluids in the actual SYNTHOIL process at the operating conditions. The viscosity of the circulating SYNTHOIL product had not been measured previously at operating conditions. Only recently have some viscosity measurements been made on SYNTHOIL 1iquid between $49^{\circ} \mathrm{C}$ and $201^{\circ} \mathrm{C} .{ }^{34}$ These measurements show that within this range, the viscosity of the centrifuged SYNTHOIL product varies from about $6500 \mathrm{cp}$ to about $6 \mathrm{cp}$. No data is available on the viscosity of the SYNTHOIL product at $450^{\circ} \mathrm{C}$. Also adding uncertainty, the viscosity of the product SYNTHOIL is a very strong function of its asphaltene content and therefore, depending on the degree of hydrogenation and liquefaction of coal, varies considerably from one batch to another. ${ }^{35}$ For this reason, the liquid phase used in the experiments had to be selected in such a way that the data obtained in these experiments, along with those existing in the literature, would cover a wide range of liquid viscosity and hence establish the effect of liquid viscosity on the characteristics of flow. Accordingly, two white mineral oils manufactured by Matheson, Coleman, and Bell under the trade names of "Blandol" and "Kaydol", with viscosities of $23.3 \mathrm{cp}$ and $137 \mathrm{cp}$, respectively, at $25^{\circ} \mathrm{C}$ were used in the experiments. The physical properties of these oils that are relevant to their flow characteristics and their dependence on temperature are shown in Table 1 . The viscosity data were obtained using an Ubbelhode capillary viscometer for the Blandol oil and a Brookfield Synchro-Lectric viscometer for the more viscous Kaydol oil. Surface tensions were measured with a platinum ring DuNouy surface tensiometer. Oil densities were determined with hydrometers.

Table 1. Physical Properties of Mineral Oils

\begin{tabular}{|c|c|c|c|c|}
\hline $\begin{array}{c}\text { Type of } \\
\text { Mineral Oil }\end{array}$ & $\begin{array}{c}\text { Temperature } \\
\left({ }^{\circ} \mathrm{C}\right)\end{array}$ & $\begin{array}{l}\text { Density } \\
(g / c c)\end{array}$ & $\begin{array}{l}\text { Viscosity } \\
\text { (cp) }\end{array}$ & $\begin{array}{l}\text { Surface Tension } \\
\text { (dyne/cp) }\end{array}$ \\
\hline Blando1 & $\begin{array}{l}22.5 \\
24.8 \\
27.0\end{array}$ & $\begin{array}{l}0.843 \\
0.842 \\
0.840\end{array}$ & $\left.\begin{array}{l}25.8 \\
23.5 \\
21.3\end{array}\right\}$ & 29 \\
\hline Kaydol & $\begin{array}{r}25.7 \\
26.8 \\
\therefore \quad 28.0\end{array}$ & $\begin{array}{l}0.876 \\
0.875 \\
0.874\end{array}$ & $\left.\begin{array}{l}134.0 \\
126.0 \\
119.0\end{array}\right\}$ & 31 \\
\hline
\end{tabular}

In the actual SYNTHOIL process, the densities of hydrogen at $450^{\circ} \mathrm{C}$ and 2000 or $4000 \mathrm{psi}$ are $0.287 \mathrm{lb} / \mathrm{ft}^{3}$ and $0.574 \mathrm{lb} / \mathrm{ft}^{3}$ respectively. Obviously, it is impossible to find a gas having a comparable density at ambient conditions. Nevertheless, study of the effect of the density of the gas phase on the flow characteristics could provide the necessary data for extrapolation of the results to higher densities. For this reason, experiments were carried out using nitrogen and helium, which provided results corresponding to a sevenfold variation in the density of the gas phase. 


\section{Slurries}

In the selection of a suitable solid particle to be used in the experiments involving the flow of gas-liquid-solid mixtures, the two most important characteristics to consider were density and the necessity of creating a "freeflowing" mixture. Some of the more obvious solids such as glass were quickly ruled out because, given their density, the settling rate was impractical in the range of the desired particle size distribution $(-100+230$ mesh $)$. A number of copolymers of the type used for water treatment and for ion exchange. columns were tested, but even when the settling rate could be brought into an acceptable range, these particles were not suitable because of their tendencies to cling to the inside glass wall or to "clump" and thereby prevent the mixture from being free flowing. Coal itself turned out to be the best of the materials tested, with its density and settling rate being relatively acceptable, but with the obvious disadvantage that it presented certain diffirultips tn visual observation of flow patterns.

Pulverized Kentucky coal furnished by Pittsburgh Energy Research Center was added to Blandol oil for making the slurry. The size distribution of this coal is shown in Table 2.

Table 2. Size Distribution of the Pulverized Coal Used in the Experiment

\begin{tabular}{cc}
\hline Percent Weight of Coal & Particle Mesh Size \\
\hline 1.1 .2 & $>80$ \\
11.7 & $80-100$ \\
16.7 & $100-200$ \\
60.4 & $<200$ \\
\hline
\end{tabular}

In the gas-slurry flow experiments, three different mixtures of 11.0 , 20.4 , and 27.1 weight percent coal in Blandol oil were used as slurries. Since most of the particles were smaller than $177 \mu \mathrm{m}$ and their specific gravity was approximately 1.1 , the coal-Blandol oil mixture could be considered as a homogeneous slurry. 24 , Densities, of the three slurries as measured by hydrometers are shown in Table 3.

Table 3. Densities of Slurries

\begin{tabular}{ccc} 
& \\
Coal (wt \%) & Temp $\left({ }^{\circ} \mathrm{C}\right)$ & Density $\left(\mathrm{g} / \mathrm{cm}^{3}\right)$ \\
\hline 0.0 & 27.0 & 0.840 \\
11.0 & 30.0 & 0.875 \\
20.4 & 27.9 & 0.918 \\
27.1 & 29.0 & 0.948 \\
\hline
\end{tabular}


Determination of the rheological properties of slurries is essential in the study of their flow behavior. As was discussed in the previous section, depending on the size and concentration of the solid particles, slurries have been reported to act like non-Newtonian liquids. 25,36 A horizontal straighttube viscometer is a very simple device to measure the rheological properties of a liquid and to determine the presence of any non-Newtonian behavior. In this device, the pressure drop between two points along the tube is measured as a function of the average velocity of the fluid in the tube. It can be shown ${ }^{37}$ that in the flow of any rheologically time-independent fluid in a tube, the shear stress at the wall, $\tau_{W}$, is related to the nominal shear rate in the tube, $\gamma$, in the following form:

$$
\tau_{W}=k^{\prime} r^{\prime}
$$

where $\mathrm{n}^{\prime}$, known as "the flow behavior index," characterizes the degree of nonNewtonian behavior of the fluid and $k$ ' is the consistency index of the fluid. For the straight-tube viscometer of length $\mathrm{L}$ and diameter $\mathrm{D}$, it can be shown that $\tau_{W}=\mathrm{D} \Delta \mathrm{P} / 4 \mathrm{~L}$ and $\gamma=8 \mathrm{u}_{\mathrm{m}} / \mathrm{D}$ so that Equation 1 becomes:

$$
\frac{\mathrm{D} \Delta \mathrm{P}}{4 \mathrm{~L}}=\mathrm{k}^{\prime}\left(\frac{8 \mathrm{u}_{\mathrm{m}}}{\mathrm{D}}\right)^{\mathrm{n}^{\prime}}
$$

where $\Delta \mathrm{P}$ is the pressure drop and $\mathrm{u}_{\mathrm{m}}$ is the average velocity in the tube. Simultaneous measurement of these two quantities in a given viscometer and a logarithmic plot of the resulting data would yield corresponding values for $n^{\prime}$ and $k^{\prime}$. For $n^{i}$ equal to one, the fluid is Newtonian and the parameter $k^{\prime}$ becomes equal to the viscosity of the fluid. On the other hand, for values of $n$ ' different than unity, the fluid is non-Newtonian (for $n$ ' $>1$ the fluid is called pseudoplastic, and for $n^{\prime}<1$ the fluid is called dilatant). Such measurements were carried out using a straight $0.42-\mathrm{cm}-\mathrm{ID}$ glass tube, $60 \mathrm{~cm}$ long. The results obtained on the three slurries used in the experiments are presented in the next section.

A Synco-Lectric Brookfield viscometer was also used to measure the viscosity of the slurries at different angular speeds. The results of such measurements and some of the apparent discrepancies with the results obtained from the straight-tube viscometer also are discussed in the next section.

\section{RESULTS}

\section{A. Gas-Liquid Flow Characteristics}

The flow characteristics were measured as a function of the superficial velocity of gas and liquid. In addition, by using two different gases, namely, nitrogen and helium, two different liquids, namely, Blandol and Kaydol mineral oils (see Section III.B), and two different test sections (of $0.7-\mathrm{cm}$ and $1.27-\mathrm{cm}$ inside diameter), the effects on flow characteristics of the density of the gas phase, the viscosity of the liquid phase, and the diameter of the tube were studied. 


\section{Pressure Drop}

Pressure drops were measured between the top two pressure taps on the test section (see Fig. 7) which were $134 \mathrm{~cm}$ and $195 \mathrm{~cm}$ from the inlet device. The experimental results corresponding to the flow of two different gases with two different liquids (producing a combination of four different mixtures) in two different test sections are presented in Figs. 8 to 13 . In these graphs, the pressure drop per unit length between the two taps has been plotted as a function of the superficial gas velocity with the superficial liquid velocity as a parameter. Qualitative agreement exists between the shape of these curves and the shape of curves reported elsewhere for other types of gas-1iquid mixtures. 12

As is mentioned above, the pressure drop, $\Delta \mathrm{P}$, as measured in these experiments, accounts for the total pressure loss due to the static head of the mixture in the tube and that due to the frictional losses (we assume that pressure loss due to accelerational effects are minimal). Arbitrary definitions have been used to separate these components from the total pressure loss. One such definition leads to the following equation: ${ }^{12}$

$$
\frac{\Delta \mathrm{P}}{\Delta \mathrm{Z}}=\left(\frac{\mathrm{V}_{\mathrm{SG}} \rho_{\mathrm{G}}+\mathrm{V}_{\mathrm{SL}} \rho_{\mathrm{L}}}{\mathrm{V}_{\mathrm{M}}}\right)\left(\frac{\mathrm{g}}{\mathrm{g}_{\mathrm{C}}}\right)+\frac{\Delta \mathrm{P}_{\mathrm{f}}}{\Delta \mathrm{Z}} \text { * }
$$

in which $\Delta \mathrm{P}_{\mathrm{f}}$ is the pressure loss due to the irreversibilities of the flow and

$$
\mathrm{V}_{\mathrm{M}}=\mathrm{V}_{\mathrm{SG}}+\mathrm{V}_{\mathrm{SL}}
$$

The first term on the right-hand side of Equation 3 represents the pressure loss due to the hydrostatic head of the mixture in the tube; however, this term does not include the effect of fractional holdup of either phase. Another term that incorporates this effect in the hydrostatic pressure loss has also been suggested in the literature; ${ }^{12}$ however, that term is not preferred because it requires knowledge of an additional flow characteristic, namely, holdup, in calculating the pressure drop.

Study of Figures 8 to 13 reveals that the total pressure drop strongly depends on the magnitudes of the liquid and gas superficial velocities. At low values of $V_{S L}$ and $V_{S G}$, the total pressure drop decreases to a minimum value with increasing gas flow velocity. This kind of behavior can be seen clearly from some of the data for the 1.27-cm-TD column in Fig. 8 and 9 , where low values of $\mathrm{V}_{\mathrm{SG}}$ are employed. In this part of the curve, the magnitude of the total pressure drop is dominated by the contribution from the hydrostatic pressure loss. Since $V_{S L} \rho_{T}$ is much larger than $V_{S G} \rho_{\beta}$, the contribution from the static head decreases with increasing values of $v_{S G}$, as seen from the first term on the right hand side of Equation 3. Also, as will be shown later, the liquid holdup in the column decreases at increasing values of $V_{S G}$ and since the liquid phase contributes to almost all of the hydrostatic head loss, this loss decreases at higher values of the superficial gas velority. However, due to the tendency of the frictional pressure drop to increase with gas velocity, the total pressure drop passes through a minimum at some point.

\footnotetext{
* Symbol definitions are listed at the end of this report.
} 


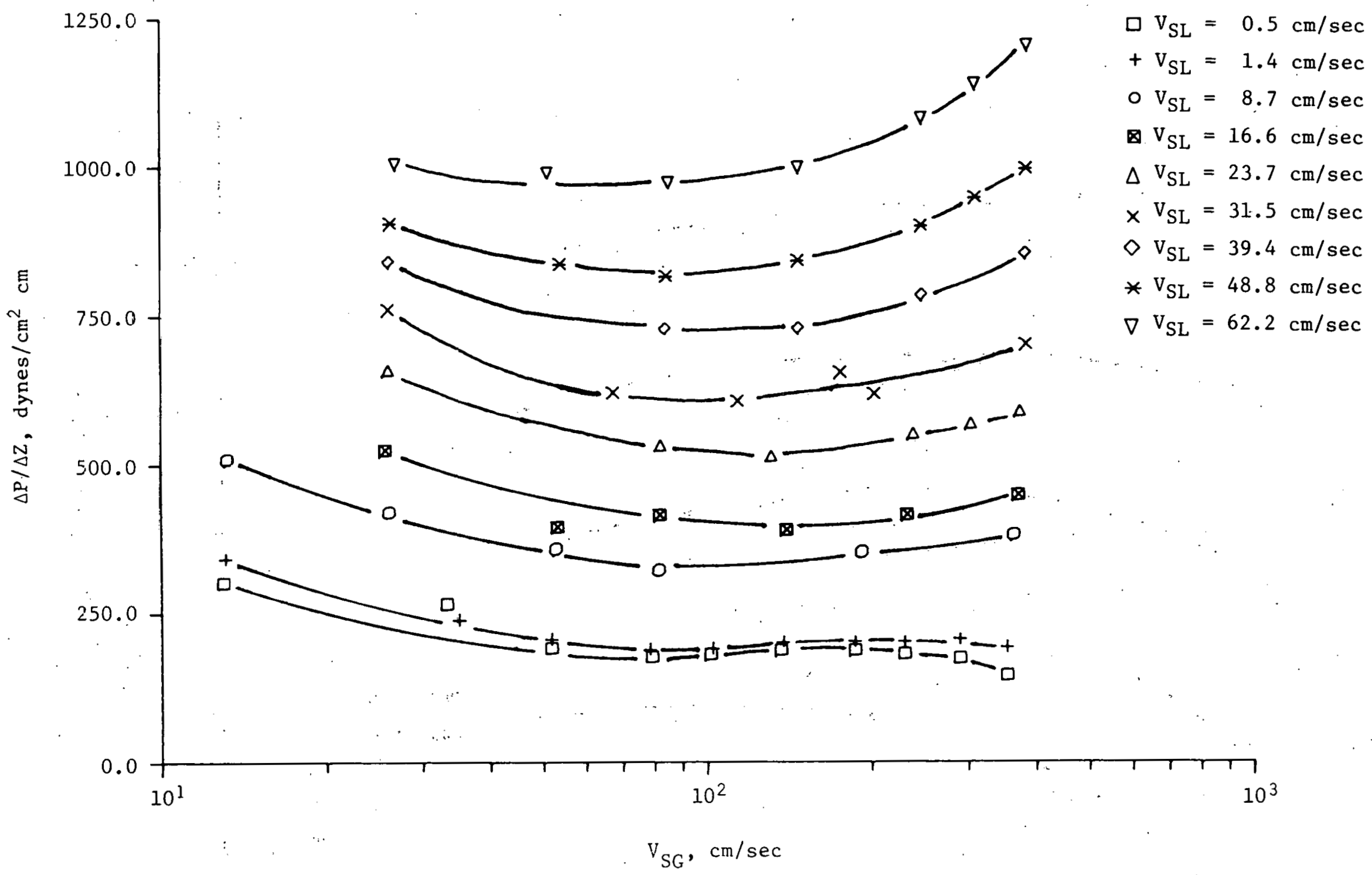

Fig. 8. Pressure Drop for the Flow of Nitrogen-Blandol 0il in the 1.27-cm-ID Tube 


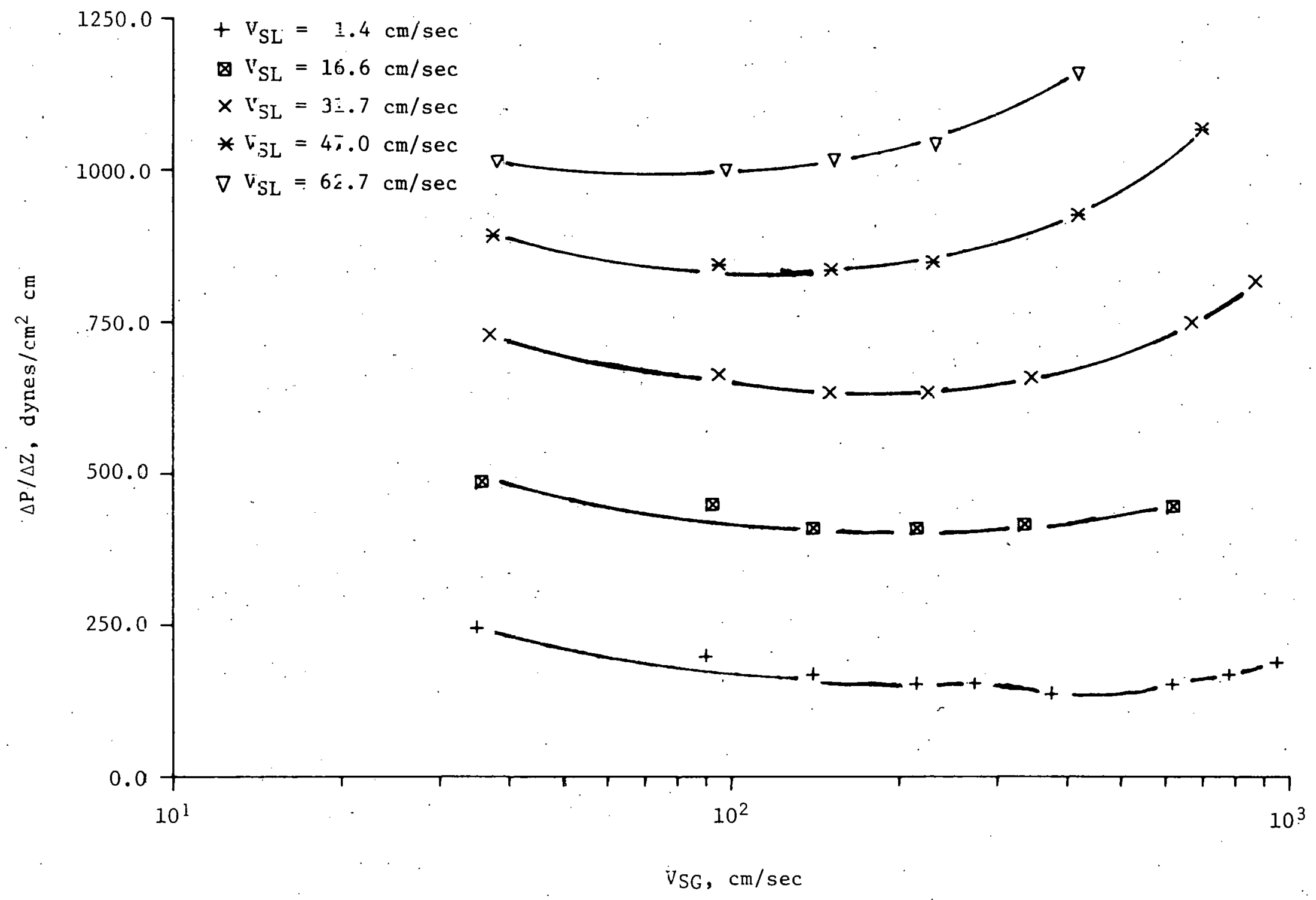

Fig. 9. Pressure Drop for the Flow of Helium-Blandal Oil in the 1.27-cm-ID Tube 


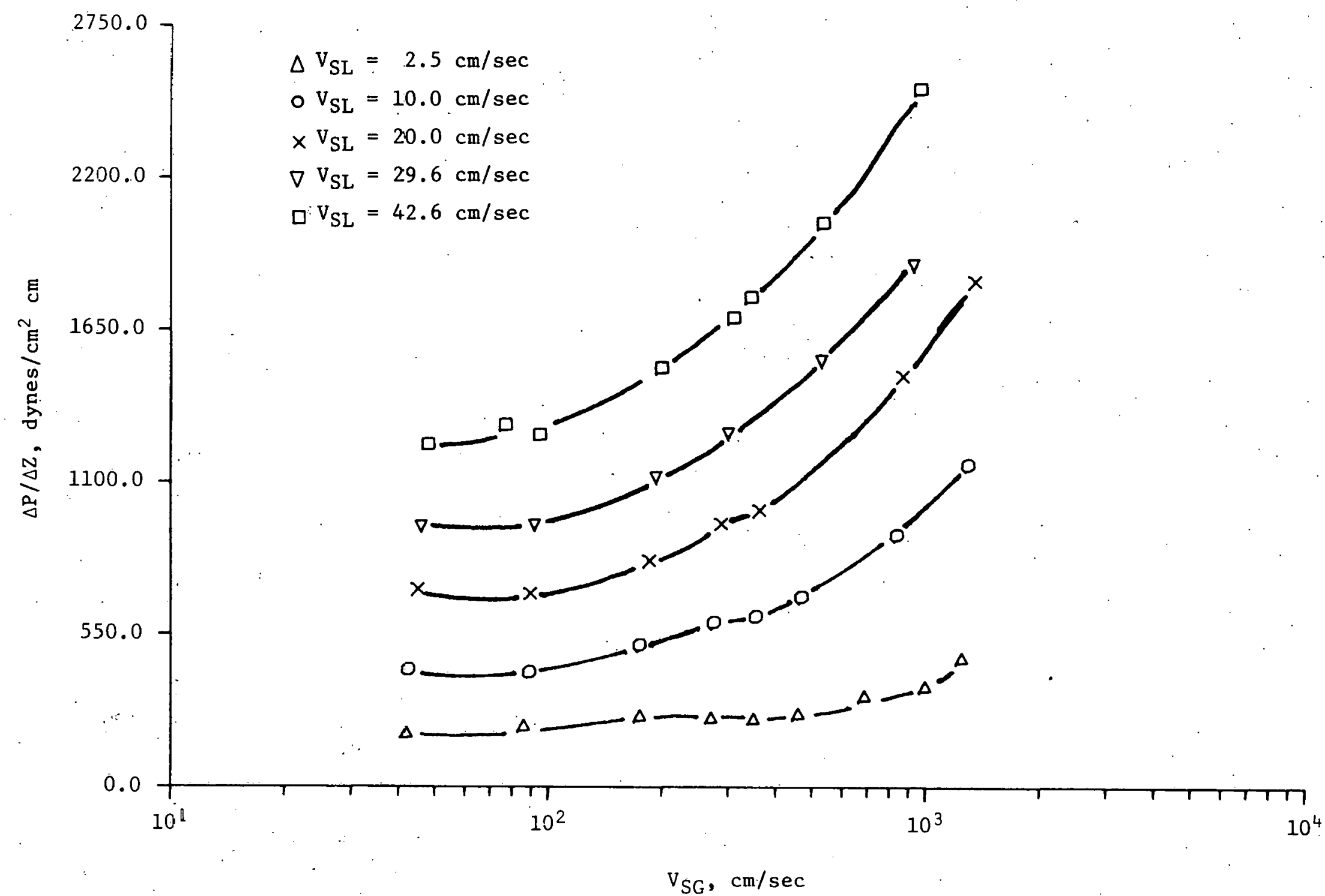

Fig. 10. Pressure Drop for the Flow of Nitrogen-Blandol 0i1 Mixture in the 0.7-cm-ID Tube 


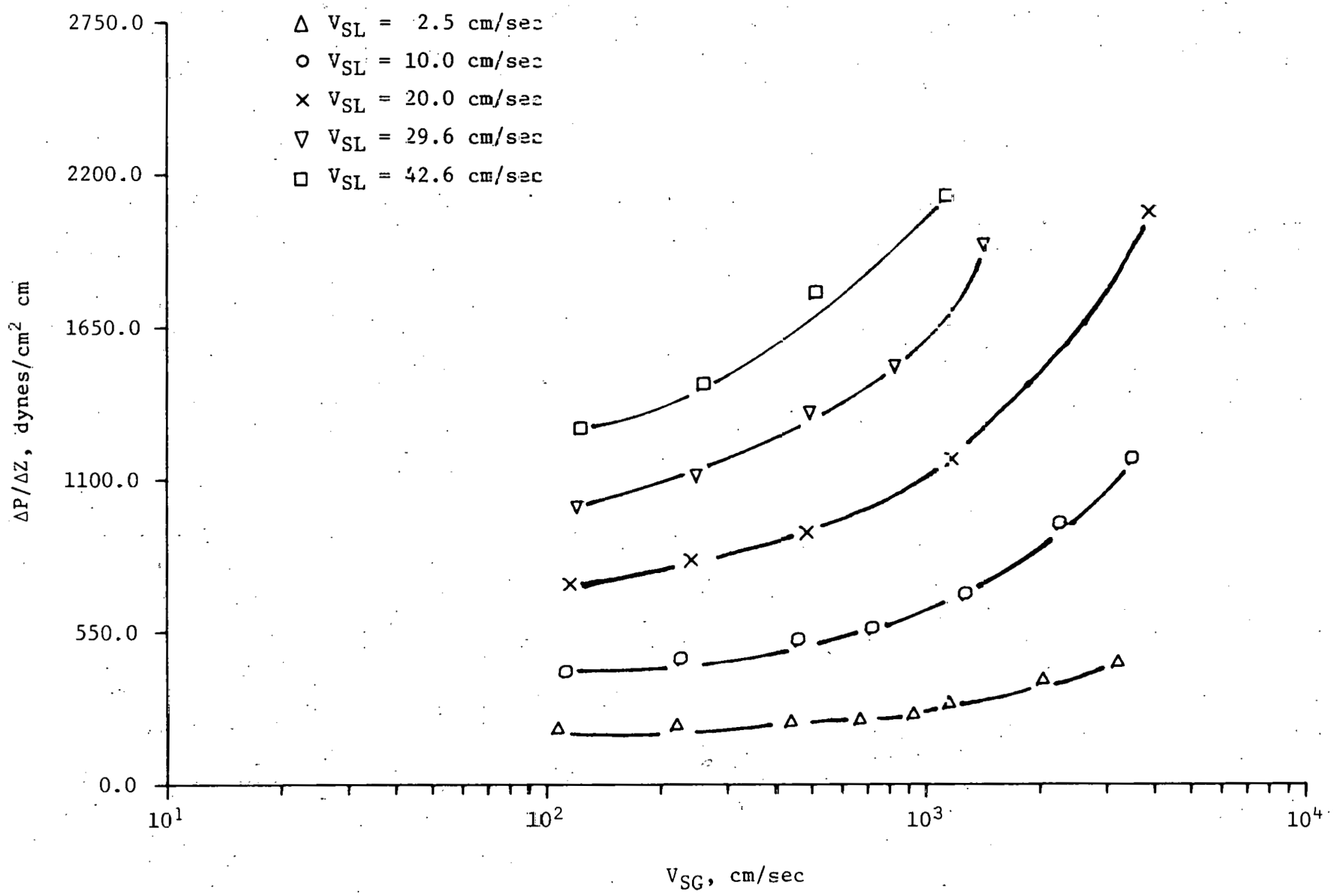

Fig. 11. Fressure Drop for the Flow of Helium-Blandol Oil Mixture in the 0.7-cm-ID Tube 


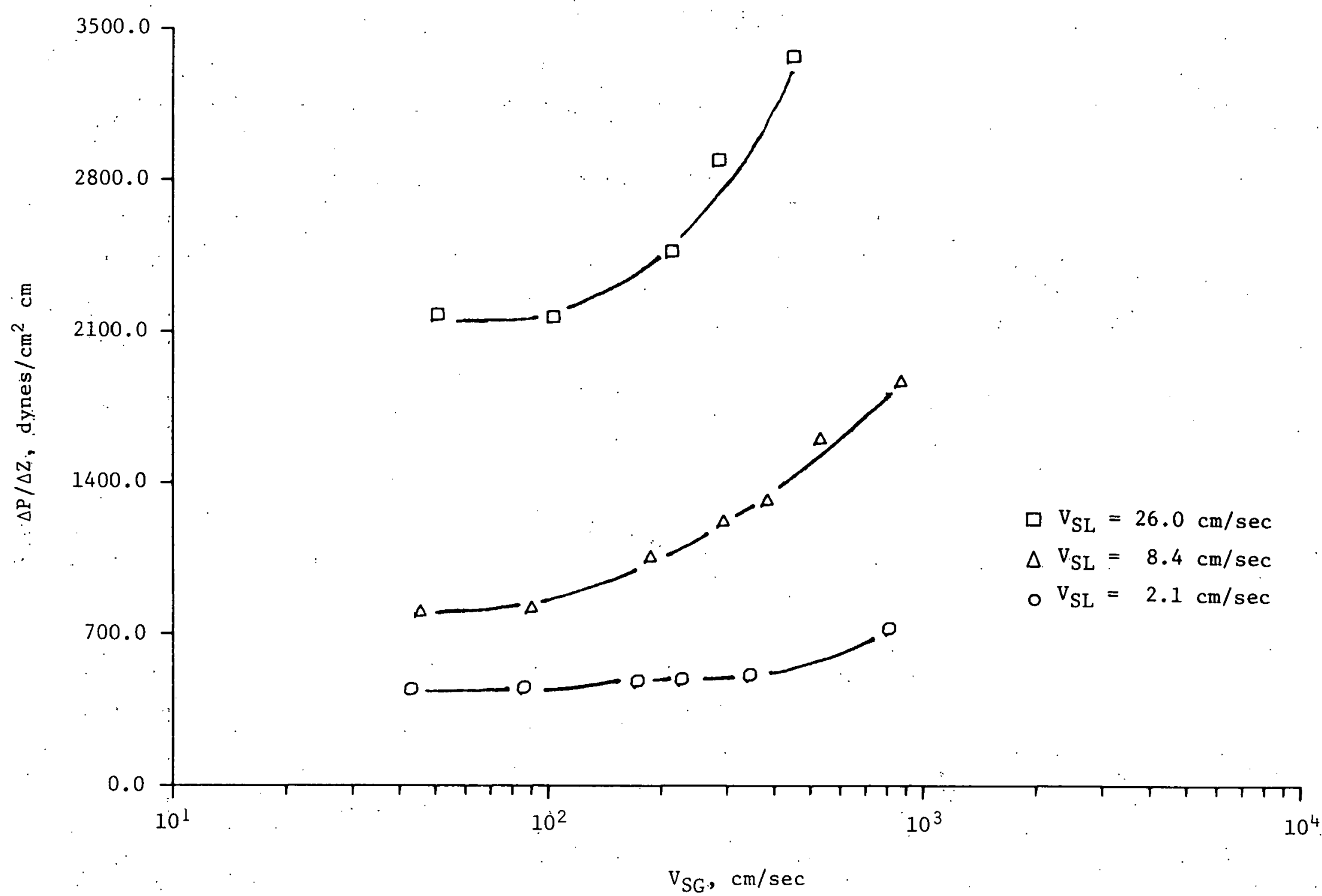

Fig. 12. Pressure Drop for the Flow of Nitrogen-Kaydo1 0il Mixture in the 0..7-cm-ID. Tube 


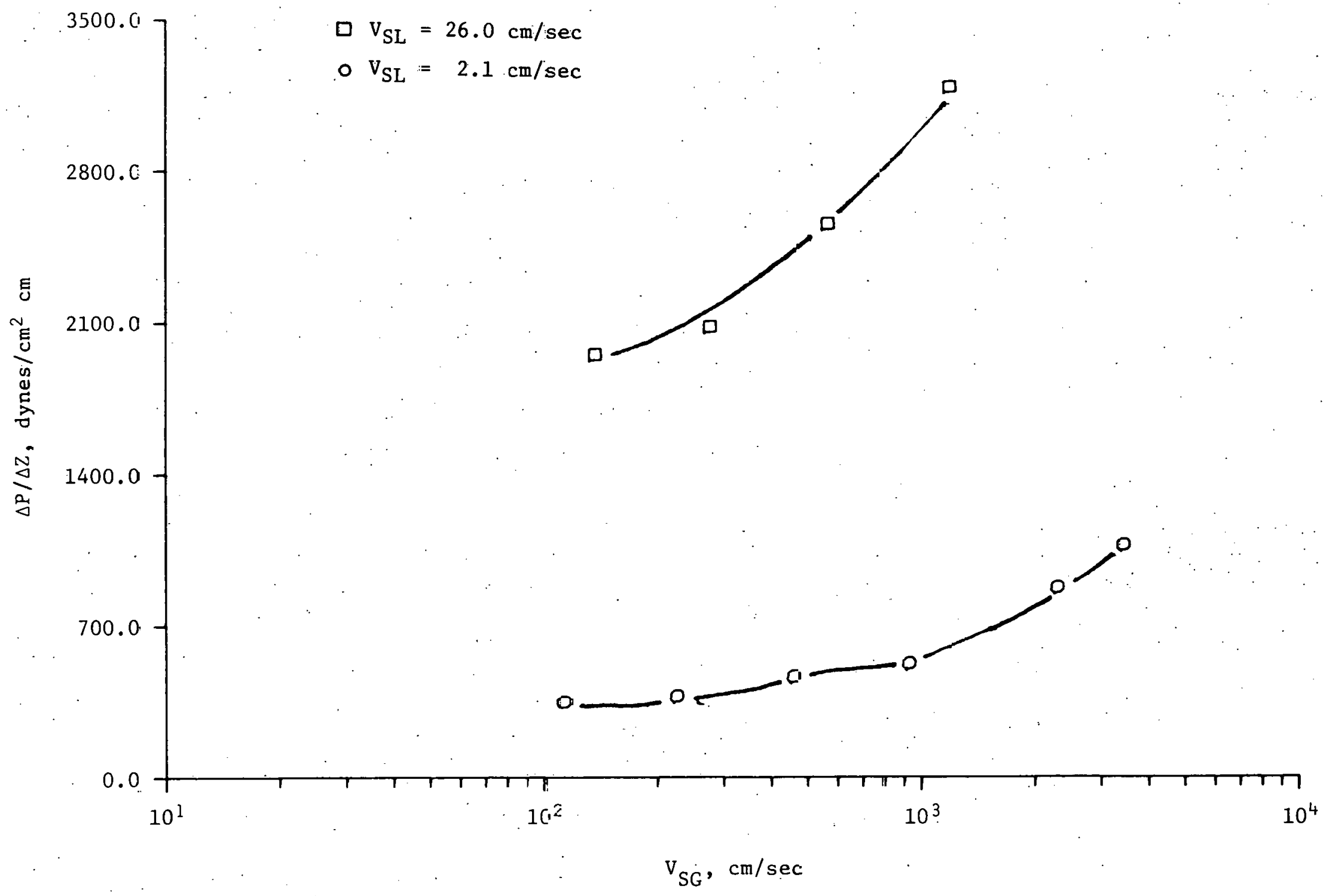

Fig. 13. Pressure Drop for the Flcw of Helium-Kaydol 0il Mixture in the 0.7-cm-ID Tube 
In the curves corresponding to low liquid velocities, after the pressure drop minimum, the pressure drop rises with increasing gas velocity until a maximum is reached. The curve then drops slightly to a second minimum and finally rises very steeply. In curves of higher superficial liquid velocity, this behavior becomes less pronounced. This can be seen more clearly in the data of Fig. 10 through 13, obtained with the $0.7-\mathrm{cm}-$ ID column, whose smaller diameter serves to create much larger values of $\mathrm{V}_{\mathrm{SG}}$ for the same mass flow rates. At intermediate ranges $\left(e . g ., V_{S L}=20 \mathrm{~cm} / \mathrm{sec}\right.$ in Fig. 10), this effect decreases to a point where it appears only as a minor change in the slope of the curve. At higher liquid velocities, the effect appears to be lost altogether.

There have been many attempts to relate the occurrence of maxima and minima in the pressure drop curves to transitions from one flow regime to another in the tube. Generally, these attempts have not been very successful; the boundaries separating different flow regimes have been located in regions other than those corresponding to maximum or minimum points in the pressure drop curves. 12 However, there is no doubt that the apparent changes in the trend of the variation of the pressure drop in the column is due to changes in (1) the flow mechanism and (2) the interactions between different dominant forces. This is especially true for the last portion of the pressure drop curve. The rapid rise of pressure drop with increasing superficial gas velocity depicts a region where the gas is in turbulent motion and the overwhelming contribution to the pressure drop comes from the irreversible component, $\Delta \mathrm{P}_{f}$, which is proportional to the square of the velocity. In this region, large inertial forces exerted by the gas phase tend to enforce the establishment of the upward flow of a wavy liquid film in the column. The irregularity of the surface of the liquid film.produced by the presence of the surface waves contributes significantly toward increasing the irreversible component of the pressure drop and causing a sharp increase in the total pressure drop in the column. The change in value of the pressure drop is so pronounced that it can be used as an indicator for the onset of film flow in the column.

Figures 8 through 13 consistently show an increase in total pressure drop with increasing superficial liquid velocity. The reason is that the magnitude of the hydrostatic and irreversible components of the total pressure drop depend on the liquid velocity, the former as a result of increase in liquid holdup and the latter due to the increase of the average velocity of the mixture in the tube.

The irreversible component of the pressure drop, $\Delta \mathrm{P}_{\mathrm{f}}$, as defined by Equation 3 , can be calculated by using the $\Delta \mathrm{P}$ data for various values of $V_{S L}$ and $V_{S G}$. Typical results are shown in Fig. 14 in which $\Delta \mathrm{P}_{\mathrm{f}}$ per unit length of the tube is plotted against the superficial gas velocity, with the superficial liquid velocity as a parameter. In general, the results for other conditions indicate that $\Delta \mathrm{P}_{\mathrm{f}}$ increases with both the gas superficial'velocity and the liquid superficlal velocity, in a manner shown in Fig: 14.

There have been several attempts to present the irreversible pressure drop data in terms of dimensionless quantities and thereby obtain general correlations that can be used for any gas-liquid mixture.11,12 One such correlation is obtained from a separated-flow model proposed by Lockhart and Martinelli ${ }^{32}$ for the horizontal flow of gas-liquid mixtures. In this model, each phase is assumed to flow independent 1y from the other phase in two separate hypothetical channels in the tube. The cross-sectional area of the 


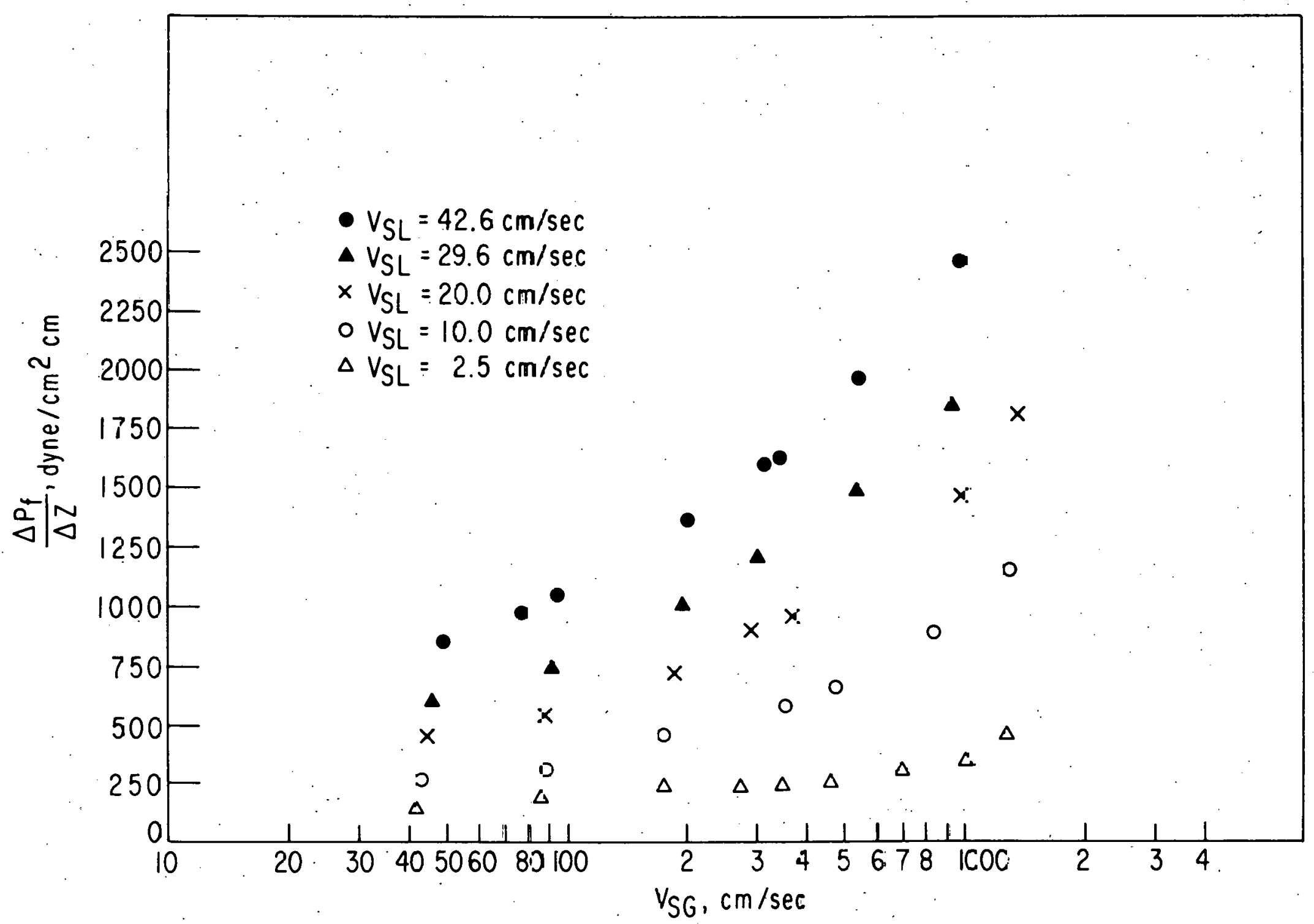

Fi3. 14. Irreversible Component of the Pressure Drop for the Flow of Nitrogen-Blandal Oil Mixture in the 0.7-CD-ID Tute 
channel for the flow of each phase is proportional to the amount of that phase in the tube. The frictional pressure drop in the tube can be correlated, when expressed in terms of $\phi_{\mathrm{L}}$ and $\phi_{\mathrm{G}}$, according to the following relationship:

$$
\left(\frac{1}{\phi_{L}^{2}}\right)^{1 / n}+\left(\frac{1}{\phi_{G}^{2}}\right)^{1 / n}=1
$$

where

$$
\phi_{\mathrm{L}}=\left[\frac{\left(\frac{\Delta \mathrm{P}_{\mathrm{f}}}{\Delta \mathrm{Z}}\right)}{\left(\frac{\Delta \mathrm{P}_{\mathrm{f}}}{\Delta \mathrm{Z}}\right)_{\mathrm{L}}}\right]^{1 / 2} .
$$

and

$$
\phi_{\mathrm{G}}=\left[\frac{\left(\frac{\Delta \mathrm{P}_{\mathrm{f}}}{\Delta \mathrm{Z}}\right)}{\left(\frac{\Delta \mathrm{P}_{\mathrm{f}}}{\Delta \mathrm{Z}}\right)_{\mathrm{G}}}\right]^{1 / 2}
$$

In the above definitions, $\left(\frac{\Delta \mathrm{P}_{f}}{\Delta \mathrm{Z}}\right)_{L}$ and $\left(\frac{\Delta \mathrm{P}_{f}}{\Delta \mathrm{Z}}\right)_{\mathrm{G}}$ are the irreversible pressure gradients for the liquid phase and gas phase, respectively, flowing as a single phase in the tube; $\mathrm{n}$ is a parameter whose value depends on the flow regime (laminar or turbulent) that would exist in the flow of either phase alone. Plotting of the quantity $\phi_{\mathrm{L}} v s$. $\phi_{\mathrm{G}}$ according to Eq. 5 implies that both axes of the coordinate would contain the desired quantity $\Delta \mathrm{P}_{f} / \Delta \mathrm{Z}$. To avoid such a situation, it is customary to express $\phi_{L}$ or $\phi_{G}$ as a function of the quantity $x$ where

$$
\mathrm{X}=\left[\frac{\left(\frac{\Delta \mathrm{P}_{f}}{\Delta \mathrm{Z}}\right)_{\mathrm{L}}}{\left(\frac{\Delta \mathrm{P}_{\mathrm{f}}}{\Delta \mathrm{Z}}\right)_{\mathrm{G}}}\right]^{1 / 2}
$$

Accordingly, the data obtained on the 0.7-cm-ID tube was plotted in terms of $\phi_{\mathrm{L}}$ against $\mathrm{X}$, as shown in Fig. 15. The Martinelli curves, 32 corresponding to two extreme valuee of $\mathrm{n}$, denoted hy $\phi_{\mathrm{T}_{\mathrm{vv}}}$ and. $\phi_{\mathrm{L}_{\tau t}}$ are also plotted in this figure. The notation $\phi_{L_{v}}$ implies that the single-phase flow of either:liquid or gas is in the laminar regime, whereas $\phi_{L_{t t}}$ corresponds to the condition that the single-phase flow of either liquid or gas is in the turbulent regime. Despite a slight scatter, the agreement between the data and the Martinel1i curves is satisfaccory. IL slivuld be noted that the Martinelli curves for $\phi_{\mathrm{L}_{\mathrm{vt}}}$ and $\phi_{\mathrm{L}_{\mathrm{tv}}}$ (the conditions corresponding to $\phi_{\mathrm{L}_{\mathrm{tv}}}$, namely, turbulent liquid 


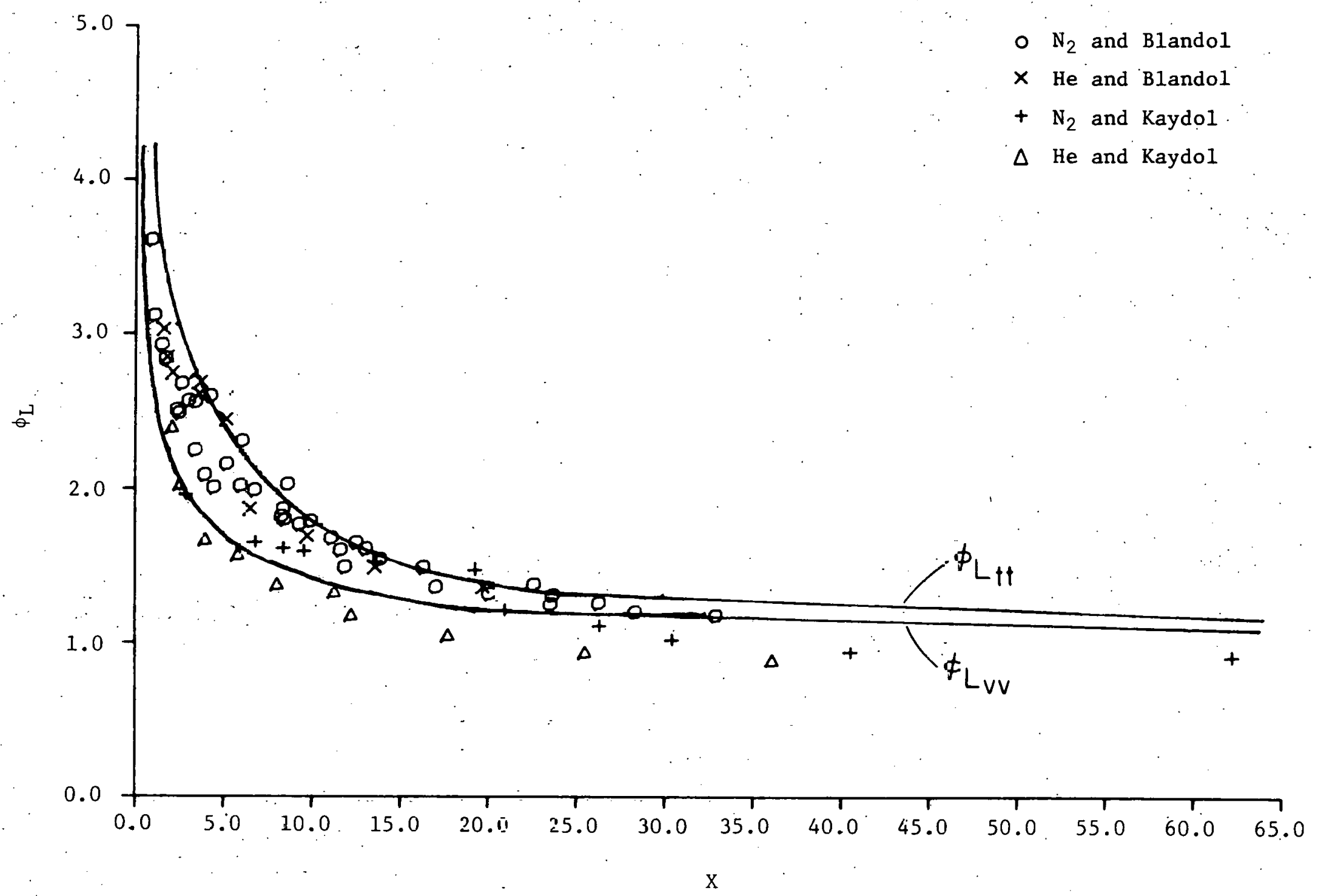

Fig. 15. Generalizarion of the Pressure Drop Data Taken from the 0.7-cm-ID Colimn"with Lockhart-Matinelli Correlations 
and laminar gas flow, are rarely considered) lie between the curves for $\phi_{L_{\mathrm{VV}}}$ and $\phi_{\mathrm{L}_{\mathrm{tt}}}$. For this reason, the scatter of the data in Fig. 15 can be explained, partly, on the basis of conditions other than laminar-laminar or turbulentturbulent flow existing in the tube. However, the main reason for scatter of the data is that the Martinelli model does not truly reflect the flow condition of the two-phase mixture in all possible two-phase flow regimes. In fact, only annular film flow truly resembles a separated flow and thus satisfies the conditions required by the Martinelli model. Most of the data taken from the 0.7-cm-ID column corresponds either to film flow or to a type of slug flow consisting of long gas bubbles and for this reason generally agree with the Martinelli curves. On the other hand, most data taken from the 1.27-cm-ID tube correspond to regimes other than annular flow or slug flow with relatively short gas bubbles and long liquid slugs. Therefore, generally poor agreement between the data of the 1.27-cm-ID tube and the Martinelli curves can be expected. In fact, such behavior was observed, as shown in Fig. 16, in which the data taken with the 1.27-cm-ID tube have been superimposed on the data of Fig. 15. Thus, using the Martinelli correlations for the estimation of.the pressure drop in the tube will be acceptable only when the existence of an annular flow (or a configuration resembling a separated flow) has been confirmed. It should be noted that (as seen from Fig. 15) the use of these correlations can only serve as a means of obtaining approximate values for the pressure drop. Exact values can be obtained only when experiments are carried out under the conditions under consideration (such as the types of fluids and the magnitudes of their flow rates).

Another source of scatter in Figures 15 and 16 is the continually changing nature of the two-phase flow. Even at great distances from the point of entrance, the flow cannot be said to be fully developed, a situation that. is normally overlooked in deriving correlations from separated models. In fact, the type of inlet device used for introducing the gas and the liquid phases into the tube has some effect on the way the two-phase flow develops in the tube and consequently on the pressure drop. As mentioned before, in all experiments, the pressure drop data were obtained between taps 3 and 4 (134 cm and $195 \mathrm{~cm}$ from the inlet device, respectively). However, to examine the dependence of the pressure gradient on the distance along the tube, a few measurements were taken between taps 2 and $3(73 \mathrm{~cm}$ and $134 \mathrm{~cm}$ from the inlet device, respectively) in the experiments with Blandol oil and nitrogen in the $1.27-\mathrm{cm}-$ ID tube. The results indicated that generally, the pressure drops between the higher taps were consistently larger than those obtained between the lower taps. Although the difference was not large, 6 percent at the most, the consistency of the data for different flow rates shows that the entrance effect is significant.

\section{a. Effect of the Viscosity of the Liquid Phase}

The use of two types of mineral oils, Blandol and Kaydo1, provided a convenient means of studying the effect of the viscosity of the liquid phase on the pressure drop. Results (typically derived from Figures 8 through 13 for two values of approximately constant liquid flow rates) are presented in Fig. 17 with nitrogen as the gas phase, and in Fig. 18 with helium as the gas phase. In the experiments corresponding to the data points of Figs. 19 and 20 , the viscosity of the Blandol oil averaged $22 \mathrm{cp}$, while the viscosity of the Kaydol oil averaged $140 \mathrm{cp}$. It can be seen clearly that the higher-viscosity 


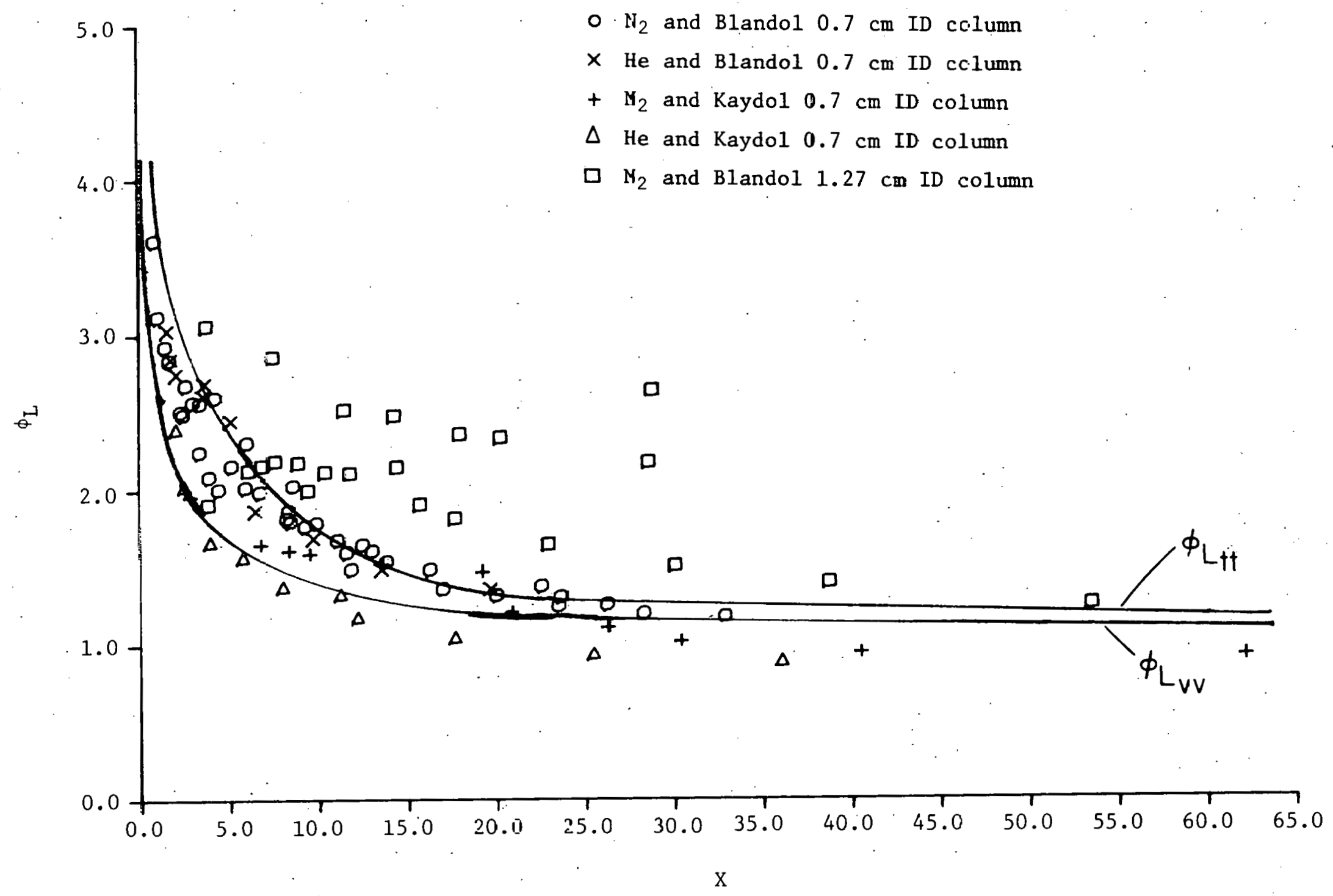

Fig. 16. Comparison of the Mata Taken from the $0,7, \mathrm{~cm}-\mathrm{dia}$ Tube wth Those from the 1.27-cm-ID Tube Correlated with the Lockhart-Martinelli Parameters 


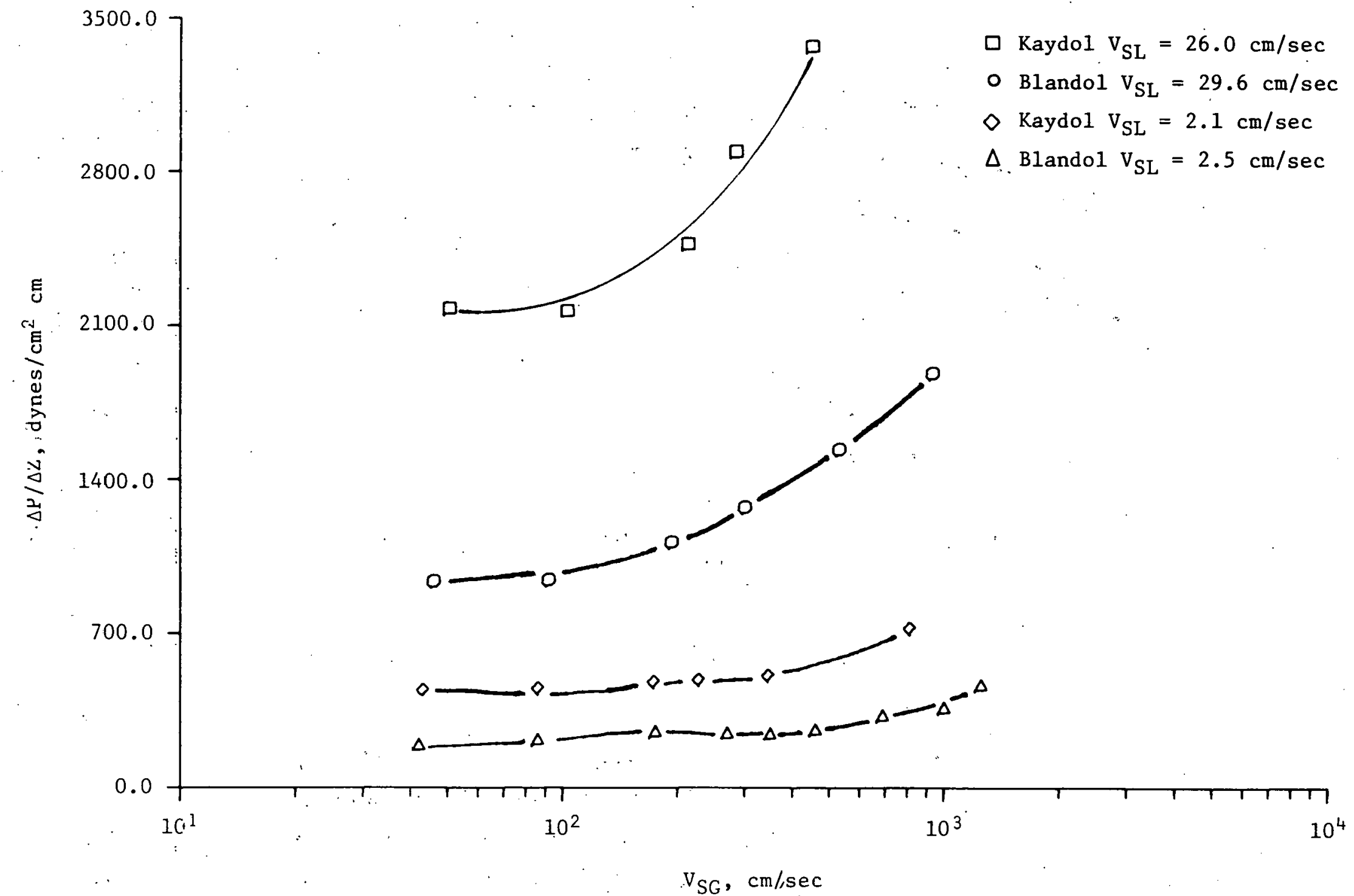

Fig. 17. Effect of Viscosity of the Liquid Phase on the Total Pressure Drop in the 0.7-cm-ID Tube When Nitrogen is Used as the Gas Phase 


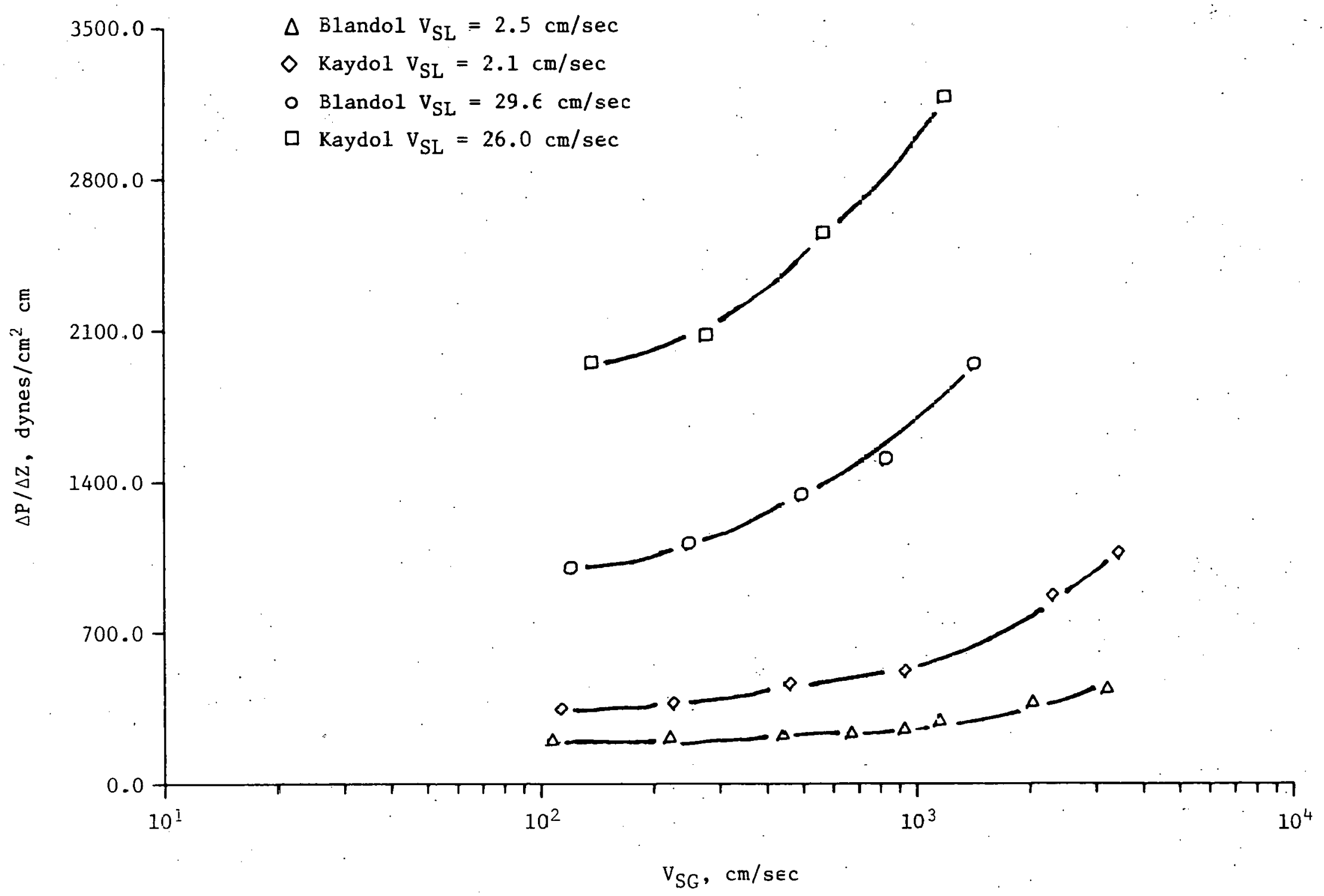

Fig. 18. Effect of Viscasity of the Liquid Phase on the Total Pressure Drop in the 0.7-cm-ID Tube Wher Helium is Used as the Gas Phase

an $\because \cdots$ 
liquid produces much larger values of pressure drop, and that this effect is greatly enhanced with increasing liquid flow rate. The viscosity effect is also found to be influenced by the type of the gas used. The increase in the pressure drop when nitrogen is used as the gas phase is generally larger than the corresponding increase when helium is used. It should be noted, how wer, that the viscosities of the two types of mineral oils vary sevenfold and that generally the enhancement of the values of the pressure drops is comparatively small, considering the large variation in viscosity. Therefore, one can expect small variations of viscosity of the liquid phase to have a minimal effect on the total pressure drop.

Part of the viscosity effect on the pressure drop can be attributed to an increase in its irreversible component through the viscosity dependence of the friction factor. In addition, as will be shown later, an increase in liquid viscosity produces a larger volumetric holdup of the liquid phase in the tube, thereby increasing the magnitude of the "true" hydrostatic pressure drop as well. Similar comparisons, for values of the superficial liquid velocities other than those presented in Fig. 17 and 18, can be extracted easily from the general data of Figures 8 through 13.

\section{b. Effect of Density of the Gas Phase}

The use of two gases (namely, nitrogen and helium) having a sevenfold variation in their density provided a means of studying the effect of the density of the gas phase on the total pressure drop. This effect is shown in Fig. 19 and 20, which include data corresponding to the use of Blandol oil and Kaydol oil, respectively, as the liquid phase. The major difference between the helium and nitrogen curves seems to occur at high gas. flow rates, corresponding to the region dominated by frictional effects. It seems reasonable to assume that the forces due to the inertia of the gas phase become increasingly important with a gradual increase in the gas flow rate and eventually become a dominant factor in establishing the characteristics of the twophase flow. Such a behavior obviously exists in Fig. 19 and 20, where at some high value of the superficial gas velocity the pressure drop produced by nitrogen becomes considerably larger than that produced by helium.

\section{c. Effect of Tube Diameter}

As can be seen from the general data in Figs. 8 through 13, the smaller-diameter column tends to exhibit much larger values for pressure drop than the larger column, for the same gas-liquid mixtures and for similar values of gas and liquid superficial velocities. Under similar conditions, the hydrostatic pressure drop as defined by Equation 3 is independent of tube diameter. Therefore, the larger values for total pressure drop in the smaller tube is entirely due Lu the resulting increase in frictional effects. A comparison of the frictional components of the pressure drop for the two columns is presented 1n Fig. 21. The data points in this figure correspond to flow of nitrogenBlandol oil mixture at the superficial liquid velocities of $8.7 \mathrm{~cm} / \mathrm{sec}$ in the $1.27-\mathrm{cm}-I D$ tube and of $10 \mathrm{~cm} / \mathrm{sec}$ in the $0.7-\mathrm{cm}-$ ID tube. The difference in magnitude of the irreversible pressure drops in the two tubes is more than the amount that can be accounted for by the slight difference in the values of the superficial liquid velocities. 


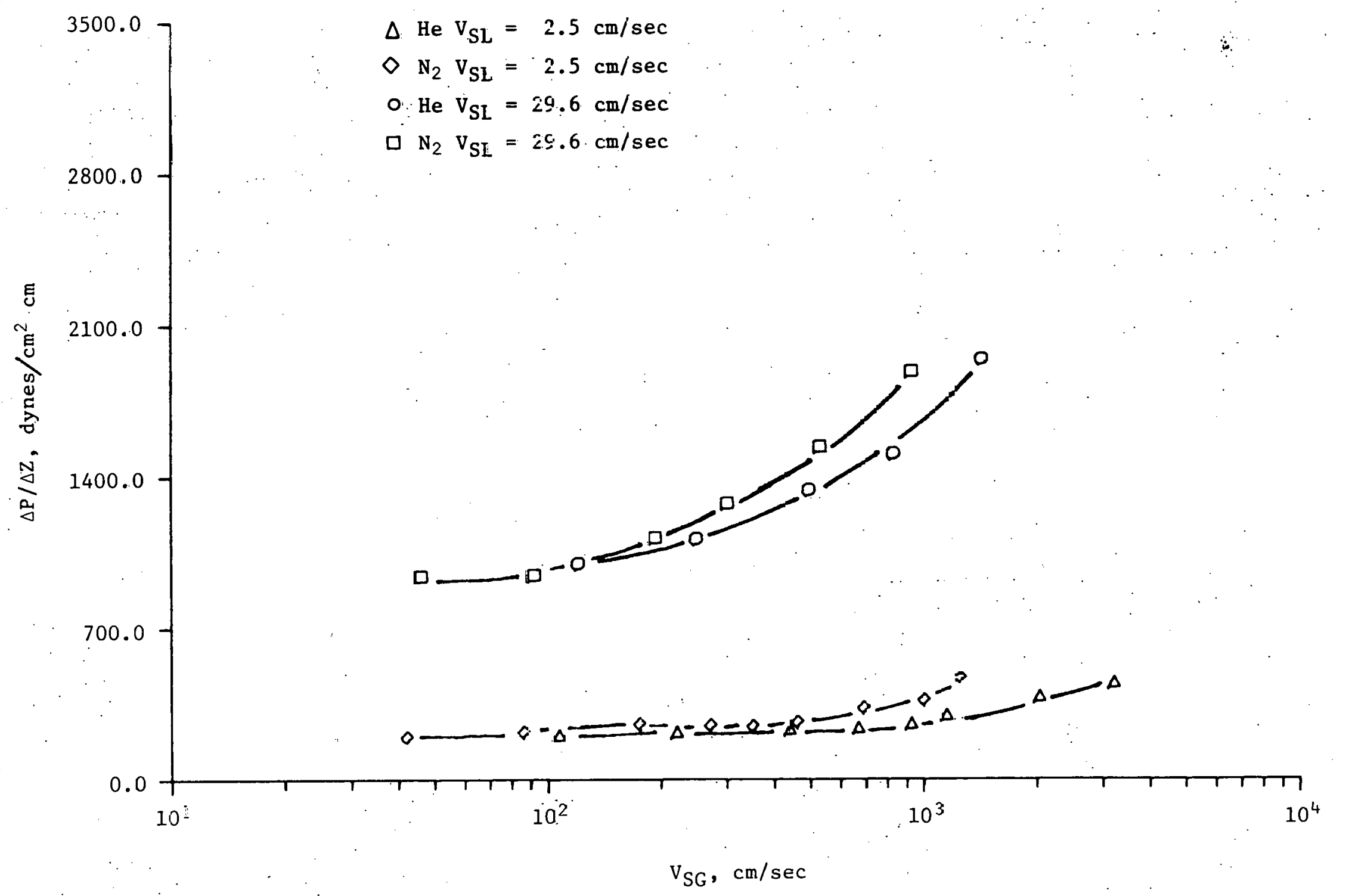

Fig. 19. Effect of the Dersity o the Gas Phase on the Total Frassure Drop in the 0.7-cm-ID Tube When the Less Visccus Blandol Oil is Used as the Liquid. Phase 


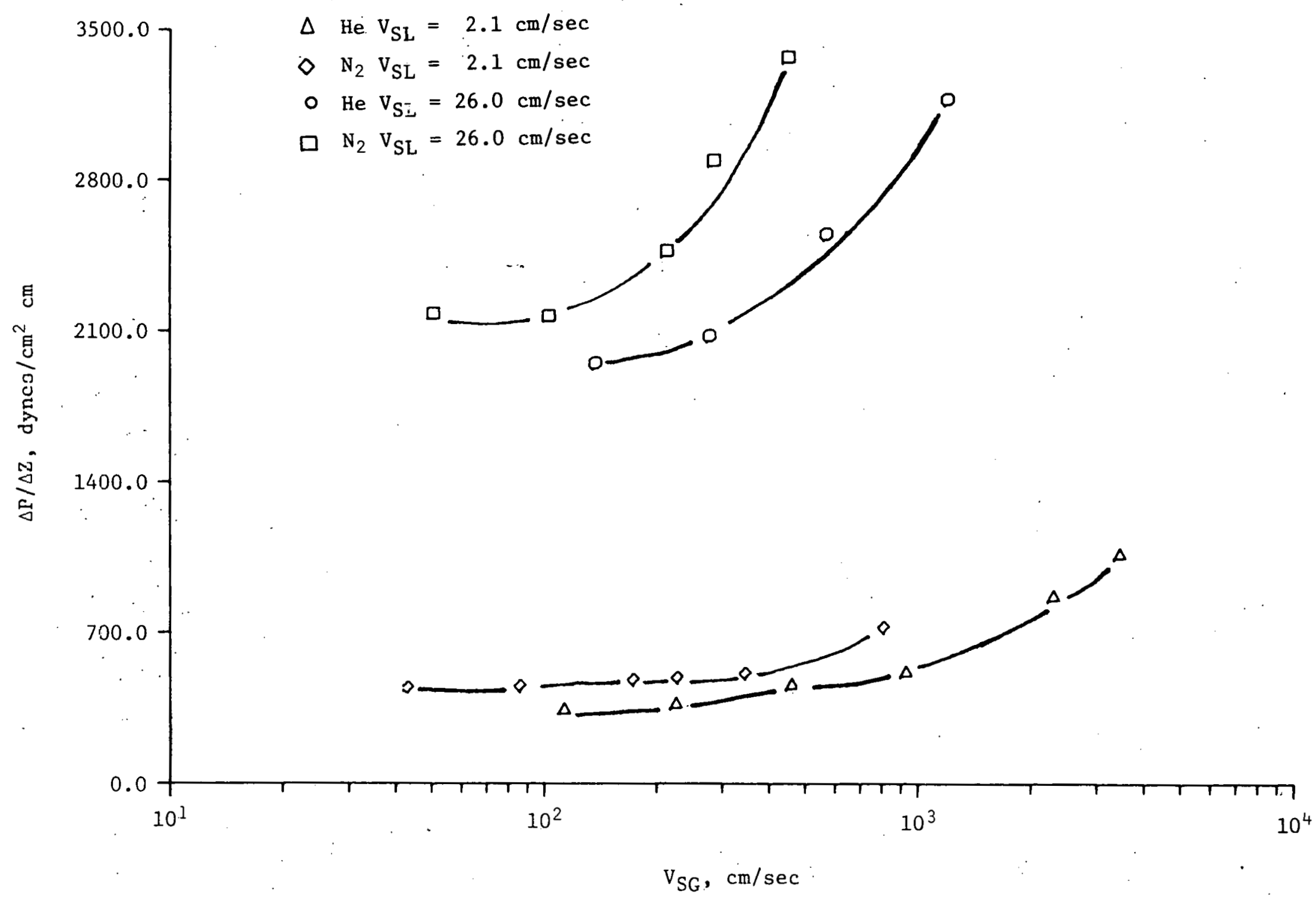

Fig. 20. Enfect of the Density of the Gas Phase on the Total Pressure Drop in the 0.7-cm-ID Tube When the More Viscous Kaydol Oil is Used as the Liquid. Phase 


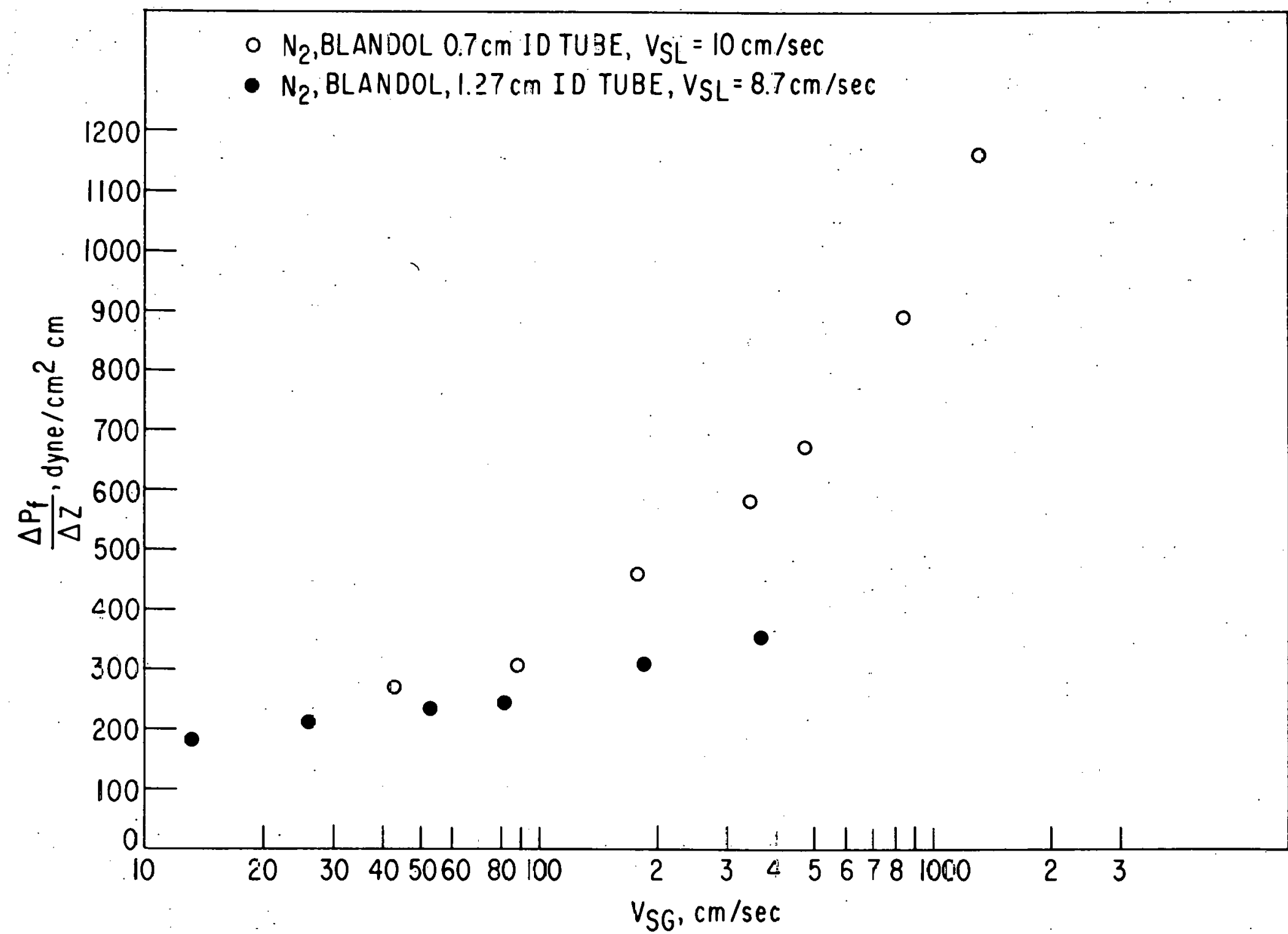

Fig. 21. Effect of the Tube Diameter on the Irreversible Component of the Pressure Drop as Observed In the Flow of Nitrogen-Blendal Oil Mixture on the $0.7-\mathrm{cm}-$ ID an $1.27-\mathrm{cm}$-ID Tubes 
Study of Fig. 21 shows that the effect of the tube diameter on the pressure drop is small at low gas flow rates (slug flow regime) but increases with increasing gas velocity. No definite explanation could be found for this behavior. It should be noted again that the irreversible pressure drop, $\Delta \mathrm{P}_{\mathrm{f}}$, as presented in $\mathrm{Fig} .21$, is just the result of the definition given by Equation 3 and does not represent the true value of the frictional pressure drop. In other words, some of the effect of the "true" hydrostatic pressure drop is still implicitly included in the $\Delta \mathrm{P}_{\mathrm{f}}$ values of Fig. 21. This effect can partly be compensated for by using the liquid holdup data in the hydrostatic pressure drop calculations in deriving $\Delta \mathrm{P}_{f}$ values that represent more closely the true value of the irreversible pressure drop. However, this procedure would not change the relative behavior of the two curves in Fig. 21, since, as is shown below, the value of the liquid holdup in the tube does not change with tube diameter.

\section{Holdup}

As is mentioned above, the volumetric fraction of the liquid phase in the tube was measured by closing the stopcock on top of the test section and simultaneously shutting of the gas and liquid inlet lines by actuating the two solenoid values (see Fig. 7). Therefore, the holdup values, calculated by measuring the volumes of liquid captured in the tube, represent a volumetric average holdup between the inlet device and the top of the test section $240 \mathrm{~cm}$ away. Data was obtained for four combinations of two-phase flow resulting from two mineral oils (Blandol and Kaydol) and two gases (nitrogen and helium) in two tubes of $0.7-\mathrm{cm}$ and $1.27-\mathrm{cm}-\mathrm{ID}$, respectively. The data obtained under different conditions are presented in Figs. 22 through 26 as the volumetric fraction of the liquid in the tube, $\alpha_{L}$, vs. the superficial gas velocity as a parameter. The results generally show that the 1iquid holdup, $\alpha_{L}$, decreases with increasing superficial gas velocity and increases with increasing superficial liquid velocity.

Generalization of the holdup data is always desired, from both academic and practical points of view. A general correlation that has been recommended for design purposes 12 is that of Hughmark and Pressburg. 31 This correlation was shown in Fig. 5. The holdup data corresponding to different conditions obtained in our experiments are compared with this correlation in Fig. 27. Despite some scatter, the quantity $X^{\prime}$ seems to be a relatively suitable parameter for correlating the general holdup data. Also, regarding the trend of the variation of $\alpha_{L}$ with $X^{\prime}$, qualitative agreement of the data with the Hughmark-Pressburg correlation is observed. However, quantitatively, the agreement is poor and the data consistently indicates higher holdup values than the Hughmark-Pressburg correlation. This kind of disagreement is not unexpected, since the correlation was derived empirically on the basis of data obtained in tubes approximately $740 \mathrm{~cm}$ 1ong, ${ }^{31}$ while the present data was obtained in tubes $240 \mathrm{~cm}$ long. Because of this developing nature of the twophase flow, holdup is a local value that changes along the tube. The existence of slip between the gas and the liquid phase causes accumulation of liquid phase near the bottom of the tube so that when steady state is reached, a profile corresponding to the axial variation of the liquid holdup is established in the tube. Because of the difficulties involved with the measurement of the local values of holdup, the shape of such a profile, especially in the vicinity of the inlet sectlul, is not known. However, due to the accumulation of liquid phase toward the bottom, it is reasonable to assume that starting 


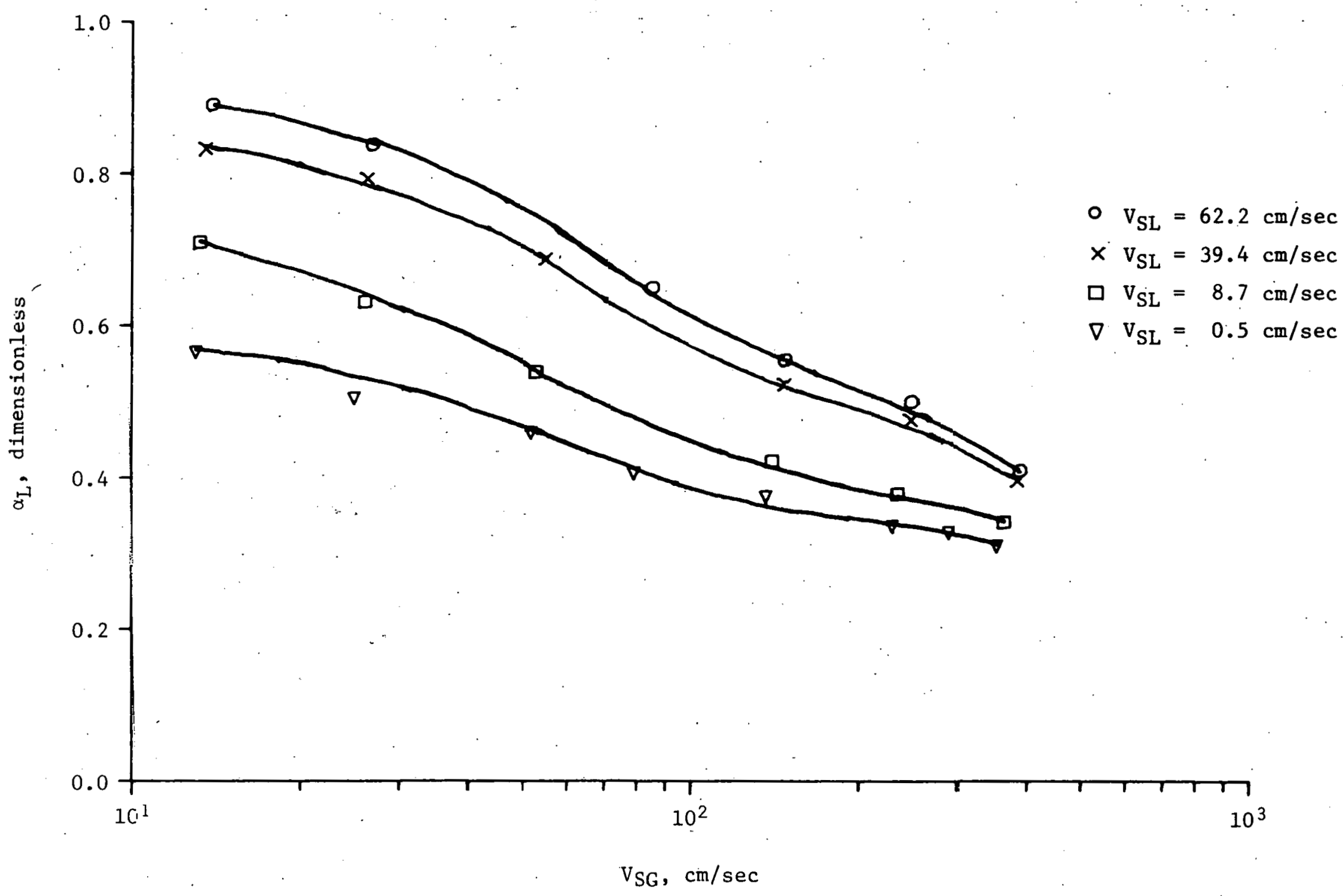

Fig. 22. Average Volumetric Liquid HolduF for the Flow of

Nitrogen-Blandol Gil Mixtures in the 1.27-cm-ID Tube 


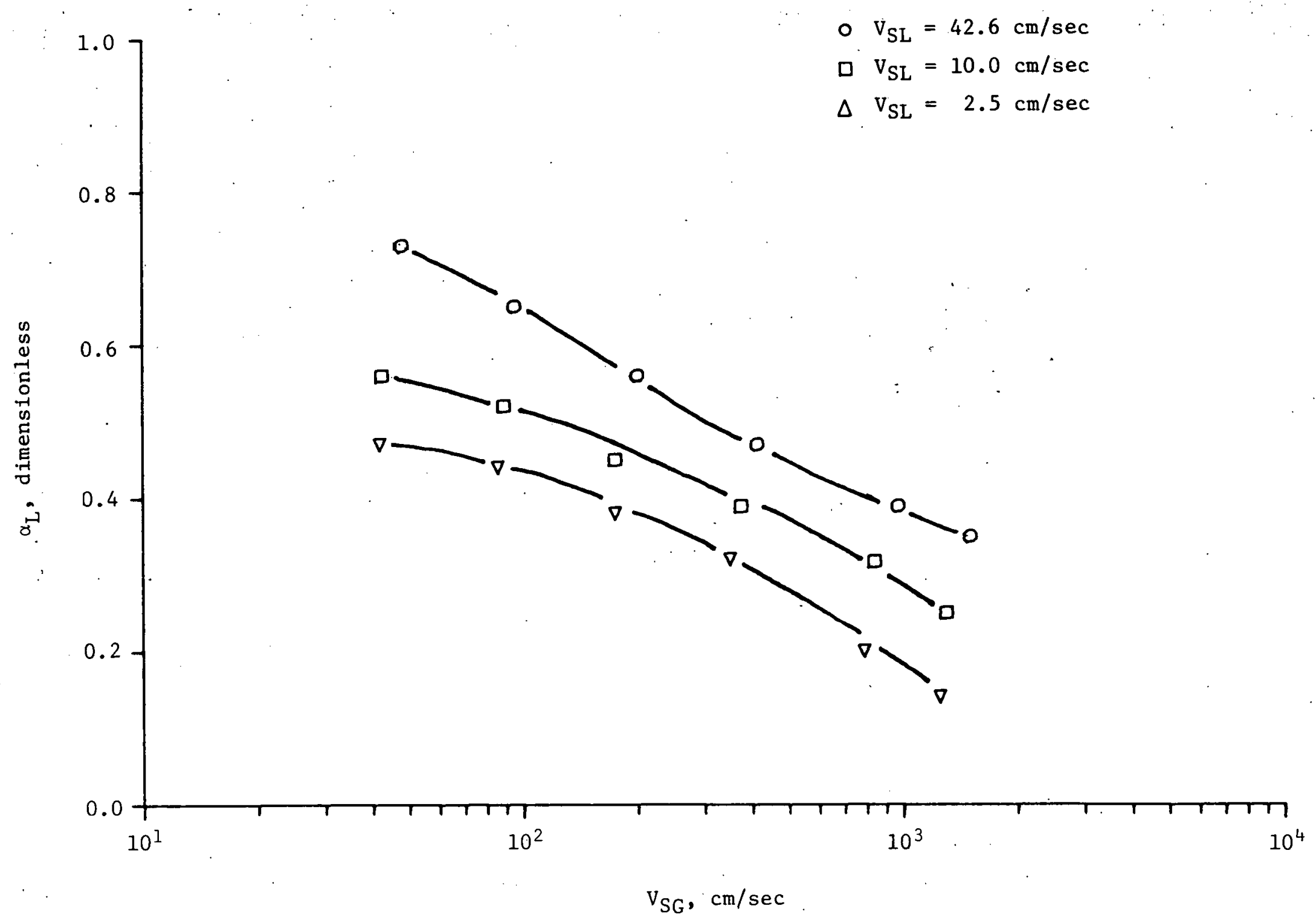

Fig. 23. Average Volumetric Liquid Holdup for the Flow of Nitrogen-Blando1 Oil Mixtures in the $0.7-\mathrm{cm}-$ ID Tube 


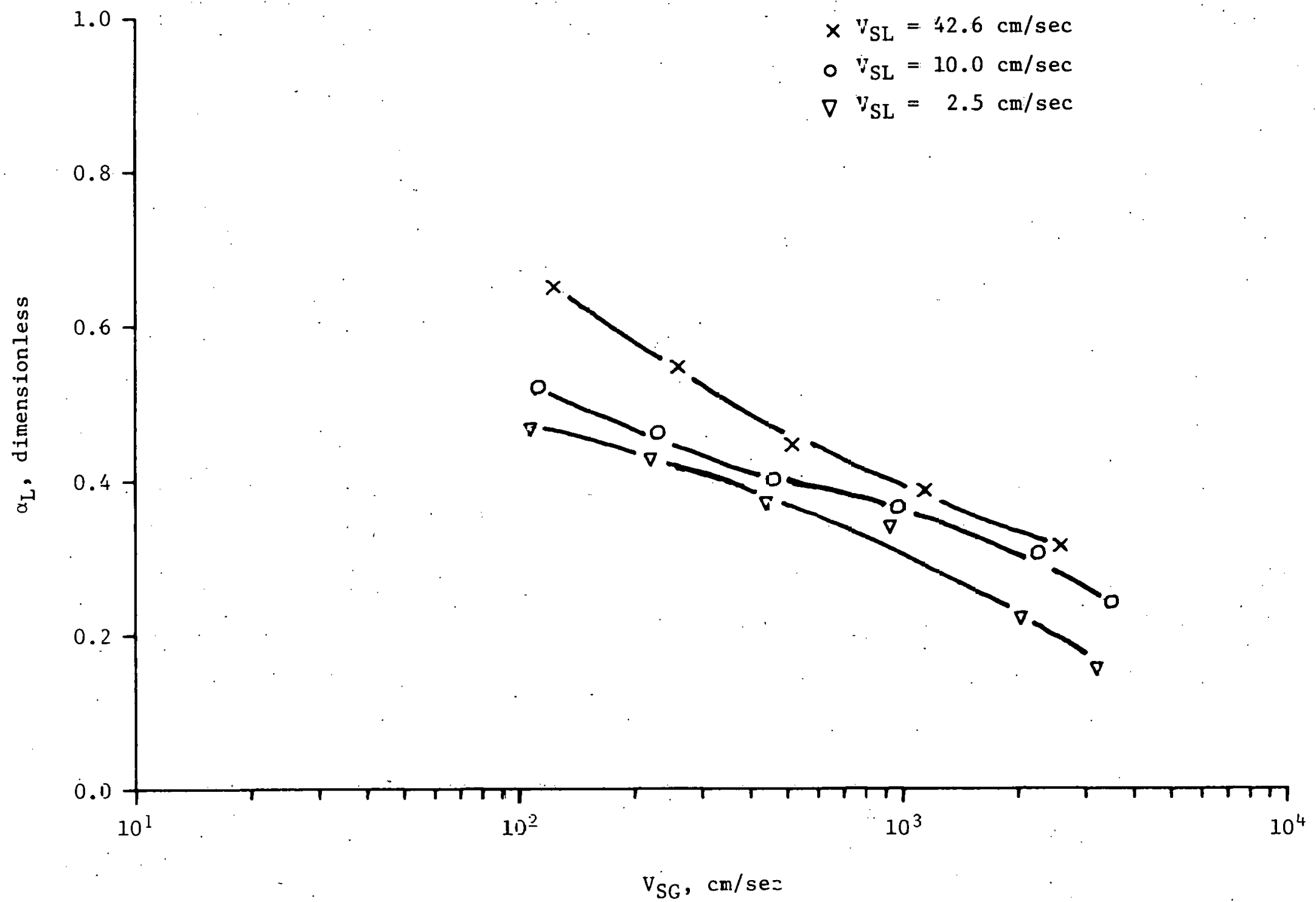

Fig. 24. Average Volumetric Liquid Holdup for the Flow of Helium-Blandol $0 i 1$ Mixtures in the $0.7-\mathrm{cm}-\mathrm{ID}$. Tube 


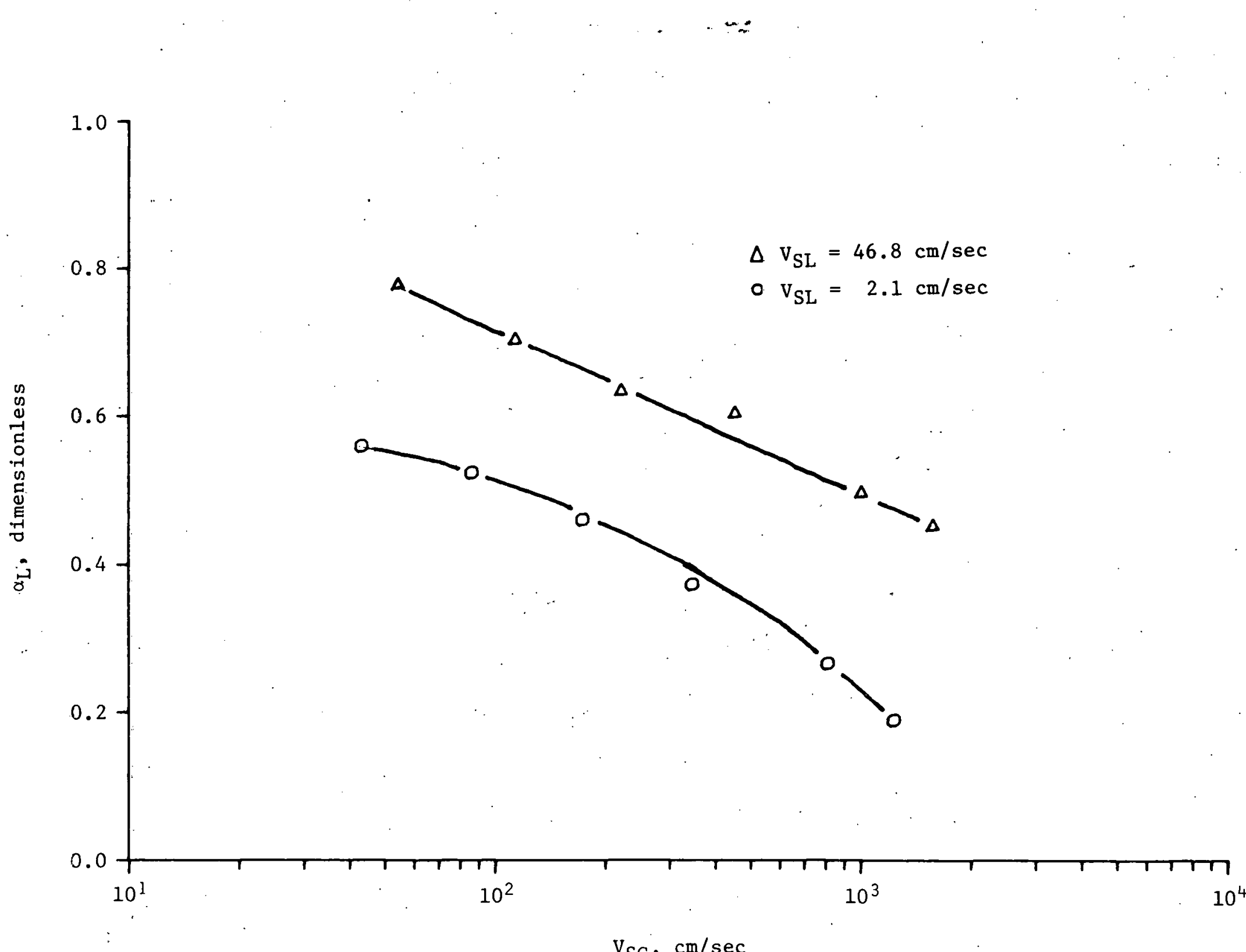

$\mathrm{V}_{\mathrm{SG}}, \mathrm{cm} / \mathrm{sec}$

Fig. 25. Average Volumetric Liquid Holdup for the Flow of Nitrogen-Kaydol Oil Mixtures in the 0.7-cm-ID Tube 


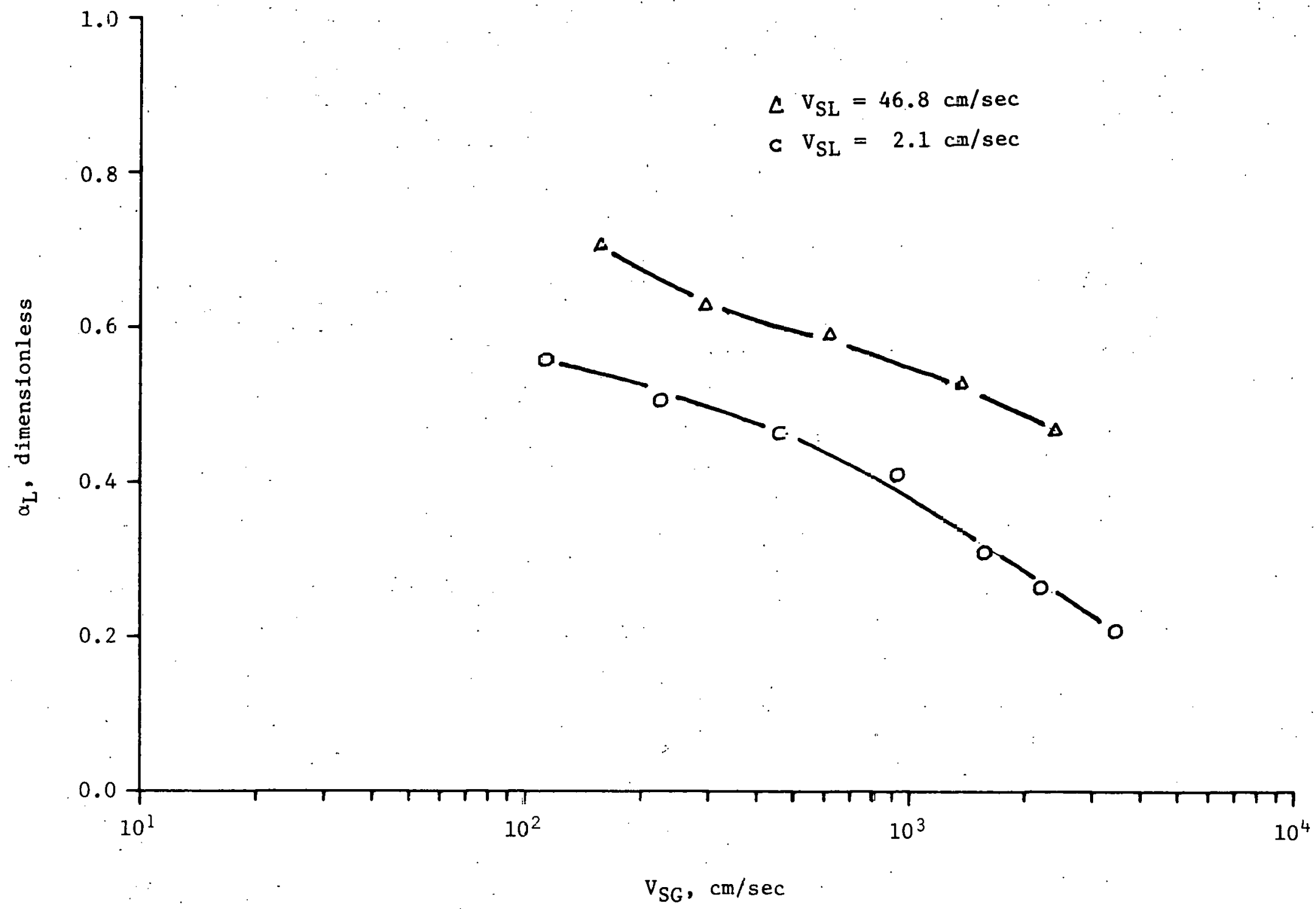

Fig. 26. Average Volumetria Liquid Holdup for the Flow of Helium-Kaydol Oil Mixtures in the $0.7-\mathrm{cm}-\mathrm{ID}$ Tibe 


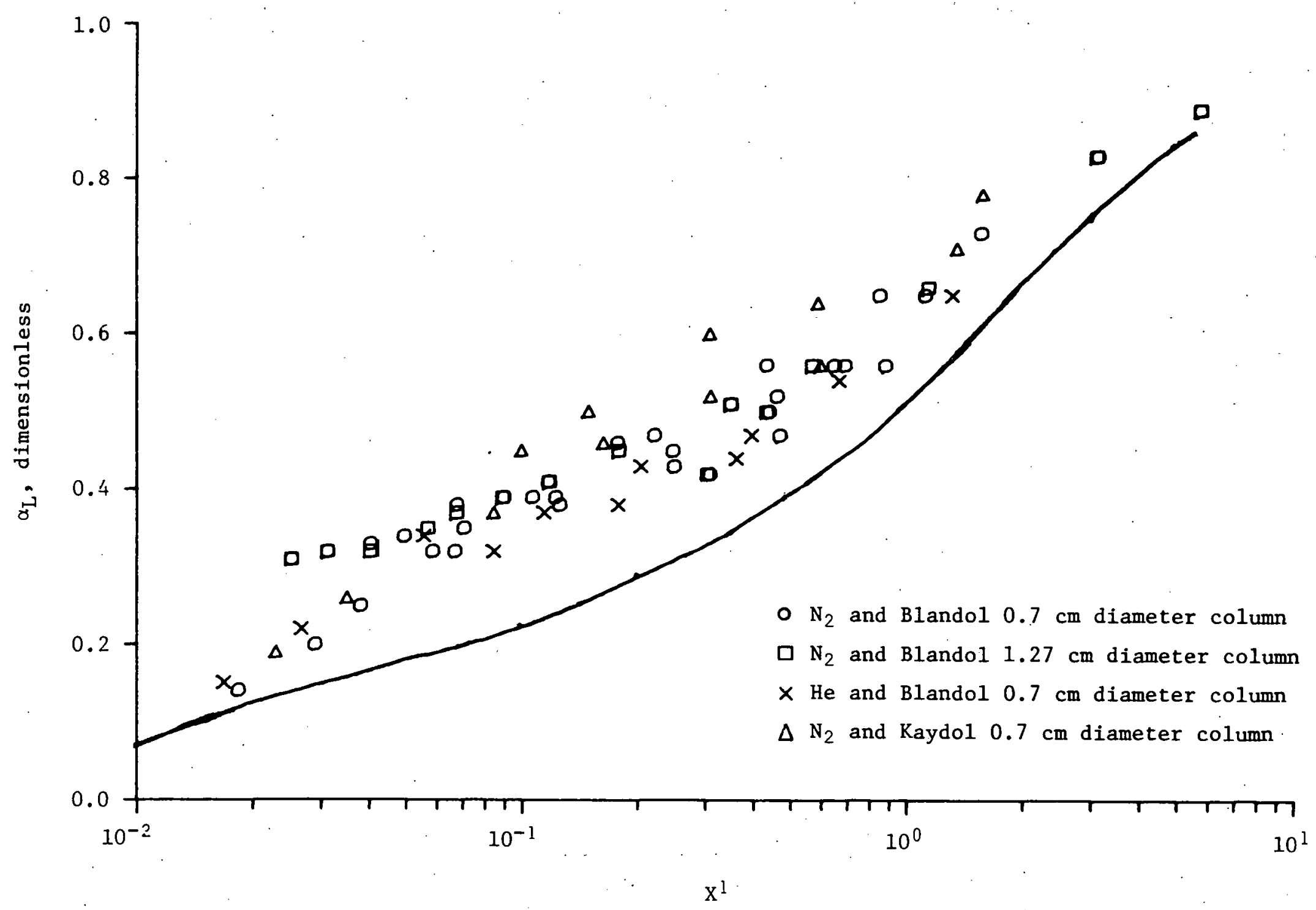

Fig. 27. Correlation of the Holdup Data with the Hughmark-Pressburg

Parameter and Comparison with Hughmark-Pressburg Correlation 
a short distance above the inlet section, the local values of the liquid holdup decrease along the tube. Such a qualitative picture of the variation of local holdup in the tube can account for the discrepancy found between the data and the Hughmark-Pressburg correlation in Fig. 27. According to this argument, the volumetric average holdup taken on a 740-cm-long tube (corresponding to Hughmark-Pressburg experiments) should be smaller than the volumetric average holdup taken on a 240-cm-1ong tube (corresponding to the data obtained in this work). An important point for consideration in comparing different data from different sources is the geometry of the inlet section used in the experiments. As is mentioned above, the developing nature of the two-phase flow along the tube depends on the geometry of the inlet section and the way the two phases are brought into contact after entering the tube.

From the discussion presented above and comparison of the data with the general correlation of Hughmark-Pressburg presented in Fig. 27, we may conclude that the application of the correlatione in the literature to a sperific case can be ueeful only for obtaining approximate values (within about 20 percent) for the liquid holdup. Accurate values can be obtained only if experiments are carried out under the required sperific conditions.

\section{1 ia. Effect of the Viscosity of the Liquid Phase}

The effert nf the viecocity of the liquid pliase un the volumetric average liquid holdup is presented in Figs. 28 and 29 which contain the data corresponding to nitrogen and helium as the gas phase, respectively. The data in these two figures, which correspond to two different values of liquid superficial velocity, have been extracted from the general data of Figs. 22 through 26. The results show that the holdup for Kaydol oil, whose viscosity averaged $140 \mathrm{cp}$ for these experiments, is consistently larger than the holdup for Blandol oil, which had an average viscosity of $22 \mathrm{cp}$. This effect seems to be the same when either nitrogen or helium was used as the gas phase. However, considering that there was a sevenfold variation in the liquid viscosity, the change in the value of the holdup was comparatively small (about 20 percent change in ho1dup is observed for 700 percent change in liquid viscosity). This behaviox can be consldered as indicating that the inertial force of the gas phase is the dominant factor in controlling the slip between the phases and consequently the holdup, and that the forces related to the viscosity of the liquid phase are less important. This can be examined more carefully by looking at the effect of the density of the gas phase on the liquid holdup.

\section{b. Effect of the Density of the Gas Phases}

Figure 30 shows a comparison nf holdup data for helium-liquid mixtures with those for nitrogen-liquid mixtures. It is seen that, for conctant mass tlow rale, the 11quid holdup produced by helium is consistently larger than that produced by nitrogen. This is another indication that the inertial force of the gas phase is a dominant parameter in causing holdup of the liquid phase. In fact, if the inertial force of the gas phase is the most dominant parameter, the holdup data corresponding to different gases should be correlated as a function of $\rho_{G}{ }^{1 / 2} V_{S G}$, regardless of the type of the gas. Therefore, for the same inertial force, the superficial velocity of the helium, compared to that of nitrogen, should be larger by a factor equal to the square root of the ratio of the densities of the two gases. For this reason, a plot of $\alpha_{L}$ vs. a modified superficial gas velocity, $\mathrm{V}_{\mathrm{SG}}\left(\mathrm{\rho}_{\mathrm{G}} / \rho_{\mathrm{N}_{2}}\right)^{1 / 2}$, was prepared as shown in Fig. 31. In this and similar plots, effects due to the density of the 


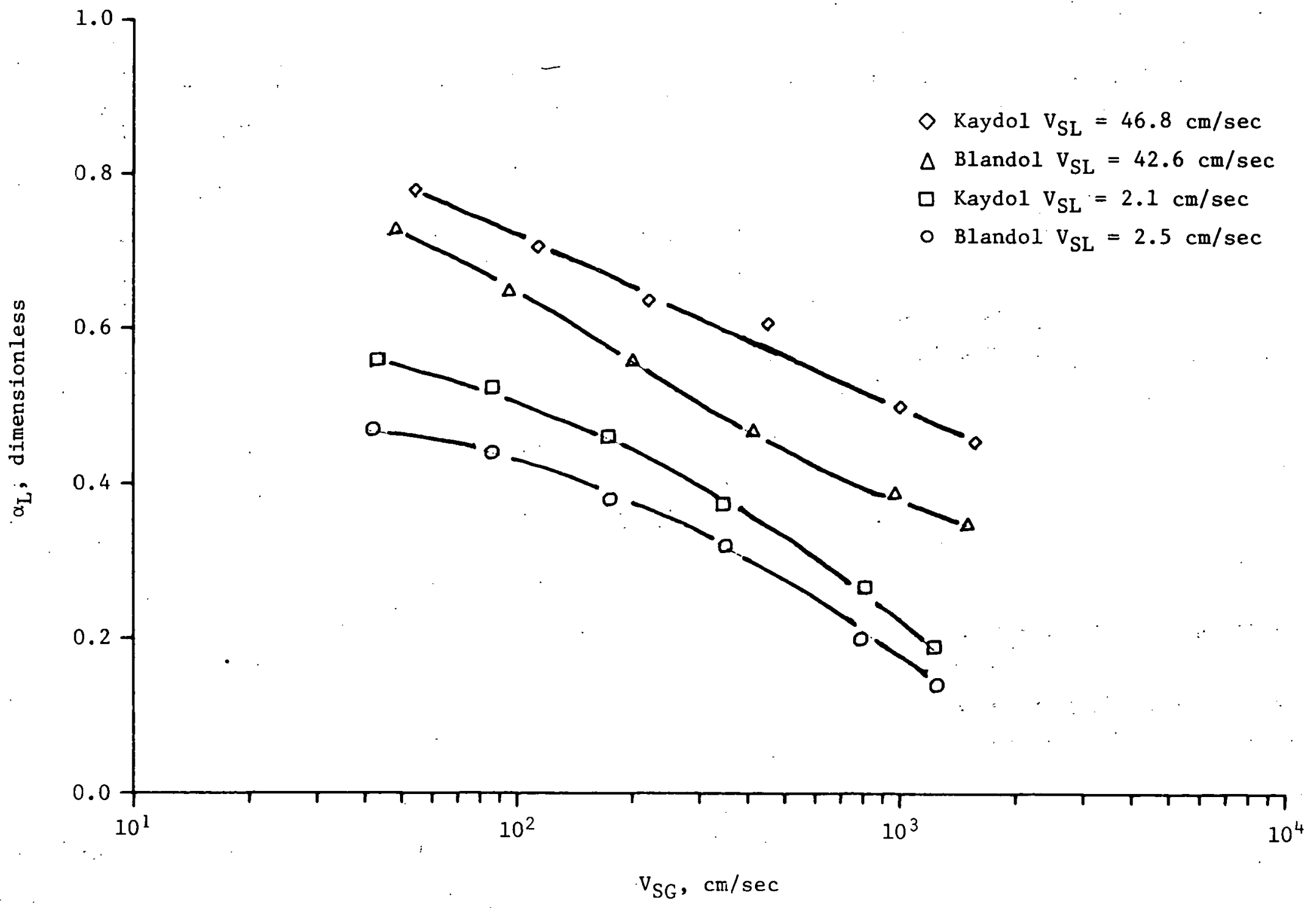

F-g. 28. Effec= of the Viscosity of the Liquid Phase on the Liquid Holdup in the $0.7-\mathrm{cm}-\mathrm{ID}$.Tube When Nitrogen is Used as the Gas Phase 


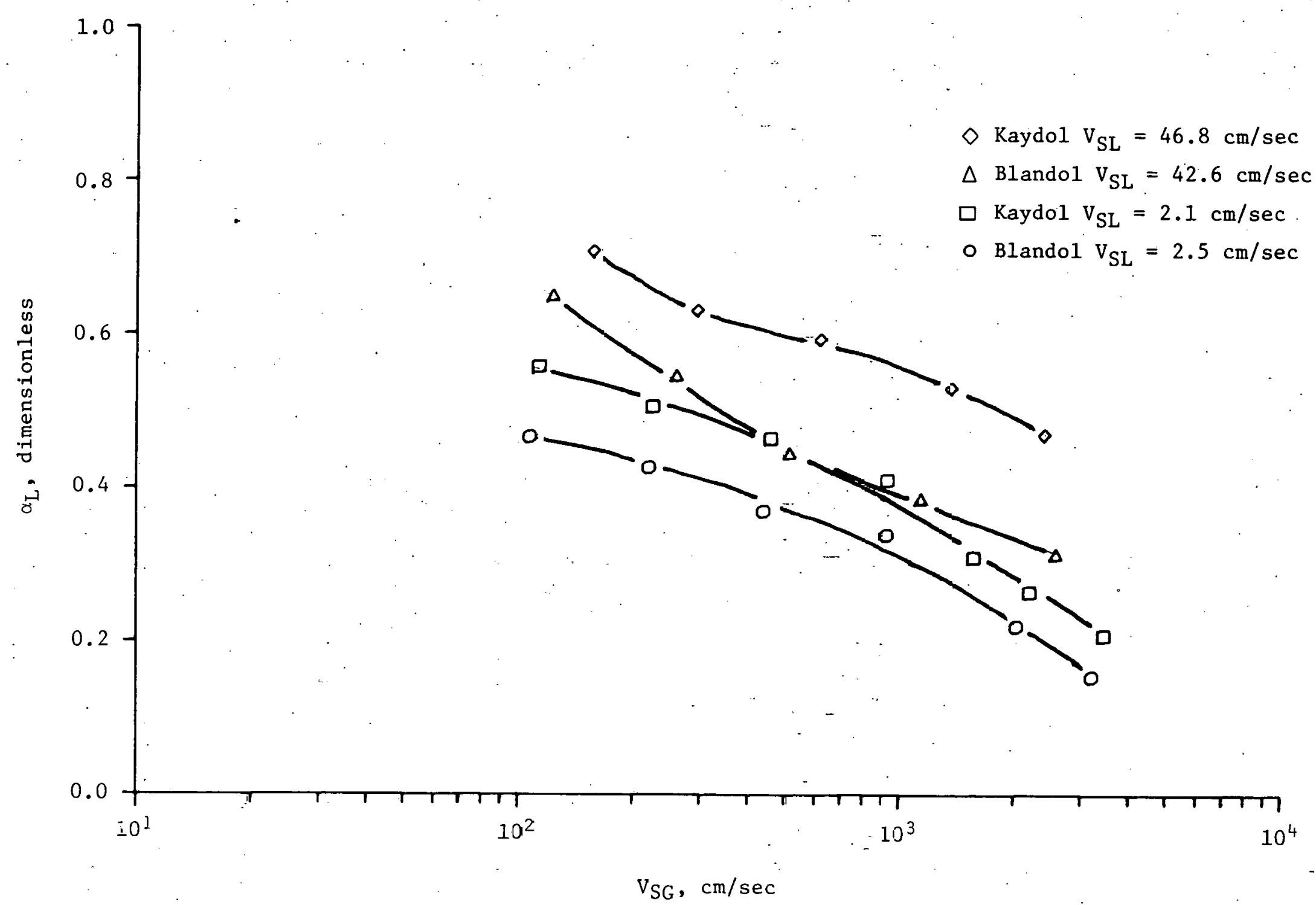

Fig. 29. Effect of the I'iscosity of the Liquid Phase on the Liquid Holdup in the 0.7-cm- $\mathbb{D}$ Fube When Helium is Used as "the Gas Fhase 


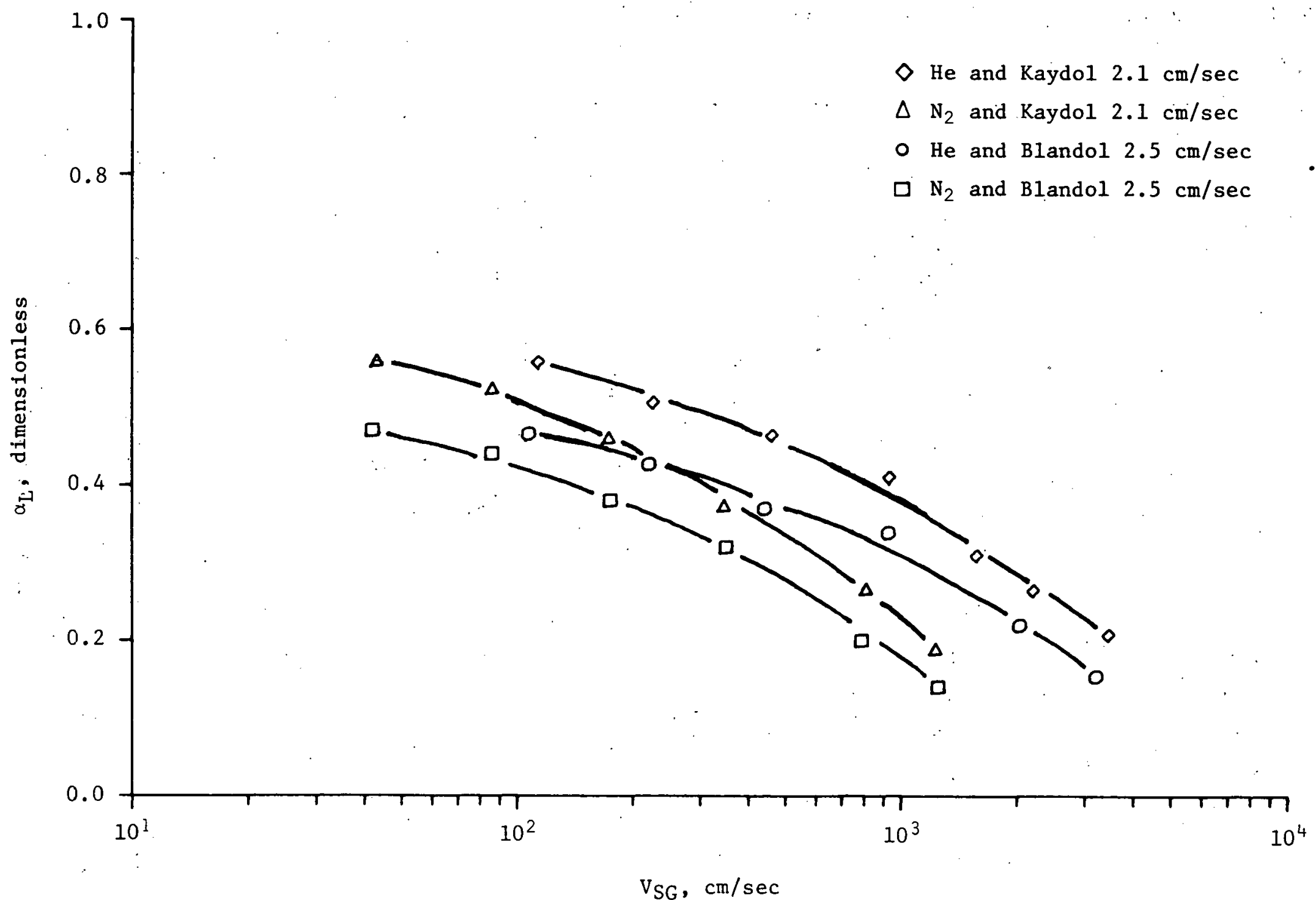

Fig. 30. Effect of the Density of the Gas Phase on the Liquid Holdup in the 0.7-cm-ID Tube 


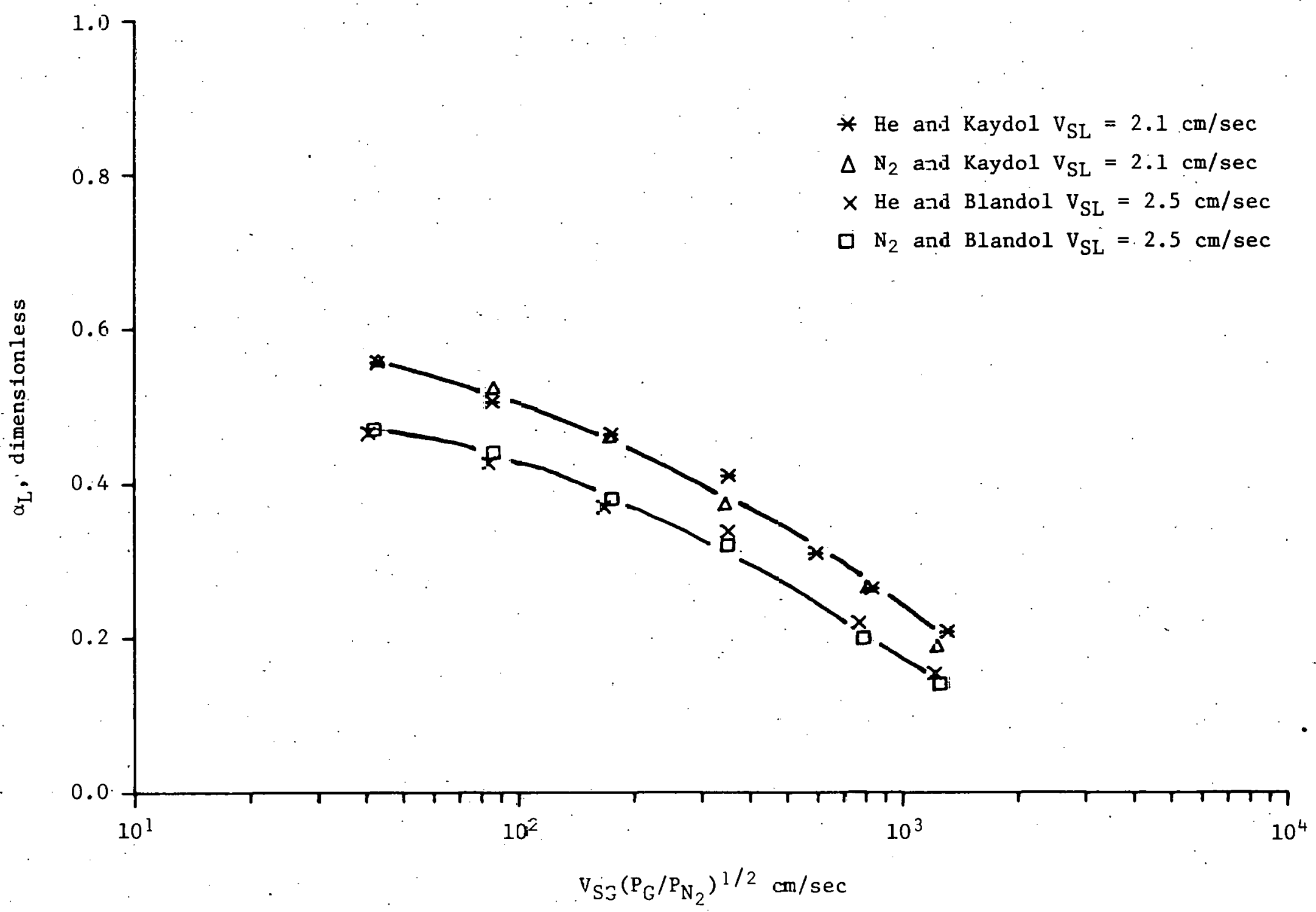

$\stackrel{+}{\infty}$

Fig. 31. Correlation of Holdup Data, Corresponding to Lifferent Gases, wi-h a Modified Superficial Gas Velocity 
gas phase on liquid holdup can be included in the value of the abscissa and regardless of the type of gas, a single curve results. This approach permits generalization of the holdup data for gases of different densities.

\section{c. Effect of the Tube Diameter}

Comparison of the data in Figs. 22 and 23 indicates that, for constant values of the gas superficial velocity and liquid superficial velocity, the liquid holdup is almost independent of the tube diameter. For film flow in the tube, when the liquid entrainment in the gas and the waviness of the film surface are neglected, the ratio of the average film thickness to the tube diameter is proportional to the average volumetric liquid holdup. Since the liquid holdup is independent of the tube diameter, we can conclude that this ratio is independent of the tube diameter too. This result can have an important application in scaleup of the processes, allowing the holdup data taken from a small column to be used for the design and analysis of large columns.

\section{Flow Patterns}

Visual observation was the only method used to determine the type of flow pattern established inside the tube as a function of gas and liquid flow rate. Preliminary attempts to photograph a diagonal sheet of the flow illuminated by a rotating laser beam proved unsuccessful in recording the distribution of the phases in the tube and hence the flow pattern. Similar attempts using flash photography did not improve the results.

There are some uncertainties involved with the use of visual observation as a basis for identification of the flow pattern. This is especially true under conditions which correspond to transitions between flow patterns. In fact, the recognition of a certain type of flow pattern in the tube, in the vicinity of transition from one flow regime to another, becomes a matter of personal judgment of the observer. For this reason, no quantitative agreement can be expected to exist between the predictions of different investigators.

The occurrence of different flow patterns is a strong function of the gas and the liquid flow rates. For this reason, a coordinate system utilizing the superficial liquid velocity as the ordinate and the superficial gas velocily as the abscissa can be used to plot the conditions under which different flow patterns will occur. Such plots are presented in Figs. 32 through 37 for different gas-liquid mixtures flowing in tubes of two different sizes. Because of uncertainties involved in identifying the type of flow near the transition regions, the location of the border lines separating these regions should be considered to be only approximately correct. For this reason, the use of Figs. 32 through 37 for identification of the flow pattern is recommended only when the gas and the liquid flow rates correspond to regions far from the border lines. The degree of uncertainty can be seen from the scatter of data in each graph.

\section{a. Effect of the Viscosity of the Liquid Phase}

Comparison of Fig. 34 with Fig. 36 and also Fig. 35 with Fig. 37, corresponding to flow mixtures that involve a sevenfold variation in the liquid viscosity, indicates that the viscosity of the liquid phase has very little effect on the location of the border lines, especially the one representing the start of annular film flow, which is of importance in the analysis 


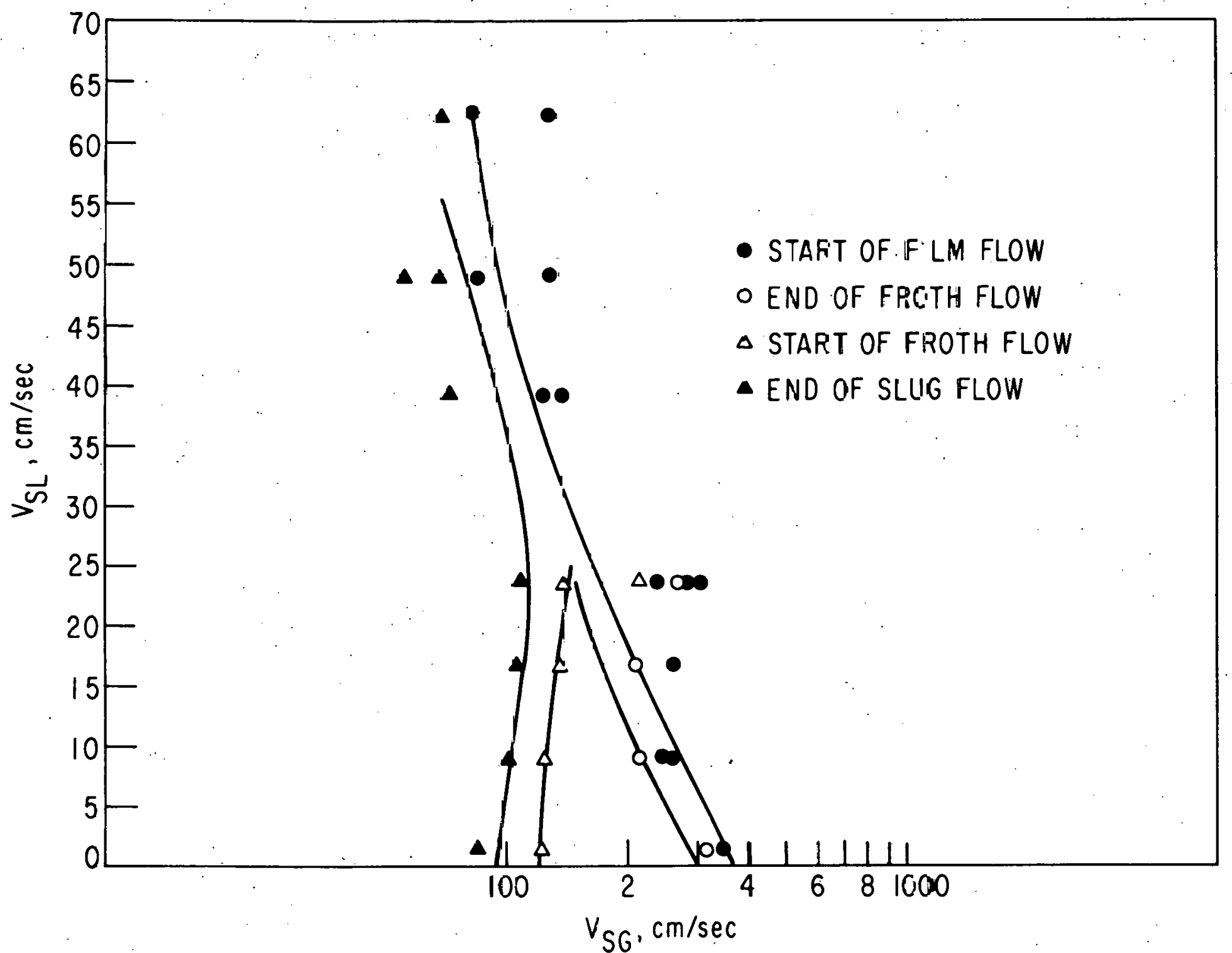

Fig. 32. Flow Patterns Corresponding to the Flow of Nitragen-Blandol Oil Mixtures in the $1.27-\mathrm{cm}-\mathrm{ID}$ Tube 


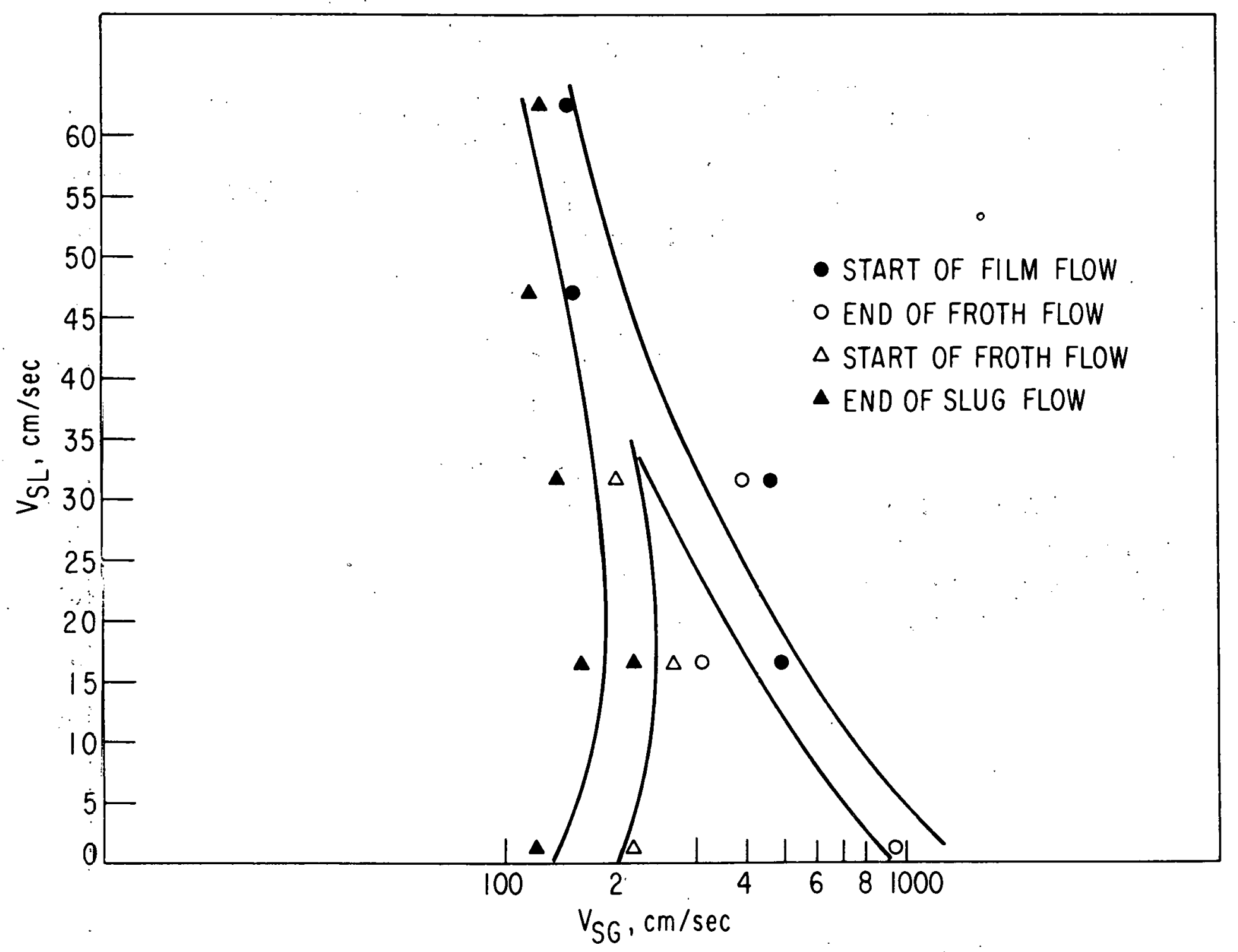

Fig. 33. Flow Patterns Corresponding to the Flow of Helium-Blandol Oil Mixtures in the 1.27-cm-ID Tube 


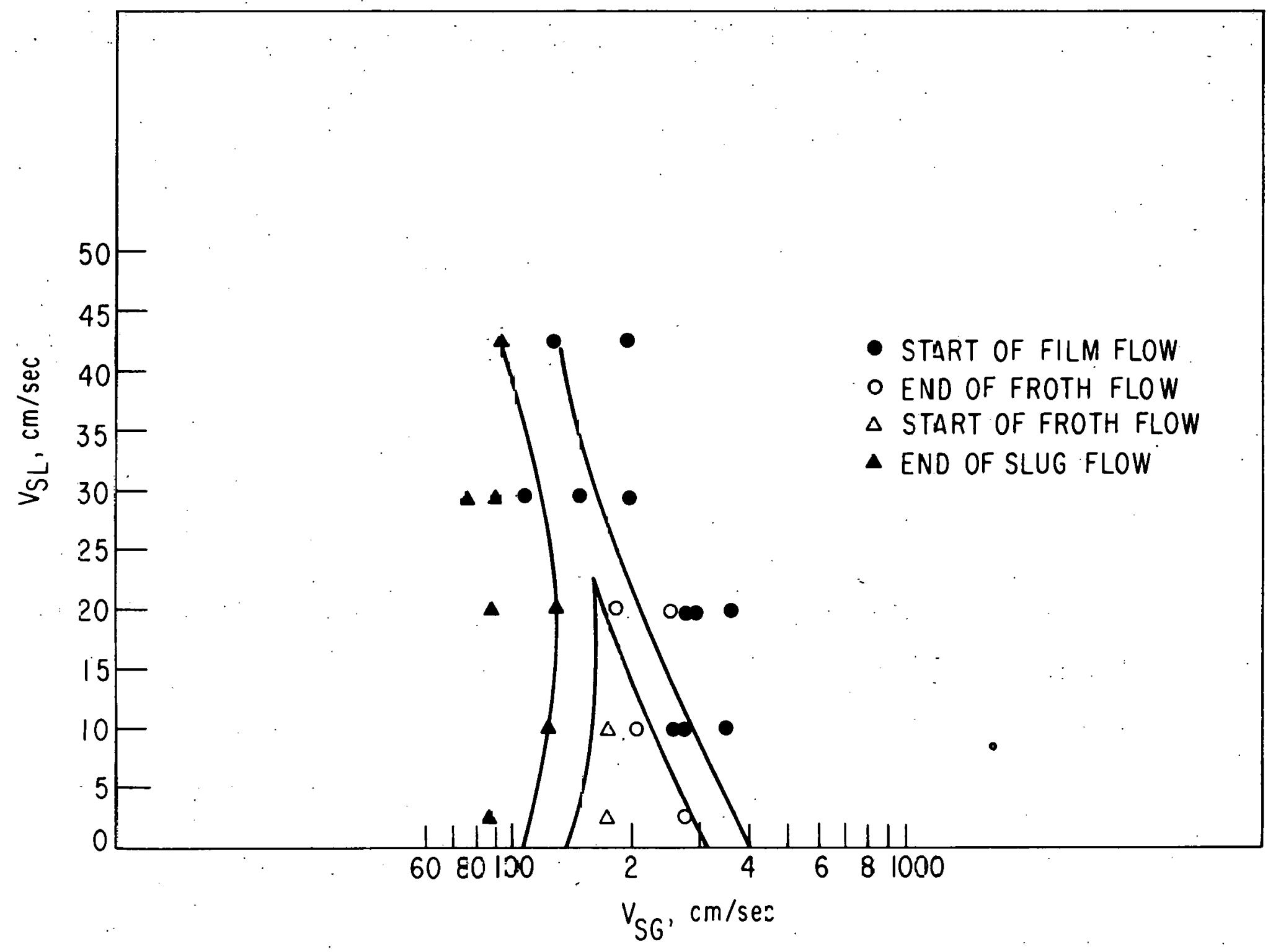

Fig. 34. Flow Patterns Corresponding to the Flow of Nitrogen-Blandol Oil Mixtures in the 0.7-cm-ID Tube .." 


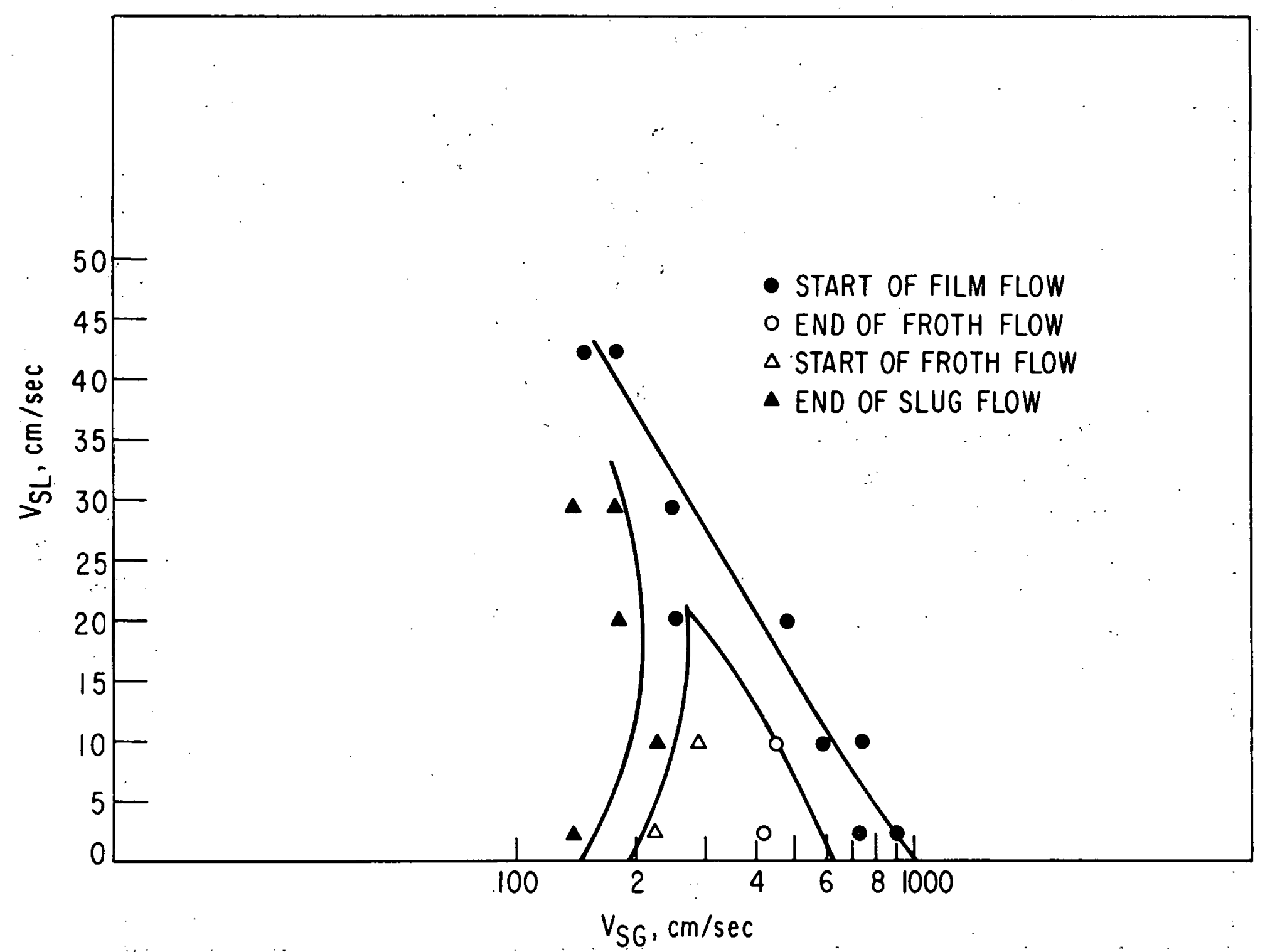

Fig. 35. Flow Patterns Corresponding to the Flow of Helium-Blandol Oil Mixtures in the 0.7-cm-ID Tube 


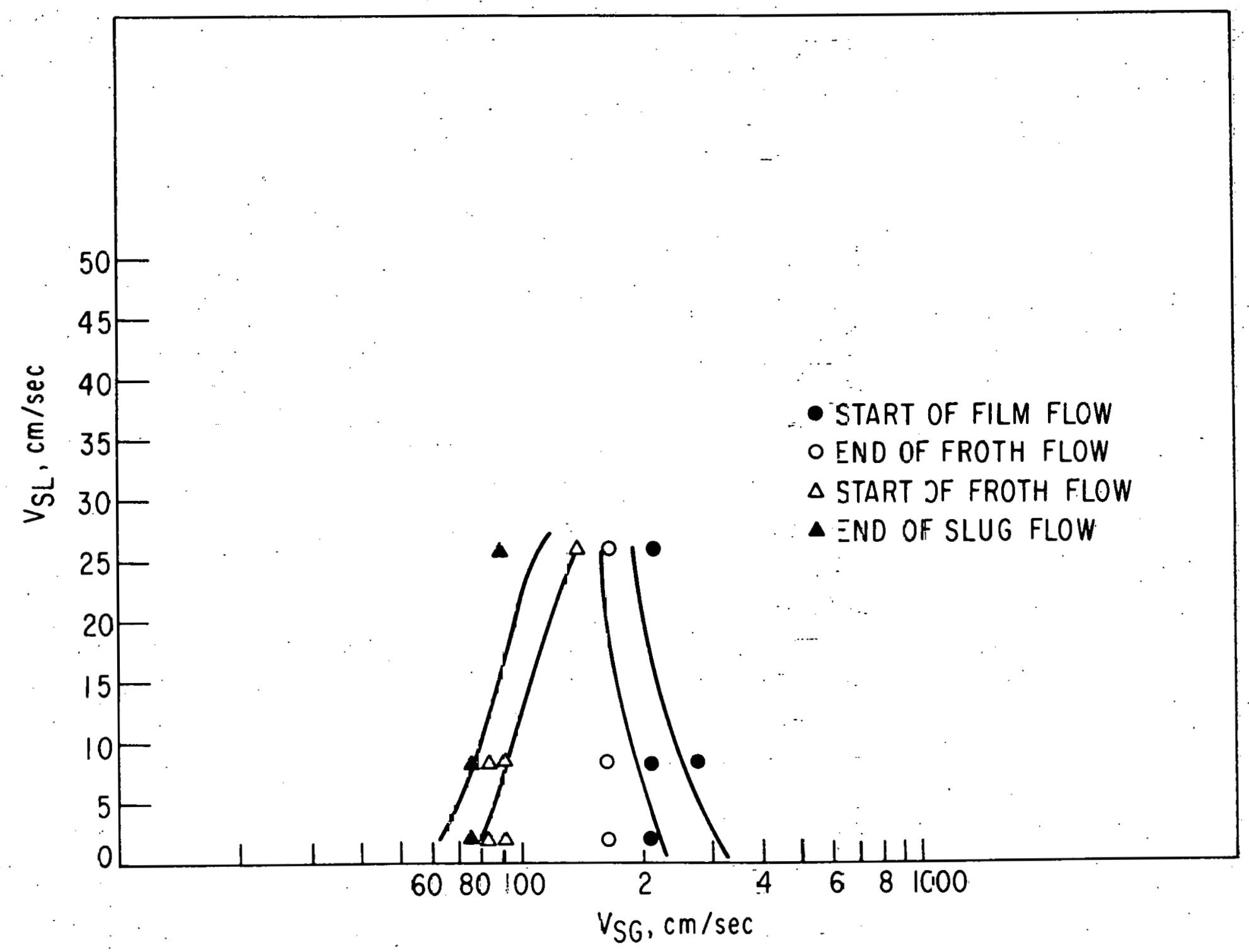

Fig. 36. Flow Patterns Corresponding to the Flow of Nitrogen-Kaydol Oil Mixtures ir the $0.7-\mathrm{cm}$-ID Tube:. 


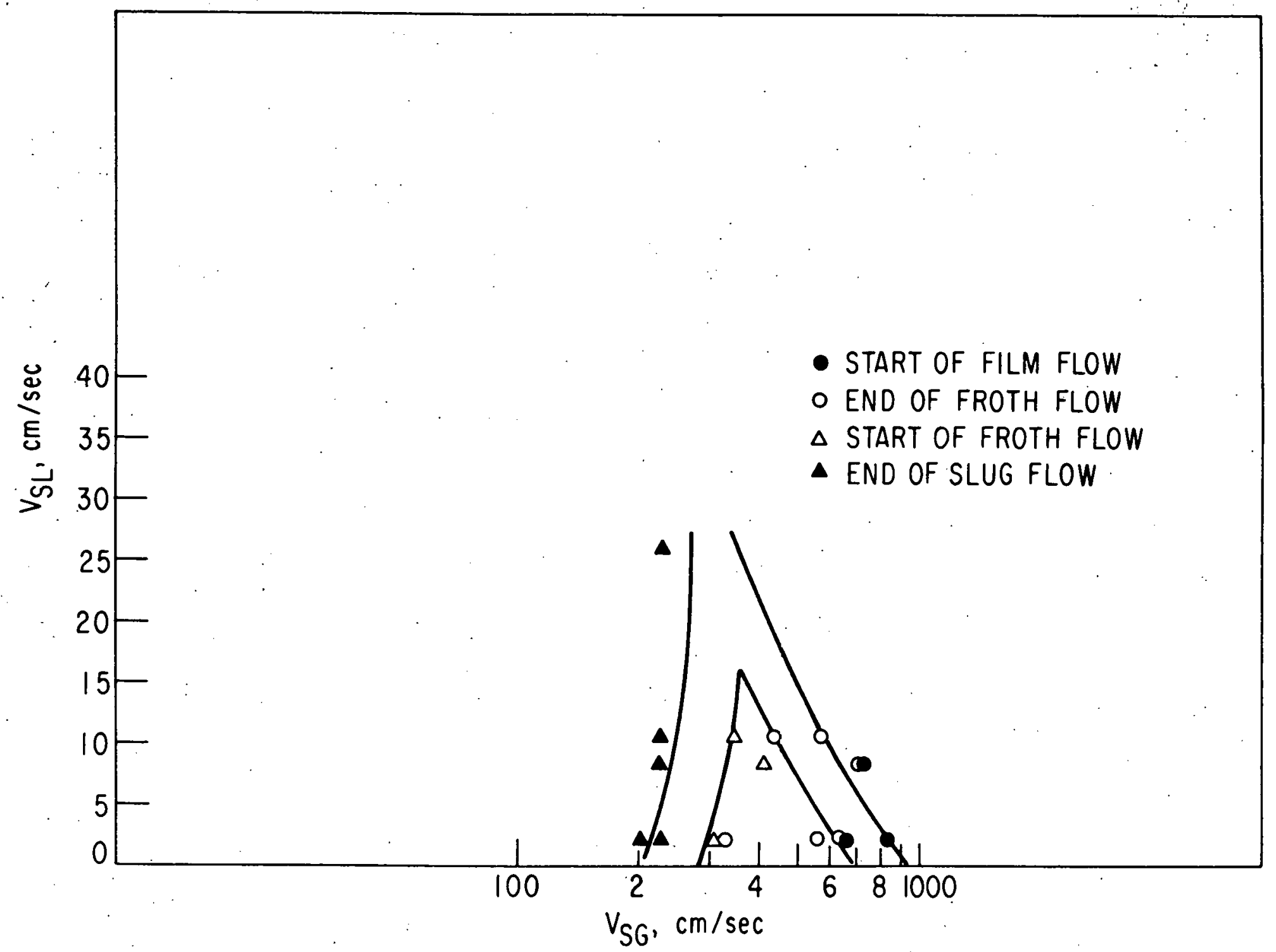

Fig. 37. Flow Patterns Corresponding to the Fiow of Helium-Kaydol Oil Mixtures in the 0.7-cm-ID Tube 
relevant to the SYNTHOIL process. This is in complete agreement with Govier's correlation (see Fig. 4) which indicates no effect of the viscosity of the liquid phase on the flow patterns. Despite such a qualitative agreement, there is a large quantitative disagreement between the location of the film border line obtained in these experiments and that suggested by Govier's correlation. The parameter $Y$ in Govier's correlation is approximately equal to 1.18 for both mineral oils. The parameter $X$ in this correlation strongly depends on the type of the gas and is equal to 1.17 or 0.61 , depending on whether nitrogen or helium is used as the gas phase. For these values of X and Y, Govier's prediction sets the start of the film flow at superficial gas velocities much higher than were actually found. For example, for the flow of nitrogen-Blandol oil mixture in the $0.7-\mathrm{cm}$-ID tube at a superficial liquid velocity of $10 \mathrm{~cm} / \mathrm{sec}$, Fig. 34 predicts the start of the film flow at a superficial gas velocity equal to $260 \mathrm{~cm} / \mathrm{sec}$. On the other hand, for the same conditions, Govier's correlation (f'ig. 4) puts the start of the film flow at a superficial gas velocity of approximately $1000 \mathrm{~cm} / \mathrm{sec}$. The fact that the bulk of the data in Govier's correlation corresponds to mixtures involving less viscous liquids, namely water, may be the reason for such a large quantitative disagreement. Although. the scatter of data makes the exact location of the film-flow border line in F'igs. 32 through 37 uncertain, it seems (especially for the helium curves) that film flow slarts at slightly lower gas velocities when the more viscous oil is used. For this reason, despite Govier's claim, there might be a visçosity effect that would push the film border line to high gas velocities when the viscosity of the liquid phase changes from about $22 \mathrm{cp}$ (for Blandol oil) to approximately $1 \mathrm{cp}$ (for water). Except for this speculation, the location of the film border line in the range of variables considered in this work was found to be insensitive to slight changes in the viscosity of the liquid phase.

\section{b. Effect of the Density of the Gas Phase}

The effect of the density of the gas phase on the flow pattern in the tube can be deduced by comparing Fig. 32 with Fig. 33, Fig. 34 with F1g. 35, and Fig. 36 with Fig. 37; each pair corresponds to the flow of nitrogen or helium with a different liquid in a differcnt tubc. The results cun= sistently show that with increased gas density, annular film flow starts at lower superficial gas velocities. Again, this is in qualitative agreement with Govier's correlation which suggests that the superficial velocity of hellum at the start of the film flow is higher than the corresponding value for nitrogen by a factor of $\left(\rho_{\mathrm{N}_{2}} / \mathrm{n}_{\mathrm{H}_{\mathrm{e}}}\right)^{1 / 3}$. Such a cube root dependence does not seem to be valid for the rata presented in Fige. 33 to 37. Instcad, it seculs that in some regions, the modification of the superficial gas velocity through multiplication by the square root of the density ratio produces greatcr success in generalizing the data and producing a single film border line for prediction of the start of annular film flow for both gases. This may be another clue that the inertial force of the gas phase is the dominant factor for onset of annular two-phase flow.

The uncertainties involved with the Jocation of the boundary line inhibit verification of the exact dependence of the flow patterns on the gas density. However, the definite conclusion that even with highly viscous liquids, film flow starts earlier with a higher density gas is valuable information. 


\section{c. Effect of the Tube Diameter}

Govier's correlation suggests that the type of flow established in two-phase flow does not depend on tube diameter. A similar conclusion can be derived by comparing the flow patterns presented in Figs. 32 and 34 and also Figs. 33 and 35. Despite the uncertainties in mapping the flow field, no significant dislocation of the film border line is observed in going from the 1.27-in.-ID tube to the 0.7-in.-ID tube.

\section{B. Gas-Liquid-Solid Flow Characteristics}

The gas-slurry experiments were conducted by mixing pulverized coal particles (see Section III.C) with the Blandol oil and pumping the mixture into the tube through the annular device in the same manner as in the two-phase flow experiments. Three slurries of $11.0,20.4$, and 27.1 wt $\%$ coal in oil were used. Procedures used to measure the pressure drop and holdup resulting from the flow of gas-slurry mixtures were similar to those used in the two-phase flow experiments. Determination of the flow patterns by visual observation became more difficult because of the dark mixture produced by the flow of coal slurry in the tube.

\section{Rheological Properties of the Slurries}

The three slurries used in the experiments behaved very much like a homogeneous liquid because the coal particles were small and their density was not much different from the density of the Blandol oil (see Section III.C). Rheological behavior of the slurries was determined experimentally, using a straight-tube viscometer of diameter $\mathrm{D}$ and length $\mathrm{L}$, and measuring the pressure drop, $\Delta \mathrm{P}$, for different values of the average velocity of the slurry, $U_{m}$, in the viscometer. The results were plotted according to Equation 2, as shown in Fig. 38. It is seen that a linear relationship exists between the shear stress at the wall, $D \Delta P / 4 \mathrm{~L}$, and $8 \mathrm{u}_{\mathrm{m}} / \mathrm{D}$, which represents a nominal shear rate in the tube. In addition, it is seen that the straight lines through the data points for each slurry pass through the origin, indicating the absence of any yield stress. This indicates that for slurries containing up to $27.1 \mathrm{wt} \%$ coal in the mineral oil, the exponent $n^{\prime}$ in Equation 1 or Equation 2 is equal to one and the slurry can be considered to be a Newtonian liquid. Apparently, as seen from the difference in the slopes of the lines in Fig. 38, increasing the coal concentration simply increases the viscosity of the slurry without affecting its Newtonian behavior. The slight scatter in the data of Fig. 38 is due to small variations of the temperature during the measurements. The viscosities of the slurries as determined from the slopes of the corresponding lines in Fig. 38 are given in Table 4.

A variable-speed Syncho-Lectric Brookfield viscometer was also used to detect the existence of any non-Newtonian behavior in the slurry. The value of the viscometer dial reading (proportional to viscosity) was found to decrease with increasing speed of rotation of the bob, indicating a dependence of the viscosity on the rate of shear, which is characteristic of non-Newtonian behavior. The disagreement between the results obtained from the straight-tube viscometer and those found with the Brookfield viscometer can be explained on the basis of the difference in ranges of measurement for the two devices. The rate of shear produced by the rotating hob of the viscometer was calculated to be less than $90 \mathrm{sec}^{-1}$ for the highest speed of rotation, 37 whereas, as can be 


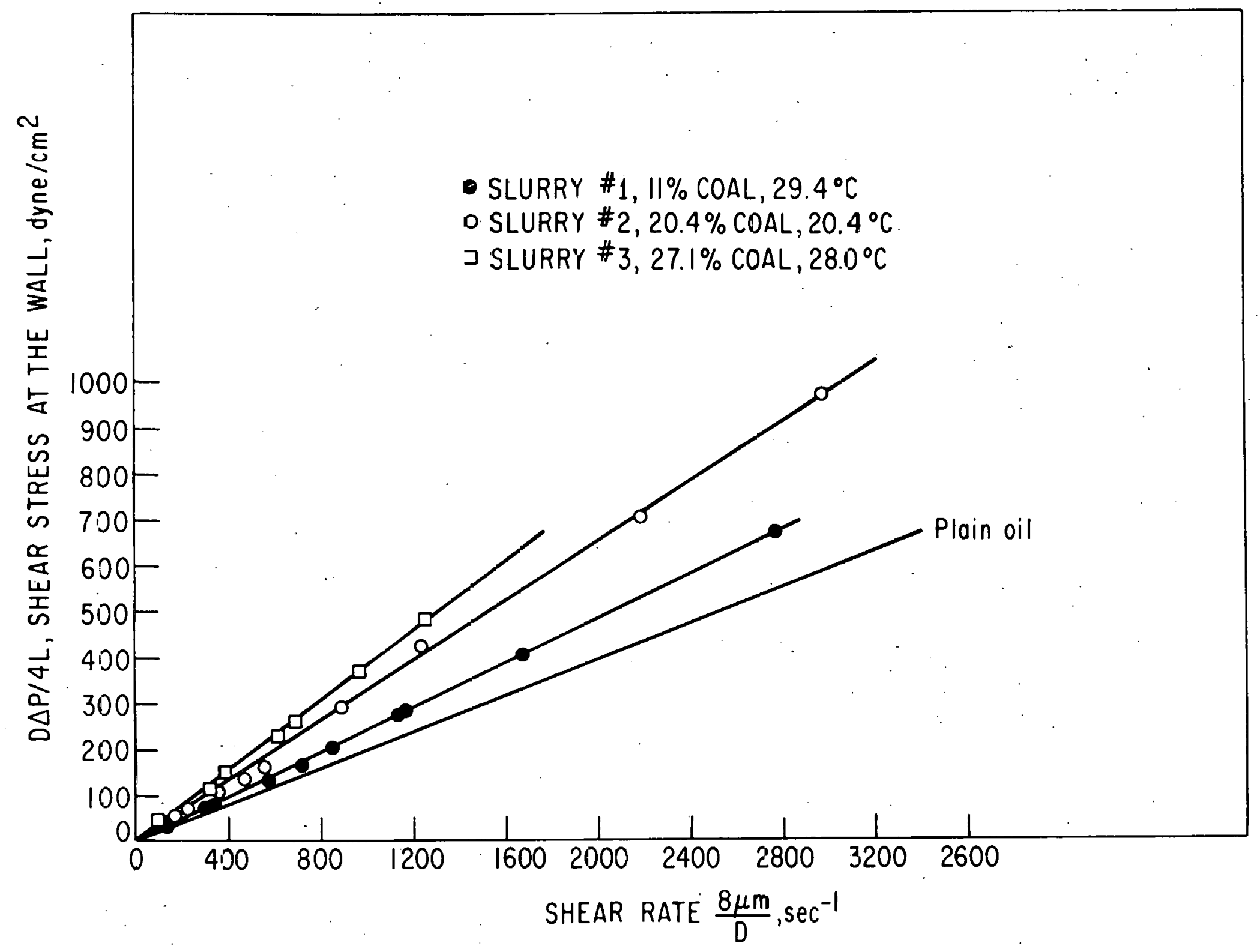

Fig. 38. Stress-Strain Relationship for Different Slurries as Determined by the Straight-iTube Viscometer 
Table 4. Viscosities of Slurries

\begin{tabular}{ccc}
\hline $\begin{array}{c}\text { Temperature } \\
\left({ }^{\circ} \mathrm{C}\right)\end{array}$ & (wt \% coal in Blandol oil) & $\begin{array}{c}\text { Viscosity } \\
(\mathrm{cp})\end{array}$ \\
\hline 28.5 & 0.0 & 19.9 \\
29.4 & 11.0 & 24.1 \\
28.4 & 20.4 & 32.6 \\
28.0 & 27.1 & 38.5 \\
\hline
\end{tabular}

seen from Fig. 38, the rate of shear in the straight-tube viscometer was generally one order of magnitude larger. For this reason, one can speculate that the slurries may possess a slight non-Newtonian behavior in the regions of low shear rates near the origin (Fig. 38). However, because of the high shear rates normally involved in the flow of two-phase mixtures, the existence of such a small region can be overlooked and the slurry can be considered a Newtonian liquid for all practical purposes. Similar viscometric experiments have indicated that slurries containing glass spheres of about $50 \mu \mathrm{m}$ and solid concentrations up to 55 wt \% exhibit no non-Newtonian behavior. ${ }^{38}$

Since the coal slurry behaves like a homogeneous Newtonian liquid, the flow characteristics of gas-slurry mixtures can be obtained from the results for gas-liquid flow (with a liquid having physical properties similar to those of the slurry). For this reason, the extensive amount of information presented earlier on the flow characteristics of gas-mineral oil mixture should apply directly to the flow of gas-mineral oil-coal mixtures. This applicability was tested by comparing the pressure drop and holdup data corresponding to the flow of gas-slurry mixtures to those of the gas-mineral oil mixtures.

\section{Pressure Drop}

Since the coal slurries act like homogeneous Newtonian liquids, one can anticipate that the total pressure drop resulting from the upflow of gasslurry mixtures would be identical to that obtained for the gas-mineral oil mixture at equivalent conditions. In fact, such a behavior was observed, as showil il Fig. 39. The pressure drop curves for the gas-slurry mixtures containing 11 wt \% coal behave exactly like the curves corresponding to gasBlandol oil mixtures. For the sake of comparison, data for pressure drop resulting from the flow of nitrogen-Blandol oil mixtures at a superficial liquid velocity of $10 \mathrm{~cm} / \mathrm{sec}$ are shown. in this figure too. Comparison of Fig. 39 with Fig. 10 reveals that the use of 11 percent coal slurry yields the same pressure drop as that resulting from the use of the plain oil.

The viscosity of the 11 percent slurry differs only slightly from the viscosity of Blandol, oil. To be exact, for the data in Fig. 39, conditions were such that the plain oil and the 11 percent slurry had viscosities equal to 22 and $24 \mathrm{cp}$, respectively. Pressure drop values are almost insensitive to such a small variation in viscosity (see Section IV.A). The viscosity of the slurry increases rapidly with coal concentration. Therefore, since the pressure drop is not totally independent of the viscosity of the liquid (or slurry) phase, one should anticipate that higher pressure drops would result for more concentrated slurries. Such behavior, which is consistent with the discussion 


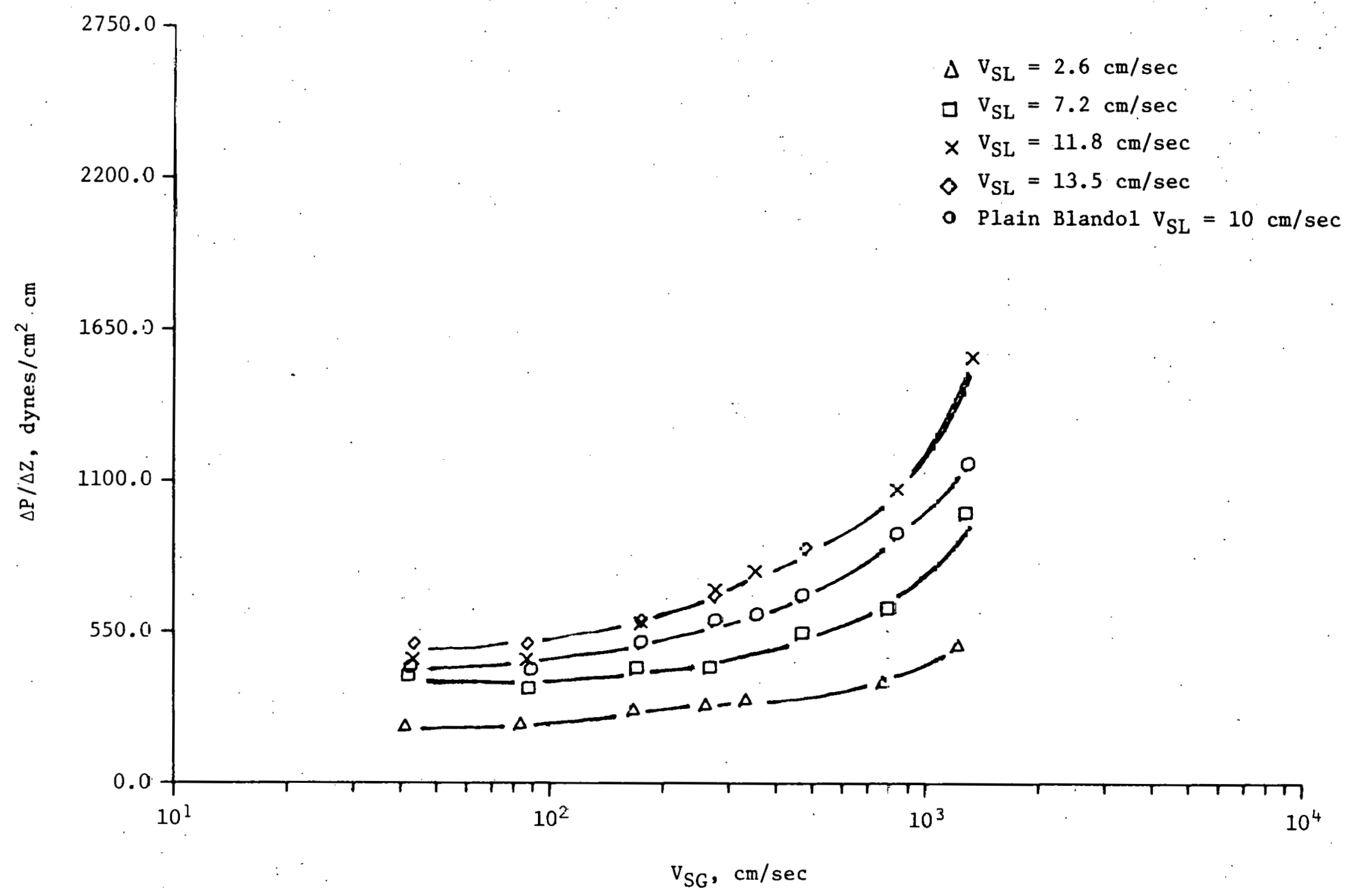

Fig. 39. Pressure Drop for the Flow of Nitrogen and 11 Percent Coal Slurry (made with Blandol oil) in the 0.7-cm-ID Tube. Also ircluded for comparison are some data points from Fig. 10 for the flow of nitrogen-3landol oil mixtures. 
presented earlier on the effect of viscosity on pressure drop, is shown in Figs. 40 and 41 for slurries of three different concentrations. The corresponding. viscosities are given in Table 4.

The scatter of data for gas-slurry experiments is generally larger than for gas-liquid mixtures. This is traceable to difficulties involved with control of the slurry flow rate using the straight-tube viscometer (see Section III.C), settling of the coal in the slurry in the reservoir, or even clogging of the pressure taps on the column by coal particles. Special precautions were taken to eliminate these problems insofar as possible.

\section{Holdup}

Holdup data for three different slurries at constant superficial liquid velocities are presented in Fig. 42. The holdup data for Blandol oil at the same superficial liquid velocity (reproduced from Fig. 23) is also shown in Fig. 42 for comparison. Despite the scatter of the data, the general behavior of the holdup curves agrees with the results presented for flow of gas-liquid:mixtures. Except for a few data points, the results generally show that more concentrated slurries produce larger holdups in the column. Since holdup is not overly sensitive to slight variations in viscosity, this increase in holdup can not be attributed entirely to the increase in viscosity at higher coal concentrations. However, increase might also be due to the additional slip between the coal particles and the liquid phase.

\section{Flow Patterns}

Flow of the coal slurry produced a dark mixture inside the tube, making visual observation for the identification of the flow pattern impractical. For this reason, the location of the boundary lines separating different flow regimes in gas-slurry flow could not be identified directly. However, the slurry behaves like a homogeneous Newtonian liquid and the results presented earlier on the flow patterns established for the flow of gas-Blandol oil mixtures can be used for the prediction of flow patterns in the gas-slurry mixtures as well. The only relevant physical property of the slurry that differs from that of the Blandol oil is viscosity which (as shown earlier) does not affect the locations of the boundary lines significantly. 


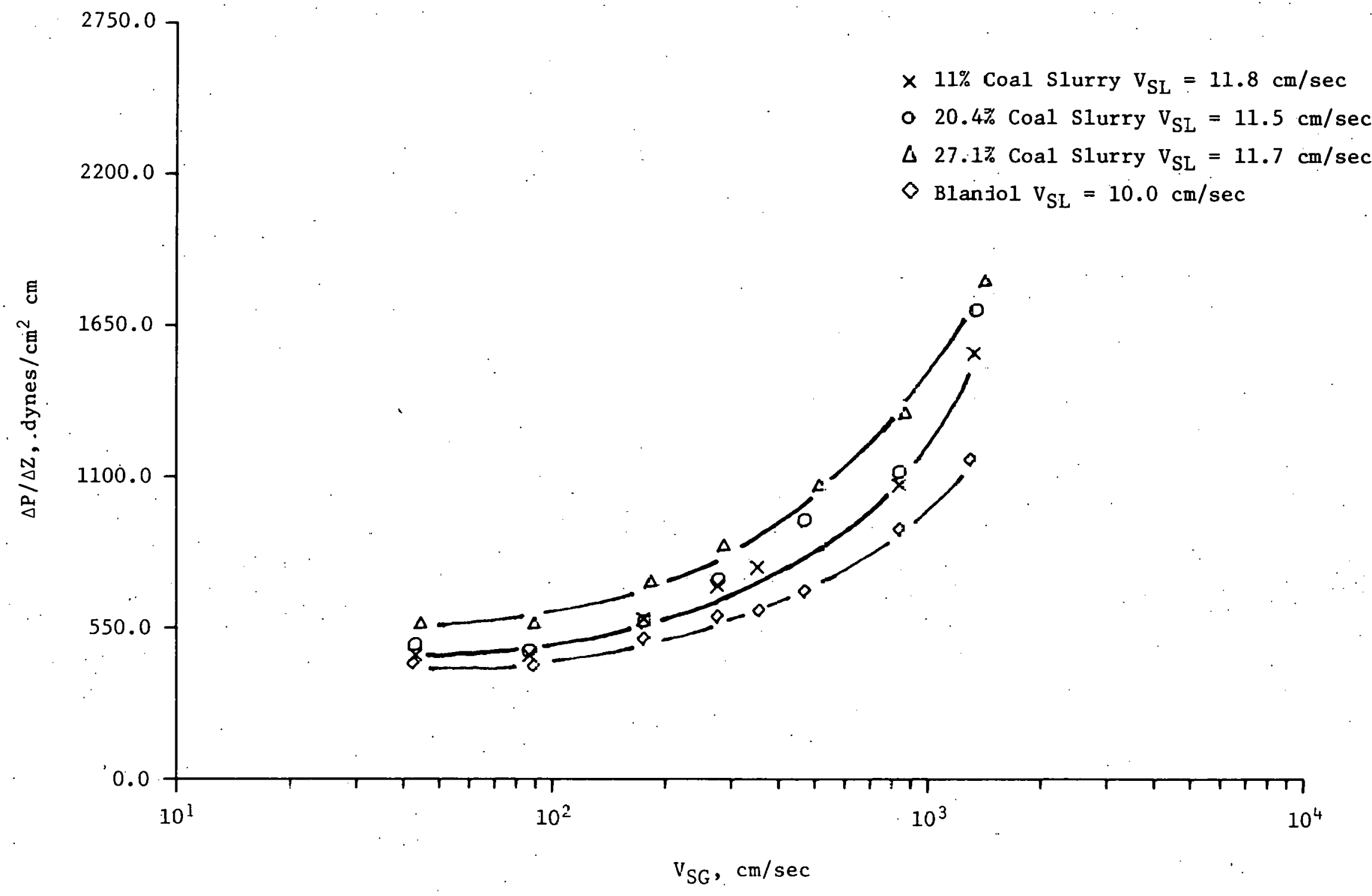

Fig. 40. Pressure Drops Corresponding to the Flow of Nitrogen-Slurry Mixtures in the 0.7-cm-ID Tube with the Concentration of the Slurry as a Parameter 


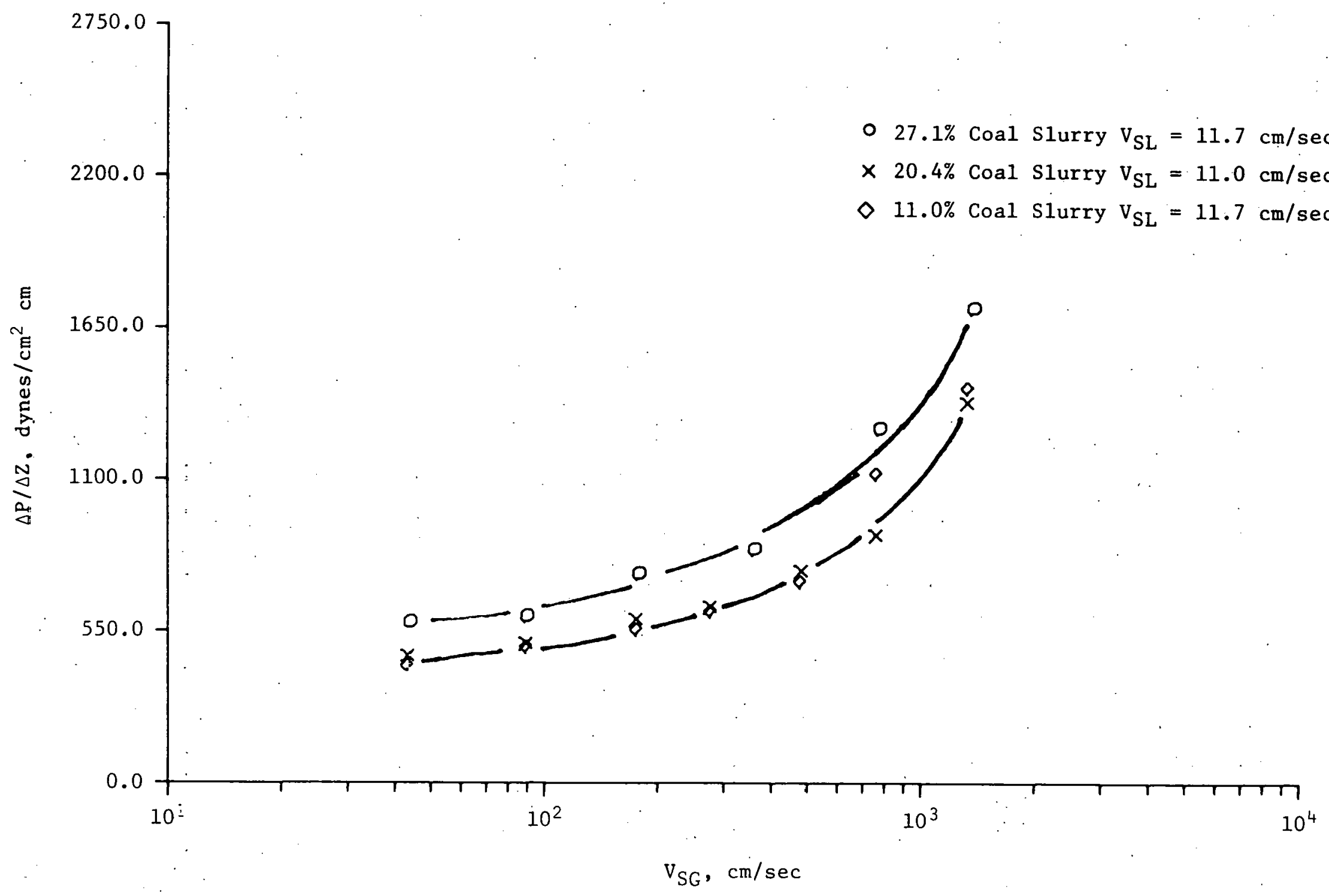

Fig. 41. Pressure Drops Corresponding to the Flow of Helium-Slurry Mixtures in the 0.7-cm-ID Tube with the Concentration of the Slurry as a Parameter 


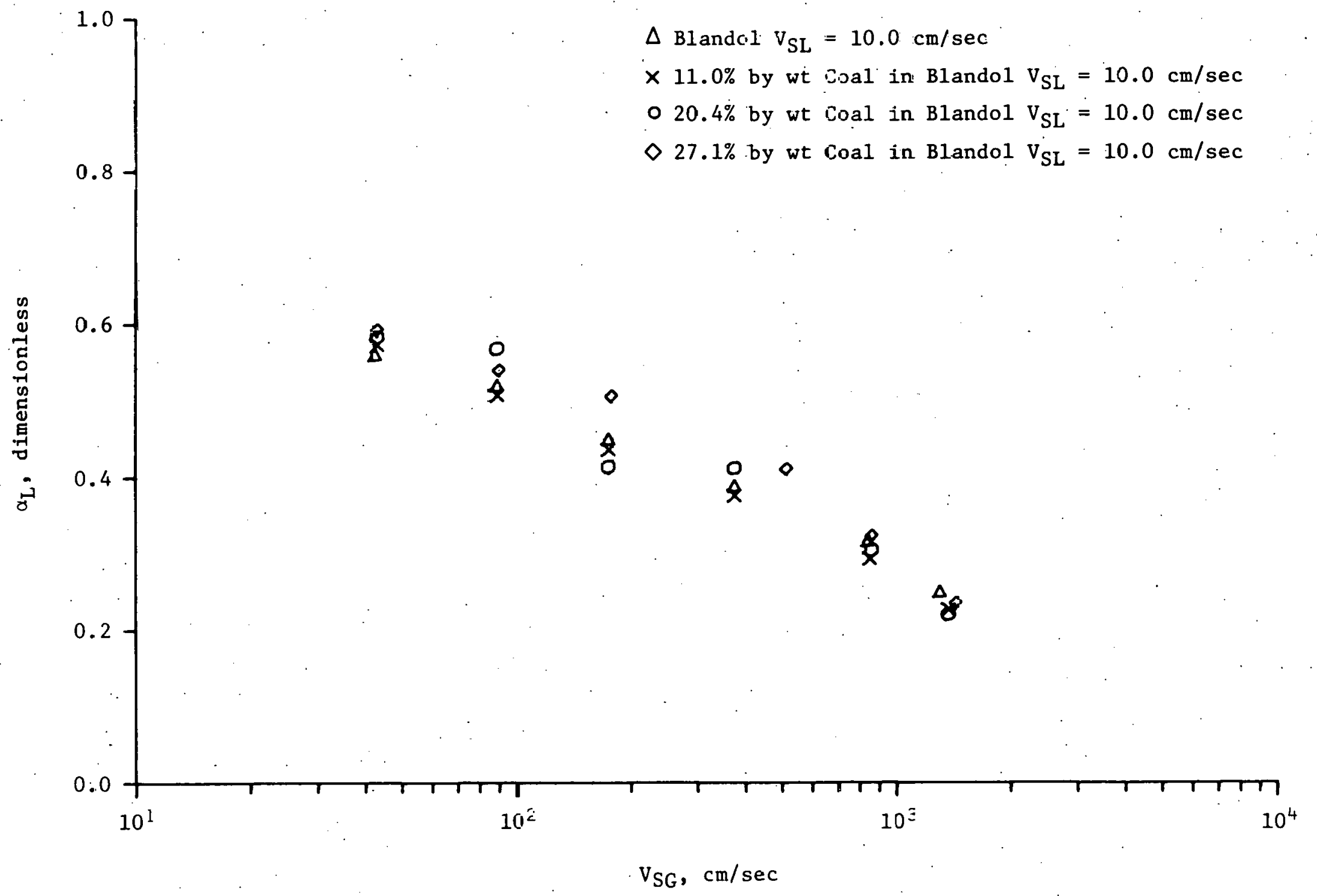

Fig. 42. Holdup Values Correspording to the Flow of Nitrogen-Slurry Mixtures in the 0.7-cm-ID Tube with the Corcentration of the Slurry as a Parameter 


\section{SUMMARY AND CONCLUSIONS}

In an experimental research program, done as a support study for the development of the SYNTHOIL and other coal liquefaction processes, data were obtained on pressure drop, liquid (slurry) holdup, and flow patterns resulting from the upward flow of gas-liquid and gas-slurry mixtures in cylindrical tubes.

The first part of the program was devoted to study of the flow characteristics of two-phase gas-liquid systems. This was done for two reasons: to test the applicability of the existing correlations at conditions of high liquid viscosity and high gas density that exist in the tubular heater of the SYNTHOIL process and (2) to use the gas-liquid flow data as a frame of reference for comparison with the results obtained in three-phase gas-slurry experiments. The use of gas-liquid mixtures consisting of nitrogen or helium and each of two types of mineral oils of different viscosities provided data showing the effect on flow characteristics of sevenfold variation in the density of the gas phase and sevenfold variation in the viscosity of the liquid phase. In addition, using two tubes of different diameters in the experiments provided a means of evaluating the effects of varying the tube diameter on the flow characteristics.

In the second part of this research program, the flow characteristics of gas-slurry mixtures were investigated. Three slurries with different coal concentrations of up to 27.1 wt \% were employed. The experimental procedure used for gas-liquid systems was repeated in the gas-slurry experiments. Data on pressure drop and slurry holdup were collected and were compared with those obtained with gas-liquid mixtures.

The following conclusions pertain to the flow behavior of the gas-liquid and gas-slurry mixtures used in these experiments:

1. The total pressure drop in the tube increases with liquid flow rate and, except for regions of low liquid and gas superficial velocities, it increases with gas flow rate too. This behavior is in agreement with the observations of other investigators.

2. If the frictional component of the pressure drop, $\Delta \mathrm{P}_{\mathrm{f}}$, is calculated as defined in Equation 3, this pressure drop can be correlated using the Martinelli parameters: Such correlation is satisfactory only in the regions corresponding to annular film flow or the kind of slug flow in which the length of the gas slug is considerably longer than the length of the liquid slug, so that the assumption concerning the existence of a separated flow model becomes valid. In these regions, the Martinelli correlations can estimate the frictional component of the pressure drop with 20 to 30 percent error.

3. Total pressure drop increases with viscosity of the liquid phase. However, this increase is small if only slight variations in viscosity are considered. The viscosity dependence of the pressure drop is also a function of the liquid flow rate, the type of the gas, and (to a smaller extent) the gas flow rate.

4. The density of the gas phase has a large effect on the total pressure drop.only at large values of the superficial gas velocity corresponding to the film flow regime. The inertial force of the gas phase becomes increasingly 
important with gradual increase in the gas flow rate and eventually dominates the establishment of the characteristics of the two-phase flow.

5. Tubes with smaller diameters produce larger pressure drops. This effect is small at low gas flow rates but increases as gas flow rate is increased.

6. The liquid holdup in the column decreases with increasing gas flow rate but increases with increasing liquid flow rate. This behavior is in agreement with observations of other investigators.

7. Generalization of the data obtained under different conditions can be done satisfactorily using the Hughmark-Pressburg parameter: However, quantitative agreement of the holdup data with the Hughmark-Pressburg correlation is poor and the bulk of the data corresponds to higher values of liquid holdup. The developing nature of two-phase flnot along the longth of the rolumn makma property like holdup a function of the length of the tube. Greater liquid holdups are obtained in shorter columns.

8. Generally, holdup increases with the viscosity of the liquid phase. However, as in the case of pressure drop, the change in holdup is negligible. when the viscosity of the liquid phase is varied only slightly.

9. For lower densities of the gas phase, larger values of liquid holdup are obtained. This behavior can be interpreted by considering the inertial forces of the gas phase a dominant factor in controlling the slip between the phases and, consequently, the holdup. On this basis, the holdup data for different gases can be correlated using a modified superficial gas velocity that includes the square root of the ratio of the densities of the two gases.

10. The 1iquid holdup does not seem to be a function of tube diameter. This means that in film flow regions, if entrainment in the gas phase and the wavy surface of the 1 iquid $\mathrm{film}$ are ignored, the ratio of the film thickness to the tube diameter is not a function of tube diameter.

11. The flow patterns resulting from the flow of gas-liquid mixtures used in these experiments generally follow the same sequence reported in the literature (slug, froth and annular flow). Quantitatively, however, the results do not agree with Govier's correlation--especially for prediction of the occurrence of film flow: For flow of the two-phase mixtures used in these experiments, film flow starts at much lower values of the superficial gas velocity.

12. Within the range of liquid viscosities employed in these cxperiments (22-140 cp), the liquid viscosity does not seem to have a large effect on the location of the f1lm flow border line. This is in agreement with Govier's prediction that establishment of the flow patterns is independent of the viscosity of the liquid phase.

13. The density of the gas phase has a pronounced effect on the location of the boundary separating regions of different flow patterns. A gas with a higher density produces film flow at considerably lower values of superficial gas velocity. By considering the inertial force of the gas phase as the dominant factor in producing film flow, one may conclude that the location of the film boundary changes with the square root of the ratio of the densities of 
the gases. Suç an effect is found to be approximately valid on the basis of data obtained in this work. Govier's suggestion, that the location of the boundary depends on the cube root of the ratio of the densities, does not seem to work as well.

14. In agreement with Govier's correlation; the tube diameter does not seem to affect the flow velocities required for the onset of the film flow pattern.

15. Within the slurry concentration range (0-27.1 wt \%) and for the size of the coal particles used, the coal slurry behaves like a single-phase homogeneous Newtonian liquid. However, the viscosity of the slurry. changes with coal concentration. For this reason, if the effect of viscosity on the flow characteristics is accounted for, the results obtained in the two-phase flow experiments are equally applicable to the flow of gas-slurry mixtures. Experimental data obtained with gas-slurry mixtures justify this conclusion. Due to additional slip between the coal particles and the liquid phase, the holdup. values in gas-slurry experiments are found to be slightly larger than the corresponding values for gas-liquid systems.

\section{NOMENCLATURE}

$$
\begin{aligned}
& \text { D Diameter of the tube viscometer, } \mathrm{cm} \\
& \text { g Acceleration of gravity, } 981 \mathrm{~cm} / \mathrm{sec}^{2} \\
& g_{c} \quad \text { Unit conversion constant } \\
& \begin{array}{l}
\mathrm{G}_{\mathrm{M}} \quad \text { Two-phase mass flow rate entering the tube }=\mathrm{V}_{\mathrm{SL}} \rho_{\mathrm{L}}+\mathrm{V}_{\mathrm{SG}} \rho_{\mathrm{G}} \text {, } \\
\mathrm{g} / \mathrm{cm}^{2} \mathrm{sec}
\end{array} \\
& k^{\prime} \quad \text { Consistency index of the fluid, defined by Eq. } 1 \\
& \text { L Length of the tube viscometer, } \mathrm{cm} \\
& \text { n . A quantity used in the Lockhart-Martinelli correlation as defined by } \\
& \text { Eq. } 5 \\
& \mathrm{n}^{\prime} \quad \text { Flow behavior index of the fluid, defined by Eq. } 1 \\
& \text { P Pressure, dyne } / \mathrm{cm}^{2} \\
& \triangle \mathrm{P} \quad \text { Pressure drop, dyne } / \mathrm{cm}^{2} \\
& \Delta \mathrm{P}_{\mathrm{f}} \quad \text { Irreversible component of the pressure drop, dyne } / \mathrm{cm}^{2} \\
& \mathrm{u}_{\mathrm{m}} \quad \text { Average velocity in the tube viscometer, } \mathrm{cm} / \mathrm{sec} \\
& \mathrm{V}_{\mathrm{M}} \quad \text { Mixture velocity in the tube }=\mathrm{V}_{\mathrm{SG}}+\mathrm{V}_{\mathrm{SL}}, \mathrm{cm} / \mathrm{sec} \\
& \mathrm{V}_{\mathrm{SG}} \quad \text { Superficial gas velocity, } \mathrm{cm} / \mathrm{sec} \text { or } \mathrm{ft} / \mathrm{sec} \\
& \mathrm{V}_{\mathrm{SL}} \quad \text { Superficial liquid velocity, } \mathrm{cm} / \mathrm{sec} \text { or } \mathrm{ft} / \mathrm{sec}
\end{aligned}
$$


$\mathrm{X}$ Lockhart-Martinelli parameter as defined by Eq. 8; also, the parameter used in Govier's correlation for flow pattern prediction $=\left(\frac{P_{G}}{P_{A}}\right)^{1 / 3} Y$

$\mathrm{X}^{\prime} \quad$ Hughmark-Pressburg correlation parameter (see Fig. 5)

$\mathrm{Y}$

Parameter used in Govier's flow pattern correlation $=\left(\frac{\rho_{\mathrm{L}}{ }_{\mathrm{WA}}}{\rho_{W}{ }^{\sigma}}\right)^{1 / 4}$

Z Distance along the test section, $\mathrm{cm}$

$\alpha_{L} \quad$ Average volumetric holdup of the liquid (slurry) in the tube, dimensionless

$\gamma \quad$ Shear rate 1 in the tube, reciprocal second

$\mu_{G} \quad$ Viscosity of the gas, $c p$

$\mu_{L} \quad$ Viscosity of the liquid, $\mathrm{cP}$

$\rho_{A}$ Density of air at standard atmospheric conditions, $\mathrm{g} / \mathrm{cm}^{3}$

$P_{G} \quad$ Density of the gas phase, $\mathrm{g} / \mathrm{cm}^{3}$

$\rho_{\mathrm{L}} \quad$ Density of the liquid phase, $\mathrm{g} / \mathrm{cm}^{3}$

$\rho_{\mathrm{W}} \quad$ Density of water, $\mathrm{g} / \mathrm{cm}^{3}$

$\sigma$ Liquid-gas interfacial tension, dyne $/ \mathrm{cm}$

${ }^{W}$ WA Water-air interfacial tension, dyine/cill

$\tau_{W} \quad$ Shear rate at the tube wall, dyne/cm

$\phi_{\mathrm{G}} \quad$ Lockhart-Martinel1i parameter, defined by Eq. 7

$\phi_{\mathrm{L}} \quad$ Lockhart-Martinelli parameter, defined by Eq. 6

ACKNOWLEDGMENT

We thank Professor .T. S. Dranoff at Northwestern Universlly for his guidance and support of graduate student participation in this program. 


\section{REFERENCES}

1. P. M. Yavorski, S. Akhtar, and S. Freidman, Converting Coal into NonPolluting Fuel Oil, Chem. Eng. Prog. 69(3), 51 (1973).

2. S. Freidman, P. M. Yavorski, and S. Akhtar, The SYNTHOIL Process, paper presented at the Clean Fuel from Coal Symposium, Institute of Gas Technology, Chicago, Illinois, June 23-27, 1975.

3. C. A. Johnson, M. C. Chervenak, E. S. Johanson, H. H. Stotler, O. Winter, and R. H. Wolk, Present Status of the H-Coal Process, paper presented at the Clean Fuel from Coal Symposium, Institute of Gas Technology, Chicago, Illinois, September 10-14, 1973.

4. K. Ostergaard, Gas-Liquid-Particle Operations in Chemical Reaction Engineering, Adv. Chem. Eng. 7, 71 (1968).

5. R. C. Darton and D. Harrison, The Rise of Single Gas Bubbles in Liquid Fluidized Beds, Trans. Inst. Chem. Engr. 52, 301 (1974).

6. R. C. Darton and D. Harrison, Gas and Liquid Holdup in Three-Phase Fluidization, Chem. Eng. Sci. 30, 581 (1975).

7. R. C. Darton and D. Harrison, Bubble Wake Structure in Three-Phase Fluid-. ization, paper presented at the International Fluidization Conference, Asilomar, California, June 15-20, 1975.

8. S. W. Gouse, Jr., An Index to the Two-Phase Gas-Liquid Flow Literature, M.I.T. Press, Cambridge, Massachusetts, 1966.

9. D. S. Scott, Properties of Cocurrent Gas-Liquid Flow, Advances in Chemical Engineering $\underline{4}, 199$ (1963).

10. G. E. Alves, Cocurrent Liquid-Gas Pipeline Contractors, Chem. Eng. Progress $66(7), 60(1970)$.

11. G. B. Wallis, One-Dimensional Two-Phase Flow, McGraw Hill Book Co., New York (1969).

12. G. W. Govier and K. Aziz, The Flow of Complex Mixtures in Pipe, Van Nostrand Reinhold Co., New York (1972).

13. A. A. Kudirka, Two-Phase Heat Transfer with Gas Injection through a Porous Boundary Surface, Argonne National Laboratory Report No. 6862 (1964).

14. G. F. Hewitt and N. S. Ha11-Taylor, Annular Two-Phase Flow, Pergamon Press, New York. (1970).

15. P. T. Cichy, J. S. U1tman, and T. W. F. Russe11, Reactor Model Development, Ind. Eng. Chem. 61(8), 6 (1969).

16. P. T. Cichy and T. W. F. Russel, Reactor Model Parometer, Ind. Eng. Chem. 61(8), 15 (1.969). 
17. J. A. Golding and C. C. Mah, Gas Absorption in Vertical Slug Flow, Can. J. Chem. Eng. 53, 414 (1975).

18. S. Goto, J. Levee, and J. M. Smith, Mass Transfer in Packed Beds with Two-Phase Flow, Ind. Eng. Chem. Process Design Develop. 14, 473 (1975).

19. N. D. Sylvester and P. Pitayagulsarn, Mass Transfer for Two-Phase Cocurrent Doumflow in a Packed Bed, Ind. Eng. Chem. Process Design Develop. 14, 421 (1975).

20. A. K. Shah and M. M. Sharma, Mass Transfer in Gas-Liquid (Horizontal) Pipeline Contactors, Can. J. Chem. Eng. 53, 572 (1975).

21. K. Akita and F. Yoshida, Bubble Size, Interfacial Area, and Liquid-Phase Mass Transfer Coefficient in Bubble Colums, Ind. Eng. Chem. Process Design Develop. 1.3, 84 (1974).

22. M. Kawagoe, K. Nakao, and T. Otake, Liquid-Phase Mass Transfer Coefficient and Bubble Size in Gas Sparged Contactors, J. Chem. Eng. Japan ㅁ, 254 (1975).

23. S. Ohshima, T. Takematsu, Y. Kuriki, K. Shimada, M. Suzuki, and J. Kato, Liquid-Phase Mass Transfer Coefficient and Gas Holdup in a Packed Bed Cocurrent Upflow Column, J. Chem. Eng. Japan 9, 29 (1976).

24. T. C. Aude, N. T. Cowper, T. L. Thompson, and E. J. Wasp, Slurry Piping Systems, Trends, Design Methods, Guidelines, Chem. Eng. 78(14), 74 (1971).

25. D. J. Jeffrey and A. Acrivos, the Rheological Properties of Suspensions of Rigid Particles, AIChE Journal 22, 417 (1976).

26. D. R. 'Oliver and A. Young-Hoon, Two-Phase Non-Newtonian Flow; Part I: Pressure Urop and Holdup. Trans. Inst. Chem. Eng. 46, T100 (1968).

27. D. K. Uliver and A. Young-Hoon, Two-Phase Non-Newtonian Flow; Part II: Heat Transfer, Trans. Inst. Chem. Eng. 46, T116 (1968).

28. R. C. Rosenhart, D. S. Scott, and E. Rhodes, Gas-Liquid Slug Flow with Drag Reducing Polymer snlutions, AIChE Journal 18, 7/1 (1972).

29. N. D. Sylvester and J. Br111, Drag Reduction in Two-Phase Annular Mist Flow of Air and Water, AIChE Journal 22, 615 (1976).

30. L. Otten and A. Fayed, Pressurs Drop and Drag Fecluction in Two-Fhase Non-Newtonian Slug Flow, Can. J. Chem. Eng. 54, 111 (1976).

31. G. A. Hughmark and B. S. Pressburg, Holdup and Pressure Drop with GasLiquid Flow in a Vertical Pipe, AIChE Journal 7, 677 (1961).

32. R. W. Lockhart and R. C. Martinelli, Proposed Correlation of Data for Isothermal Two-Phase, Two Component Flow in Pipes, Chem. Eng. Progress 45(1), 39 (1949). 
33. J. Fischer et al., Physical Parameters in SYNTHOIL Process, Argonne National Laboratory Report ANL-76-47 (1976).

34. J. Fischer et al., Physical Parameters in SYNTHOIL Process, Argonne National Laboratory Report ANL-76-2 (1975).

35. H. W. Sternberg, R. Raymond, and S. Akhtar, SYNTHOIL Process and Product Analysis, paper presented at the Symposium on Chemistry of Hydrocracking and Hydrotreating, ACS 169th National Meeting, Philadelphis, 1975.

36. F. M. Brea, M. F. Edwards, and W. L. Wilkinson, The Flow of Non-Newtonian Slurries through Fixed and Fluidized Beds, Chem. Eng. Sci. 31, 329 (1976).

37. W. L. Wilkinson, Non-Newtonian Fluids, Pergamon Press, New York (1960).

38. A. Acrivos, Stanford University, Private Communication. 
Distribution of ANL-76-116

\section{Internal:}

J. Fischer (30)

$H$. Huang

R. Lo

W. Podolski

A. Jonke

L. Burris

D. S. Webster

E. G. Pewitt

A. Tevebaugh

J. Royal

$\mathrm{J}$. Young
D. Fredrickson

T. Bump

T. Mulcahey

S. Lee

A. Melton

P. R. Fields

A. B. Krisciunas

ANL Contract File

ANL Libraries (5)

TIS Files (6)

ExLELHA 1:

ERDA-TIC, for distribution per UC-90d (253)

Manager, Chicagn nperations officc

Clicic, Chicago Matent Group

President, Argonne Universities Assuciation

Chemical Engineering Division Review Committee:

R. C. Axtmann, Princeton Univ.

R. E. Balzhiser, Electric Power Research Institute

J. T. Banchero, Univ. of Notre Dame

D. L. Douglas, Gould Inc.

P. W. Gilles, Univ. of Kansas

G. M. Rosenblatt, Pennsylvania State Univ.

S. Akhtar, Pittsburgh Energy Research Center

S. Alpert, Electric Power Research Institute

C. Bagge, National Coal Association, Washington

J. Butt, Northwestern Univ.

N. Cochran, Office of Coal Research, U. S. Dept. of Interior

A. L. Conn, Amoco Oil Cu., Naperville, Ill.

K. Corey, Div. of Coal Conversion and Utilization, USERDA

V. Dranoff, Northwestern Univ.

D. Fischer, Laramie Energy Research Center

J. F. Flagg, Universal Oil Products Co.

R. Giberti, Kennecott Copper Corp., T,exington, Maco.

W. Guuse, Office of Coal Research, U. S. Dept. of Interior

O. J. Hahn, Univ. of Kentucky

G. Hill, Electric Power Research Institute

W. S. Jones, Office of Asst. Adm. for Fossil Eileigy, USERUA (3)

G. Long, Northern Illinois Gas Cn.

R. M. Lundberg, Commonwealth Edison Co., Chicago

P. S. Lykoudis, Purdue Univ.

A. Maimoni, Lawrence Livermore Laboratory

G. A. Mills, Div. of Fossil Energy Research, USERDA

J. Nichols, Oak Ridge National Taboratory

W. H. Peters, Massachusetts Institute of Technology

R. Rozsa, Lawrence Livermore Laboratory

B. Rubin, Lawrence Livermore Laboratory

A. F. Sarofim, Massachusetts Institute of Technology 
F. Schora, Institute of Gas Technology, Chicago

$M$ : Steinberg, Brookhaven National Laboratory

Tetra Tech, Inc., Arlington, Va.

R. E. Vener, Div. of Coal Conversion and Utilization, USERDA

C. W. Whitten, Peabody Coal Co., Columbia, Tenn。

I. Wender, Bureau of Mines, Pittsburgh

W. Wiser, Univ. of Utah

R. L. Zahradnik, Div. of Coal Conversion and Utilization, USERDA

Van Nostrand Reinhold Company, New York, NY 